
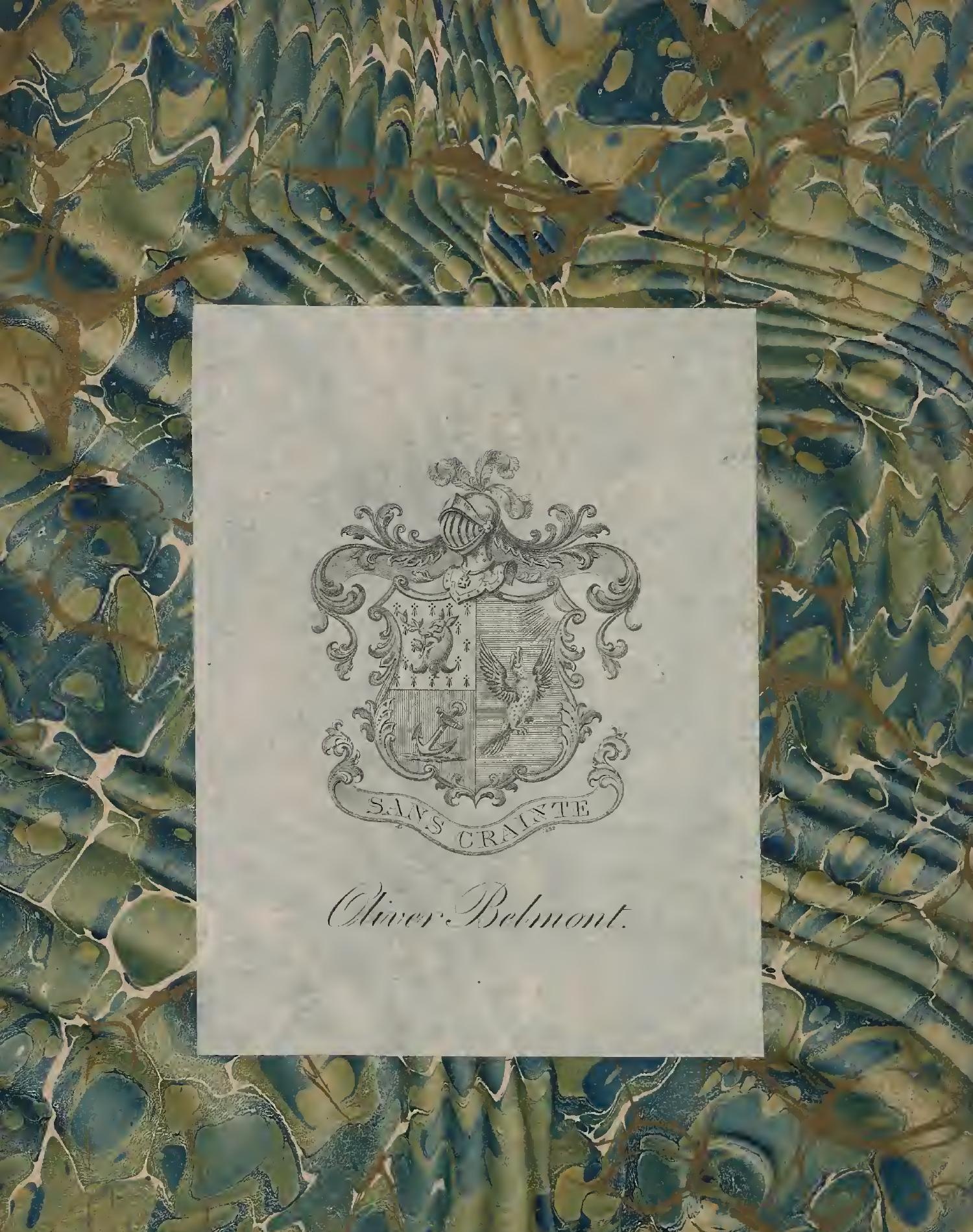

$$
\text { Nuterese }
$$

(a)

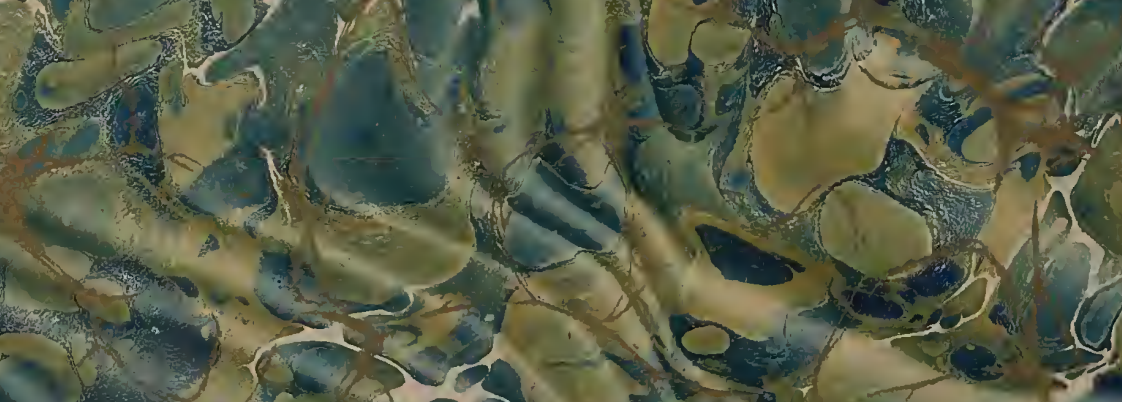

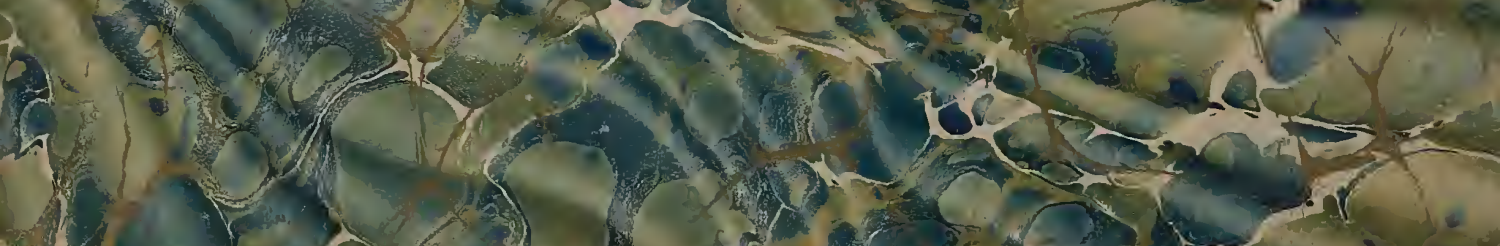




\section{$4=0 \pi$}

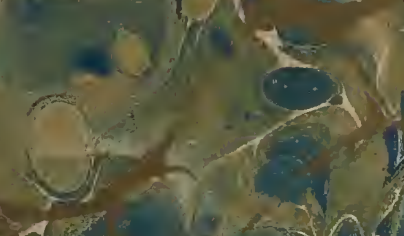

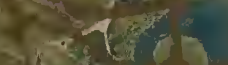

a.

2. $=12$

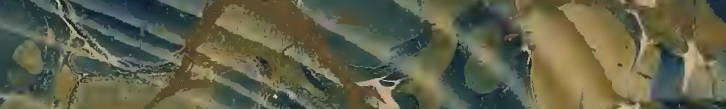

is

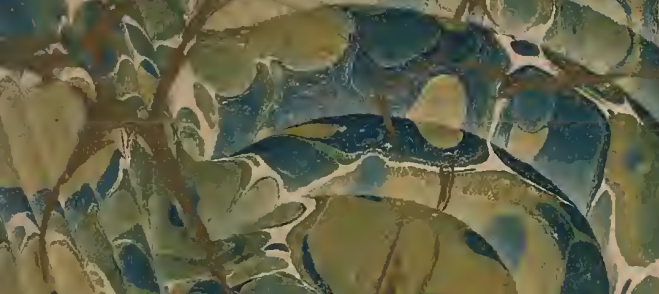

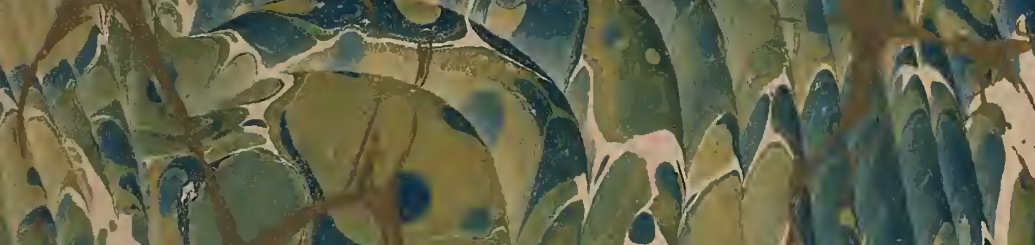

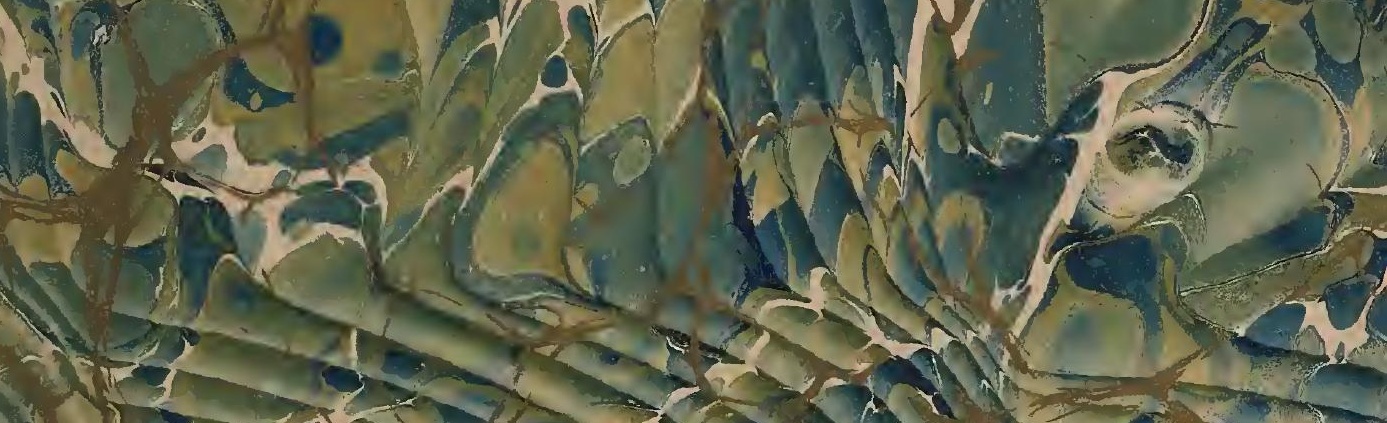

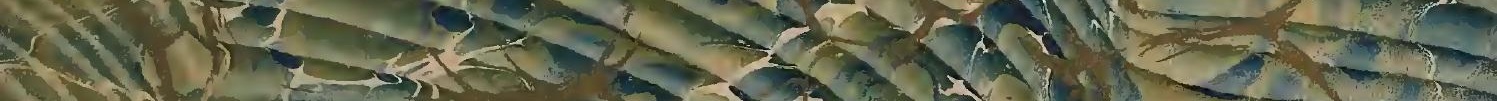
$\log$

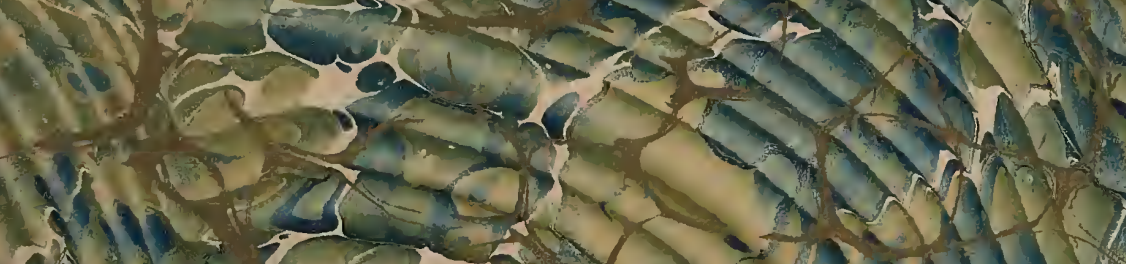

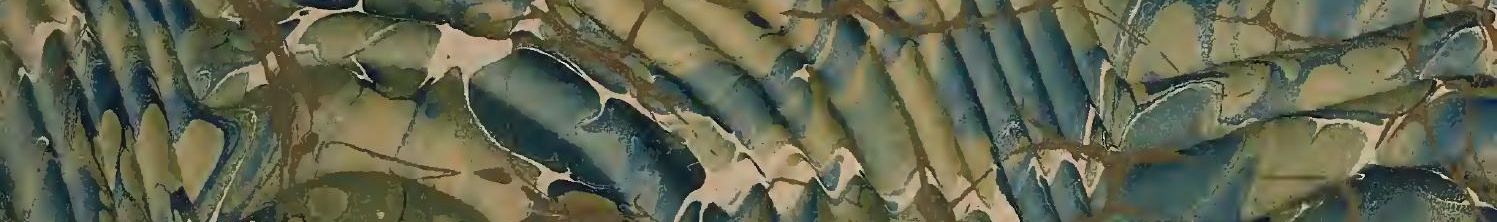

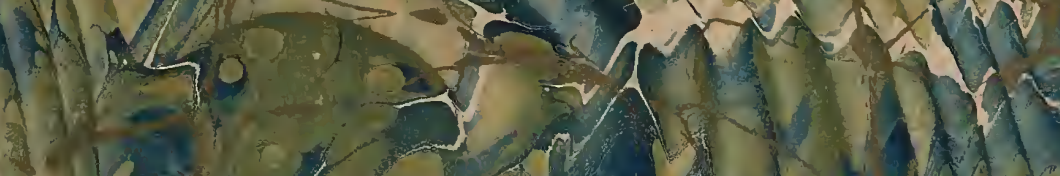

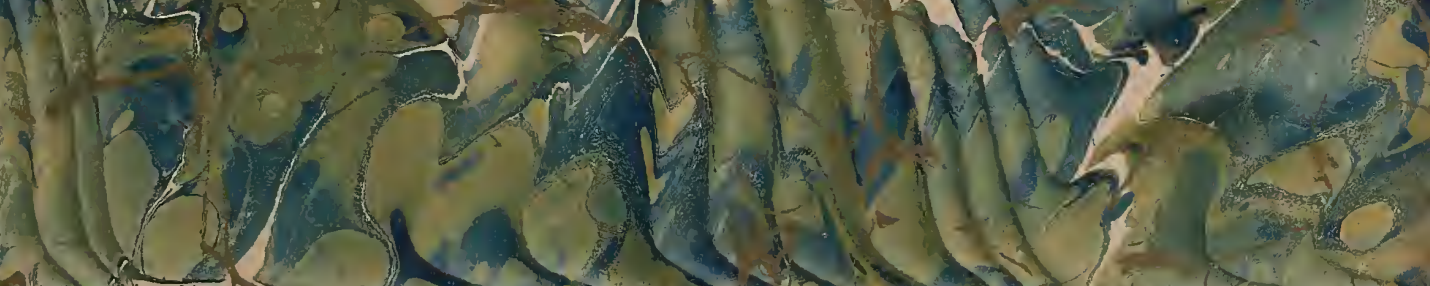

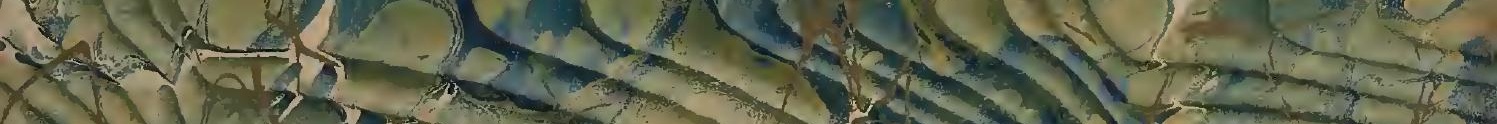

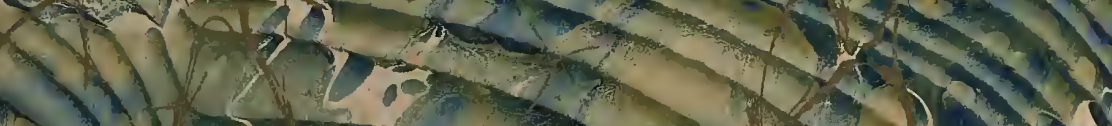

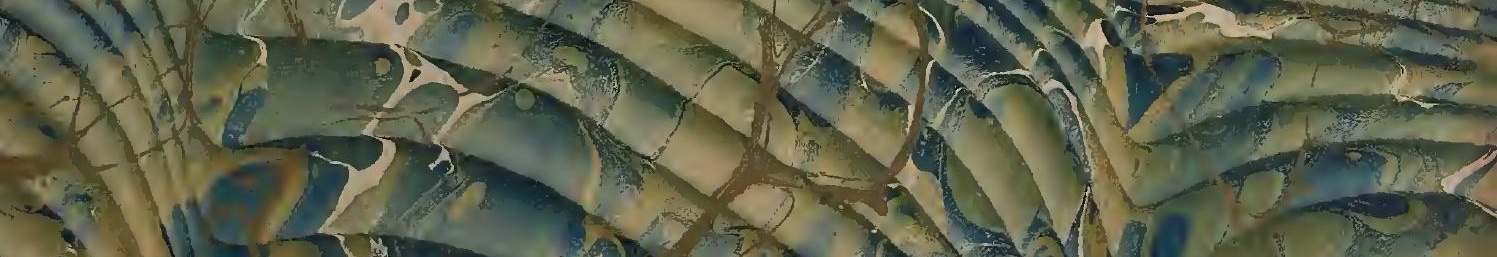
$+2 \sqrt{2}+3 x$ 







\title{
PRINCIPLES
}

\author{
OF \\ M O D R N R D I N G, \\ FOR
}

GENTLEMEN. 




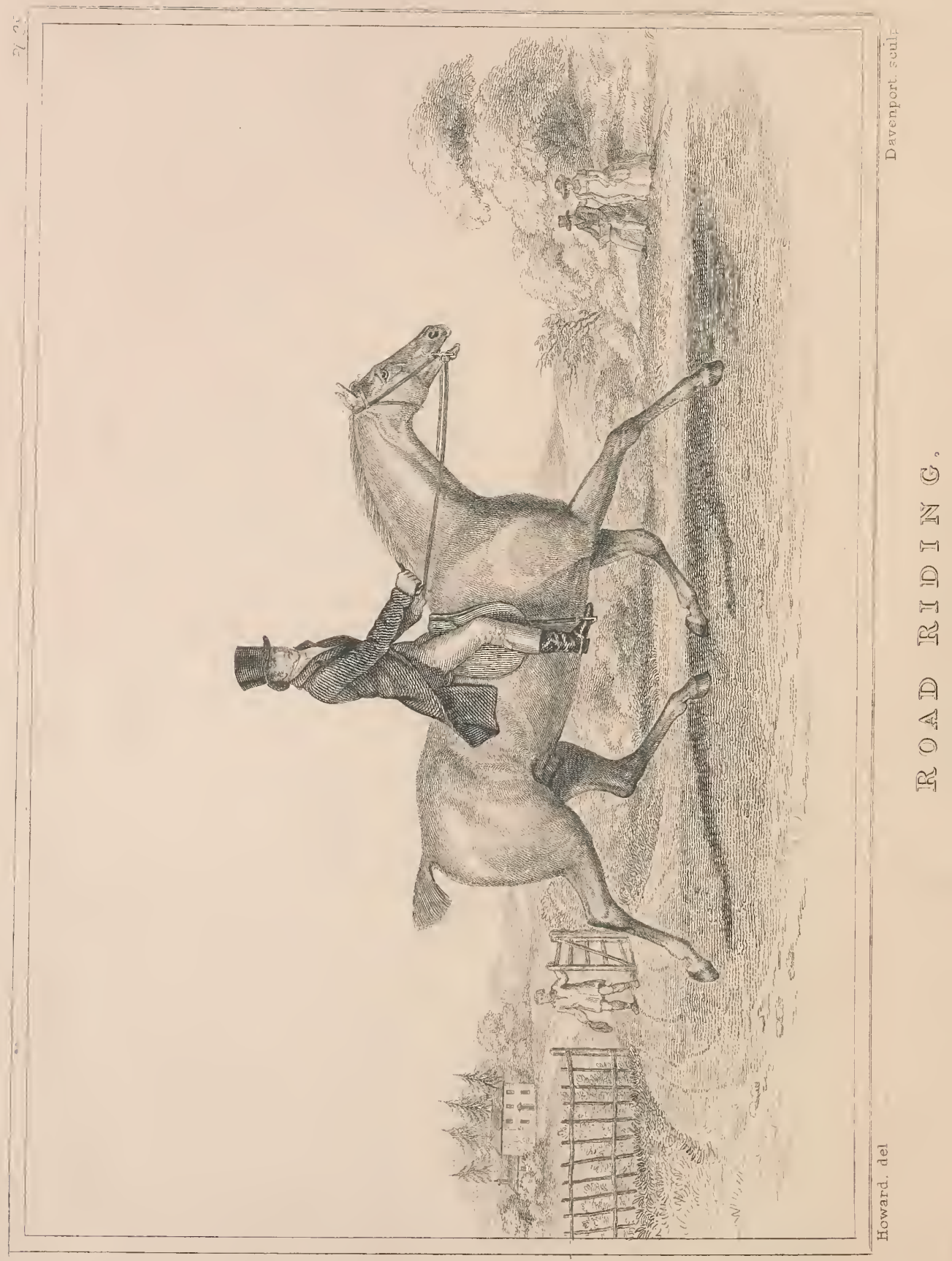




\title{
PRINCIPLES
}

OF

\section{O D E R N R D I N G,}

FOR

\section{GENTLEMEN;}

\author{
IN Which
}

THE LATE IMPROVEMENTS

OF

THE MANEGE AND MILITARY SYSTEMS

ARE APPLIED TO PRACTICE

ON THE

韭romenade, the zhoad, the fféld, and the Course。

BY JOHN ALLEN,

RIDING MASTER, SEYMOUR PLACE, BRYANSTONE SQUARE.

\section{LONDON :}

PRINTED FOR THOMAS TEGG, NO. 73, CHEAPSIDE;

R. GRIFFIN, AND CO. GLASGOW; AND J. CUMMING, DUBLIN.

1825. 



\section{ADVERTISEMIENT.}

IN this work, the chief labour of the anthor has been to concentrate, in the smallest space, every thing really useful which has appeared on the Subject of Riding,-to add thereto every recent improvement, - to express both in more simple and intelligible language,-and to give the whole a more systematic and impressive arrangement.

He has, accordingly, unreservedly profited from all the best writers on the sub- 
ject, as well as from the practice of the Military Schools, where, by the simplicity and practical nature of the methods adopted, more is done in one lesson than, in the other schools, is effected in twenty*.

While he has avoided all those peculiarities of military riding which result from the adaptation of its methods to bodies of men, he has omitted none of those natural and simple improvements which its teachers were compelled to make, in order both quickly and surely to instruct their pupils.

* The result of this is that the military schools are crowded with gentlemen, while the others are almost entirely deserted by them; and that they begin even to be frequented by those ladies who are aware of the privacy, the selectness, and the orderliness of the system adopted in them at the hours appropriated for the instruction of ladies. 'This is hard indeed on the old teachers. Let them improve their methods! 
ADVERTISEMENT.

vii

He, therefore, flatters himself that, at a time when riding has become so fashionable an exercise, his work will more than any preceding one ensure the security, ease, and grace of the rider, both in the practice of the manege, the only true and fundamental system, and in its application to the Promenade, the Road, the Field, and the Course. 


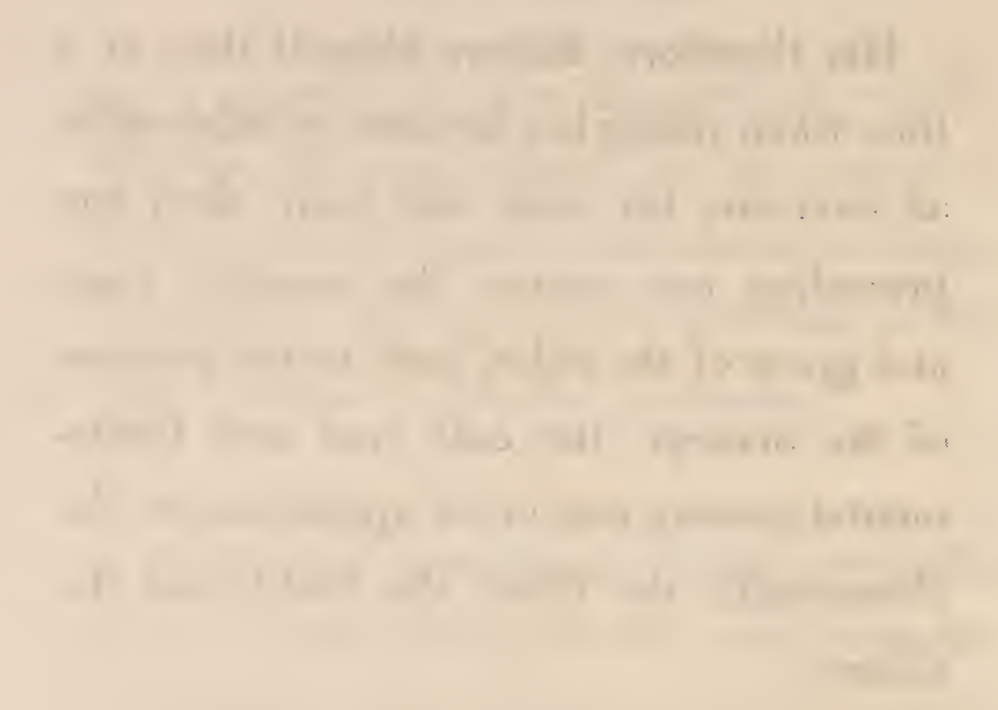




\section{CONTENTS.}

\section{PART I.}

OF THE HORSE, ITS EQUIPMENTS, AND THE MODES OF RIDING.

Chap. I. Of the natural Paces of the Horse ...... 3

Chap. II. Of the Saddle and Bridle......... 7

Section I.-Of the Saddle........... 7

Section II.-Of the Bridle........... 11

Chap. III. Of the Modes of Riding ......... 26

\section{PART II.}

OF MOUNTING, DISMOUNTING, ETC.

Chap. I. Of Mounting by distinct Steps....... 33

Section I.-Preliminary............. 33

Section II.-Of Mounting by distinct Steps . 34 
Cha P. II. Of Dismounting by distinct Steps......

Сна P. III. Of other Modes of Mounting, \&c. ...

Section I.-Of Mounting and Dismounting without Pauses-On the Off Side-Taking up the Stirrups .............. 41

Section II.-Of Mounting and Dismounting without Stirrups .............. 49

Section III.-Of Disposing the Reins..... 49

\section{PART III.}

OF THE SEAT, THE BALANCE, AND THE HAND.

Cha P. I. Of the Manege Seat .......... 47

Section I.-Preliminary............. 47

Section II,-General Division into Parts ... 48

Section III.-Position of particular Parts . . 49

Section IV.-Concluding Remarks ...... 55

Chap. II. Of the Balance ............ 58

Cha P. III. Of the Hand............. 62

Section I.-Preliminary........... 62

Section II._Of Holding the Reins...... 62

Section 1II.-. Of the Correspondence and Appui .................... 63

Section IV.—Of the Qualities of the Hand. . 68 


\section{PART IV.}

OF THE AIDS.

Cha P. I. Of the Aids of the Hand ......... 79

Section 1.-Preliminary............ 79

Section II.-The Five Positions when the Reins are separate............ 80

Section III.-The Five Positions when the Reins are not separate.$\ldots \ldots \ldots \ldots .82$

Chap. II. Of the Aids of the Body.......... 85

Chap. III. Of the Aids of the Legs......... 89

Cha P. IV. Of Animations, Soothings, and Correc-

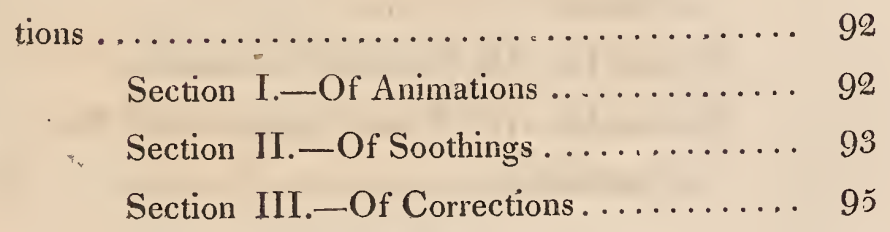

\section{PART V.}

OF THE DIRECT PACES.

Chap. I. Of the Walk................ $10 \mathrm{I}$

Section I.-Of the Walk generally and particularly ................. 101

Section II._Of Turns in the Walk ..... 105

Section III.-Of Wheels in the Walk .... 108 
Section IV.--Of Changes and Demivolts in the Walk. .................... 111

Section V.-Of the Stop in the Walk..... 114

Section VI.-Of Going Backward in the Walk ..................... 117

Chap. II. Of the Trot .............. 122

Section I.-Of the Trot in general ...... 122

Section II.-Of the Kinds of Trot....... 124

Section III.-The Trot in particular ..... 126

Section IV.-Of Turns, Stops, \&c. in the

Trot $\ldots \ldots \ldots \ldots \ldots \ldots \ldots \ldots \ldots \ldots \ldots$

Chap. III. Of the Gallop ............. 133

Section I.-Of the Gallop in general, and of its Kinds................... 133

Section II.-Of the Canter in particular ... 136

Section III.-Of Turns, Changes, Stops, \&c. in the Gallop ............... 145

\section{PART VI.}

OF THE LATERAL PACES.

Crya P. I. Of Shoulder-in, \&c. ............ 157

Section I.-Preliminary ............ 157

Section II.-Of Bending ........... 158

Section III.-Of Shoulder-in. ......... 158

Section IV._-Of Changes, \&c. in Shoulderin . .......................... 167 
CONTENTS.

xiii

Chap. II. Of the Passage .............. 169

Section I.-Of the Passage in general . . . . 169

Section II.-Of the Kinds of Passage .... 170

Section III.-Of the Passage in particular. . 172

Section IV.-Lesson on the Passage ..... 179

Cha P. III. Of the Terre-à-terre ........... 187

Section I.-Of the Terre-à-terre in general. . 187

Section II.-Of the Terre-à-terre in parti-

cular .................... 188

\section{PART VII.}

OF CIRCLING, LEAPING, AND CRITICAL SITUATIONS.

Chap. I. Of the Circle ................ 193

Chap. II. Of Leaping $\ldots \ldots \ldots \ldots \ldots \ldots \ldots \ldots$

Section I.-Of Leaping in general ....... 198

Section II.-Of the Standing Leap ...... 201

Section III.-Of the Flying Leap ....... 208

Chap. III. Of critical Situations ........... 213

Section 1.-Preliminary ........... 213

Section II.-Of Rearing........... 215

Section III.-Of Kicking ........... 218

Section IV.-Of Plunging ........... 219

Section V.-Of Shying, \&c. ......... 221

Section VI. - Of Restiveness ......... 222 


\section{PAR'T VIII.}

OF THE CURB, STIRRUPS, AND SPURS.

Page

Chap. I. Of the Curb, \&c. ...............231

Section I.-Preliminary.............. 231

Section II._Modes of Holding the Reins. . 232

Section III.-Of Shifting the Reins...... 234

Section IV.-Of Separating the Reins .... 237

Section V.-Of Changing the Reins ...... 238

Section VI._Of Adjusting the Reins..... 239

Section VII.-Of the Position of the Hand. 242

Section VIII.—Of the Management of the

Curb ....................... 243

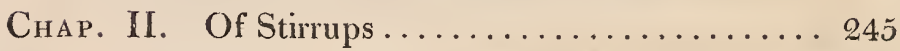

Chap. III. Of Spurs............... 247

\section{PART IX.}

OF ROAD RIDING, HUNTING, AND RACING.

Chap. I. Of Road Riding ...............251

Chap. II. Of Hunting................ 261

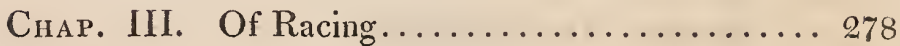


DIRECTIONS FOR PLACING THE PLATES.

Plate Page

I. Parts of the Horse ............... 1

II. Mounting $\ldots \ldots \ldots \ldots \ldots \ldots \ldots \ldots$. 34

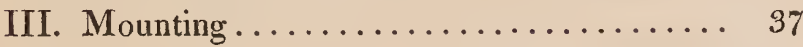

IV. Seat $\ldots \ldots \ldots \ldots \ldots \ldots \ldots \ldots \ldots \ldots, 38$

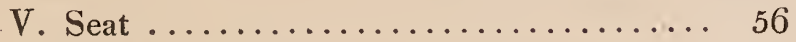

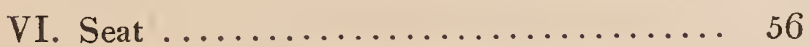

VII. Persian Seat ................ 56

VIII. Roman Seat ............... 57

IX. Grecian Seat ................ 57

X. Walk ........................ 101

XI. Changes and Demivolts ........... 111

XII. Changes and Demivolts .......... 113

XIII. Halt . . . . . . . . . . . . . . 117

XIV. Trot .................... 132

XV. Cantering right forward ........... 134

XVI. Cantering disunited ............ 135

XVII. Cantering left forward ............ 135

XVIII. Long Change................... 147

XIX. Shoulder-in ................... 160

XX. Paces . . . . . . . . . . . . . . 160

XXI. Passage . . . . . . . . . . . . . . . . 178

XXII. Lesson on the Passage.............. 179

XXIII. Terre-à-terre . . . . . . . . . . . . . . . 187

XXIV. Lesson of the Circle . . . . . . . . . . . . 195

XXV. Leaping, Plate 1. . . . . . . . . . 201

XXVI. Leaping, Plate 2. .............. 201

XXVII. Leaping, Plate 3. . . . . . . . . . . 201

XXVIII. Road Riding .......... facing the Title.

XXIX. Trotting . . . . . . . . . . . . . . . . . . . . . . . . . . . . . .

XXX. Galloping . . . . . . . . . . . . . 277

XXXI. Hunting Leap . . . . . . . . . . . . . . . 277

XXXII. Racing . . . . . . . . . . . . . 278 

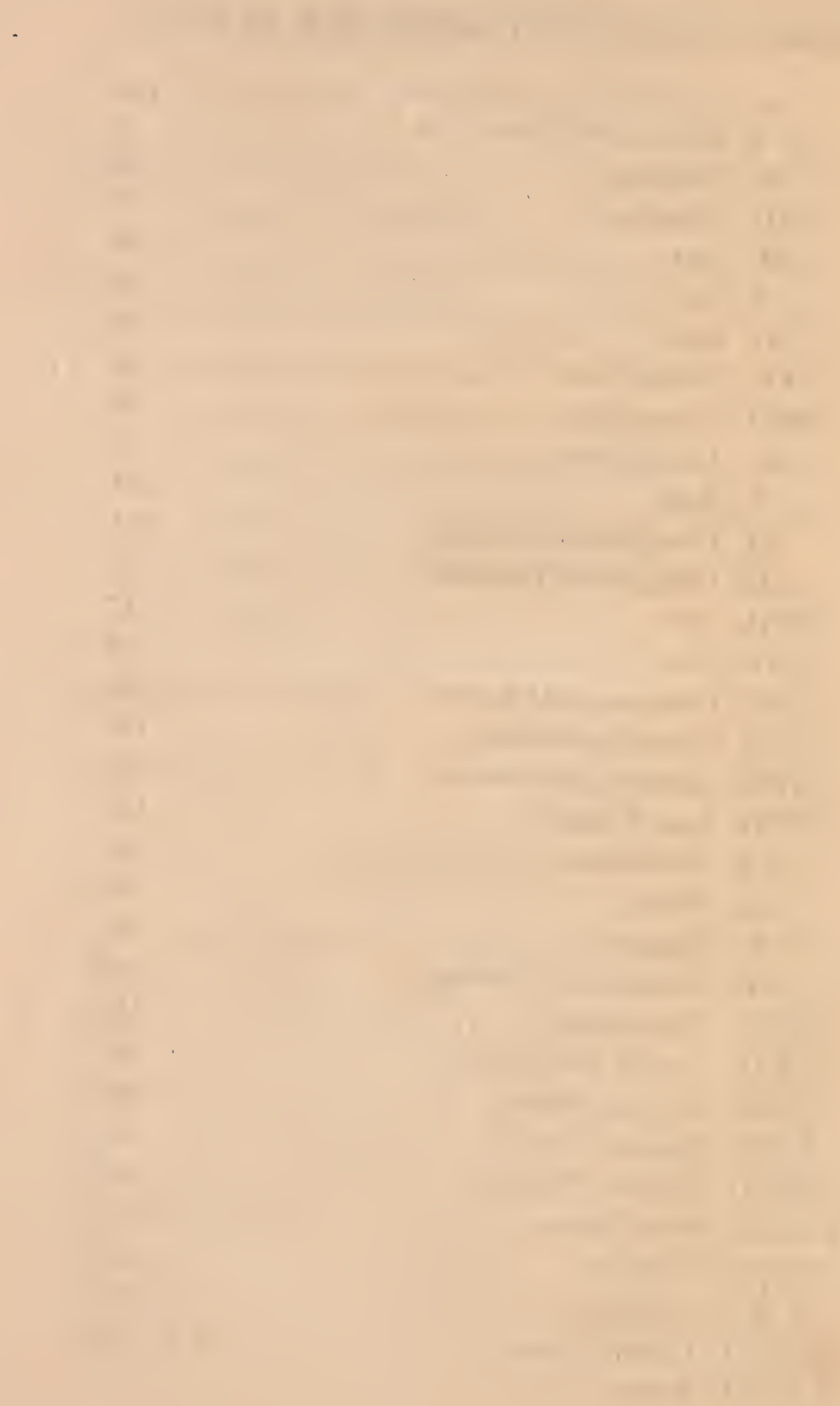



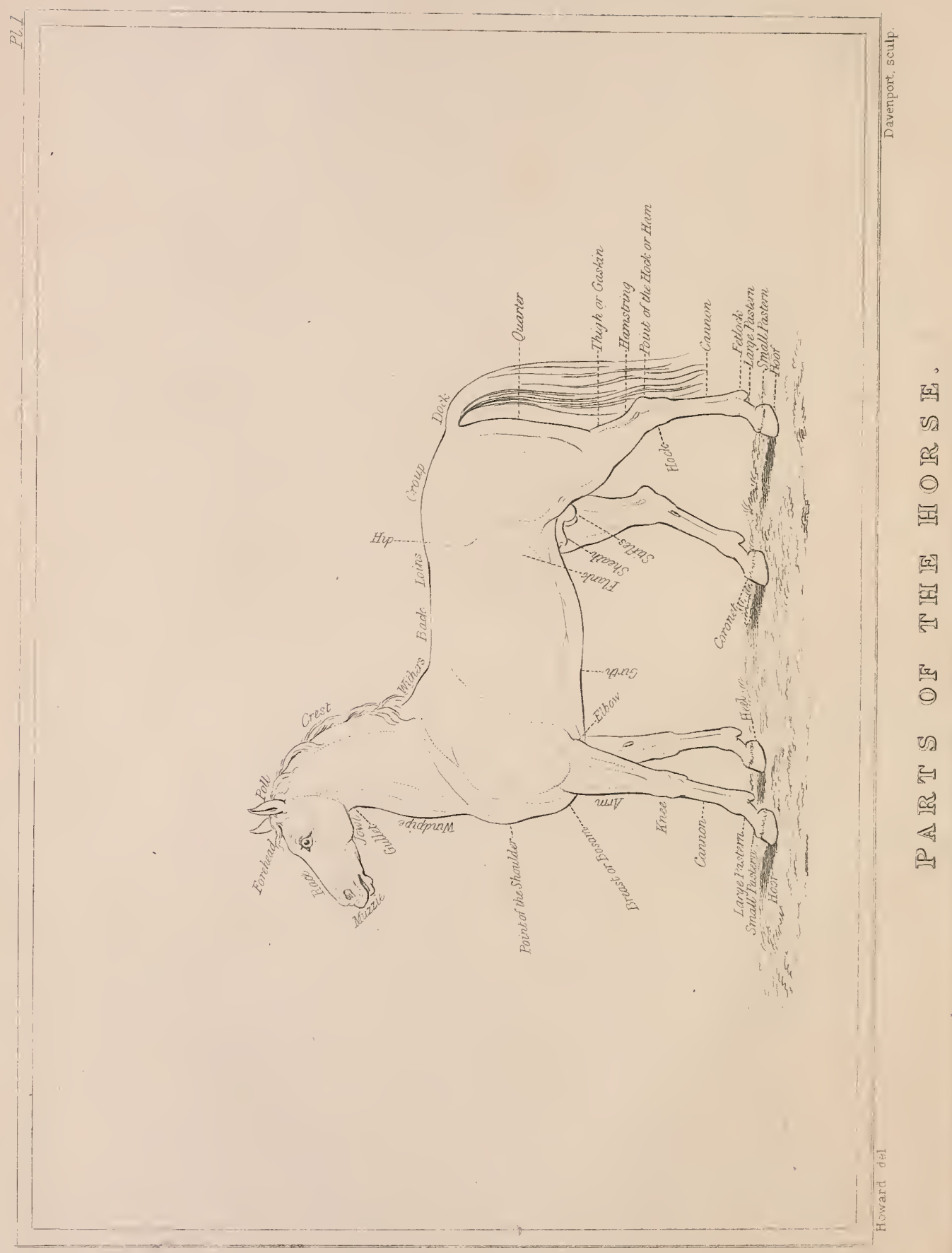




\title{
PRINCIPLES
}

\author{
$\mathrm{OF}$ \\ M O D E R N R D I N G.
}

\section{PART I.}

of THE

HORSE, ITS EQUIPMENTS, AND THE MODES OF RIDING. 



\section{PART I.}

OF THE HORSE, ITS EQUIPMENTS, AND THE MODES OF RIDING.

\section{CHAPTER I.}

OF THE NATURAL PACES OF THE HORSE.

THE natural paces of the horse are the Walk, the Trot, and the Gallop. These are all distinguished by the action of the legs and the beats of the feet, which mark a sharp, flat, slow, or rapid time.

I. The Walk is the most languid pace, being performed with less exertion than the others.

The action of the Walk is that motion of the legs in which one at a time is off the B 2 
ground, and three on; marking four distinct beats, as each foot in rotation comes to the ground in the following order:-The off fore foot, leading first, marks one; the near hind foot, two; the near fore foot, three; and the off hind foot, four.

Here though the feet follow each other quickly, yet the languor of the action makes the beats flat.

II. The Trot is a more animated pace, proceeding from the walk; for when we urge the horse to proceed faster than he can by moving one leg after the other, we oblige him to take up two at a time.

In the Trot, the off fore foot and the near hind foot mark one beat; and the near fore foot and the off hind foot mark another beat; so that in this action there are two legs crosswise off the ground, and two legs on, which in their alternate change of situation mark the time of one, two. 
Here the beats are sharp, and quick, in proportion to the degree of animation and extension.

III. The Gallop is a pace of still higher animation, and more exertion than the trot, and proceeds from the trot as the trot does from the walk; for when we press a horse in the trot beyond his capacity, or animate him with the legs while we retain him with the hand, we compel him to raise his two fore legs after each other, which commences the action of the Gallop.

The action of the Gallop is in the following order, when leading with the right leg.-The near fore foot is first raised from the ground; then the off fore foot. These come to the ground in the same order. The near fore foot marks one beat or time: the off fore foot, passing the other, while both are in the air, comes to the ground more forward, is the leading foot, and marks the second beat. The hind feet follow in like manner. The near hind foot marks a third beat; and the 
P. I.

off hind foot, passing, comes to the ground more forward, and marks a fourth beat. Thus the action of the Gallop is by means of the two fore legs leading close after each other; and the hind legs immediately following in like order.

Here, when the gallop is united and true, the feet mark a regular, sharp, and quick time, of one, two, three, four.

IV. The Amble may perhaps be considered as a natural pace of the horse; because most foals following their dams amble more or less to keep up with them. The difference between the walk and the amble is, that two legs of a side are raised in the latter at one and the same instant, and so on vice versâ. 


\section{CHAP. II. \\ OF THE SADDLE AND BRIDLE.}

Section I. Of the Saddle.

The saddle must be considered first with relation to the horse, and secondly with relation to the rider.

I. With regard to the horse, the saddle prevents the friction he would endure if barebacked, or if he had merely a cloth on; and it distributes the weight of the rider to the parts most capable of bearing it.

Without a saddle, the horse would sustain the weight in the middle and weakest part of the back; but with a saddle, the rider's weight is distributed, as the saddle has bearings before and behind, but none in the middle. 
Hence it is evident, that the saddle should be proportioned to the size of the horse; the bearings before being clear of interference with the plate-bone, and not extending further behind than within four inches of the hips.

The bearing of the saddle should be equal on every part it is intended to touch; and the closer it comes, so that neither the weight of the rider nor settling of the pannel can bring it to injure the withers or chine, the better.

The rider should, therefore, examine with his finger from the bearing of the side of the withers to the point of the tree, whether it appears to have equal pressure; and the same around the hinder part of the saddle.

If there be space for the finger between the pommel and the withers, and between the chine and back part of the saddle, it probably will not injure the horse, unless the tree, being weak, spread with the weight of the rider, or the pannel is newly stuffed. 
If, on the contrary, the points are so narrow that the saddle cannot come to its bearings till the girths or the weight of the rider bring it down, the pressure at these points may occasion heat and inflammation; and the same is true as to the hind part of the saddle.

If, again, the saddle come down on its bearings, and the points are short, and stand so wide as not to touch, and the pommel so high as not to injure the withers (being the plan on which saddles are made to suit any horse), still a saddle with such contracted bearings cannot be said to fit, and when long journeys are taken in hot weather, inflammation will be produced.

If a saddle do not fit, the pannel cannot be stuffed so as to insure its not injuring the horse; and where it does fit, superfluous stuffing should be avoided, as causing the saddle to shift its place, \&c.

II. With regard to the rider, it must be observed, that a saddle may form a most 
unpleasant seat for him, though it fit the horse.

The best test of the propriety or adaptation of the seat is, when the rider, without stirrups and without effort, easily falls into and keeps his proper situation in the saddle; for, when the seat is improperly shaped, he will be shifted and placed insecurely.

When the saddle is on the horse's back, the lowest part of the seat should be rather behind the centre of the saddle. There the weight of the body will fall, and the thighs be permitted to keep their proper position.

We have no hesitation in mentioning Jackson* as the best maker of gentlemen's saddles in London. His admirable improvements also in ladies' saddles render them the only ones fit to be used, as we have elsewhere shown. 
Section II. Of the Bridle.

Tнe bridle consists of reins and bits ; for the latter term may be applied to any piece of metal introduced into the horse's mouth for the purpose of restraint.

I. A short iron rod, made rather wider than the mouth of the horse, and provided with a hook or ring at each extremity for fastening the reins to, affords us an instance perhaps of the greatest possible simplicity in the construction of a bit; and such a one only slightly curved forwards, to allow more liberty for the tongue, is at present in general use for the heavier kind of draft horses.

A rod similar to the former, in two pieces, and connected by a joint in the middle, is the next in point of simplicity, and is in common use for horses of light draft, as in those employed for the curricle, coach, \&c.

1. The next in point of farther complication of parts, and which scarcely can be said 
to differ from the former, is the common snaffle. This is provided with two cross pieces, which rest against the lips or sides of the mouth externally; for, as the snaffle is intended for the saddle horse, and the reins go to the hands, these cross pieces are useful in preventing the bit from being drawn through the mouth.

The distinction between a bridon and snaffle is of little consequence; for, on all occasions, the cross pieces of the latter are most convenient; and the bridon is merely an imperfect snaffle.

To give the greatest ease possible, a large and highly polished bit is necessary.

On the other hand, to give the greatest degree of severity to the mouth piece of the snaffle, it is twisted while hot in a spiral form, and is made to present by this means a sharp, rough, and unequal surface to the jaw, being capable, according to the degree of sharpness, of pressing the bars or lips with greater 
or less severity. The different degrees of punishment which this kind of bit is capable of inflicting will perhaps be found sufficient for all the purposes of correction.

2. The next kind of bit in use for horses is the curbed bit; which, as it is an instrument of much greater complication of parts than the snaffle, so it appears to have been of comparatively recent date.

Stripped of all unnecessary trappings, this instrument consists of the following essential parts :-a mouth piece; two side branches, or inflexible rods of iron, firmly fixed to the former; a chain passing from side to side, behind the chin, including the jaw; two eyes or rings at the upper extremity of these branches, serving to fasten them to the head stall, and stay them in the mouth, and leaving the chain attached to them; two other rings at the lower extremity of the above branches receiving the reins, which pass to the hand, or sometimes in draft horses to the hook of the saddle, as 
a bearing rein. These are all the parts really necessary to constitute the curb.

The bits thus formed being placed in the mouth, and the chain passed round the lower jaw, the branches, it will be readily seen, become powerful levers when drawn backwards, acting upon the mouth piece as a centre, and squeezing, by means of the chain, whatever interposes between it and the mouth piece, with a force equal to the length of lever afforded by the lower branch.

This force, it will be perceived, is regulated not only by the length of the lever below the mouth piece, but also by the greater or less distance at which the chain is placed from it. The chain is usually fixed to the eye of the cheek piece, where the head stall is fastened: if, therefore, this part is very long, it is evident it must moderate or counteract the power and effect of the lower end of the branch, and render it less severe, by bringing the centre of motion nearer to the middle of the lever. 
It appears manifest, from the construction of this instrument, that its whole force is exerted upon the jaw itself, and that it has power to pinch the bars with violence, even to the fracture of the bone; and this with very powerful branches has sometimes happened. It can also bruise and totally destroy the tender covering of the inside of the mouth, and the skin beneath the jaw.

From considering its mode of operating, it might reasonably be doubted whether it does in reality stop the horse by its power and opposed force, as is generally conceived at present, or rather by the severity of the pain it inflicts; for should the horse arm himself against this, it is totally insufficient to arrest his course ; of which instances occur in runaway horses every day.

We may now speak of the particular parts of the curb.

The mouth piece of the curb is usually provided with an upset or arch in the middle of 
P. I.

it, as it would, if perfectly straight, rest on the tongue, and occasion an unpleasant restraint. This passage for the tongue is often made so narrow and small by the bit makers, that one would apprehend they scarcely had a right idea of its use. It should not, however, be high. From the circumstance of its allowing a passage for the tongue, it has been called by some, the liberty; and, for the same reason, by others, the porte; hence we have the porte-mouth bit, vulgarly called among the bit makers and grooms the Portsmouth bit; and by a supposed counter expression to this term, we probably get the Weymouth bit.

The straight part of the mouth piece which rests upon the bars of the jaw is termed by the French le canon, and by the old English writers the jeive. This part should be well polished, and may be made of any proper figure, as that of a cylinder, cone, oval, globe, pear shape, \&c. It is obvious that the effect of the curb, as far as it respects the bars, will be correspondent to the thickness or thinness, 
smoothness or roughness, of this part:- the larger and broader it is, the more surface it covers; and thus the pressure, by being distributed over more points, becomes less felt. The enlargement, however, of the canon or jeive should not to be carried to an excess. To render these irons less irritating to the mouth, and to avoid their friction upon the bars, the jeives are provided with loose movable rollers of well polished iron, which readily turning on the axès of the bits, very considerably diminish their severity. 'These movable pieces may also be useful in preventing the horse from catching and holding the bit in his teeth.

The chain is the part most essentially necessary to give effect to all the other parts of the curb, and may be placed, as we have already noticed, at any given distance above the mouth piece; its operation being more powerful, as this distance is exceeded by the length of the branches. 
P. I.

The chain is fastened on one side to the eye of the banquet where the head-stall is fastened; on the other, to a hook hanging from the same part. This chain, as it is at present used, is composed of iron links or rings, so bent, or indented, as to form, when put together, one uniform nearly flat surface; and these links, by twisting or untwisting, may be made to present a surface with any degree of roughness to the chin.

The larger and thicker the rings are, provided they are smooth and well polished, the easier the effect of the chain.

When great tenderness is required, this chain may be covered with leather or cloth ; or where still greater delicacy is desirable, the curb may be made wholly of leather, without any chain.

In the view we are taking of the construction of the bit, the sides have been considered as straight, plain levers of indeterminate 
length: this is, however, in practice, often varied.

By some, to prevent the horse from catching the bit in his mouth (when in the straight kind this is not prevented by a chin strap), the branch is made with an arch or semicircle in the middle, like the letter $\mathrm{C}$, turned backwards. Still, however, whether bent into that or any other shape, it is the length of the lever, and its strength, which alone give the power.

As to the cheek piece or banquet, its eye commands and gives efficiency to the rest of the bit, or, in other words, decides the distance of the chain from the mouth piece, or centre of motion. The eye, or hole at the upper end of the branch, should be so placed as not to hurt the cheek.

The most useful bit of the curbed kind appears to be the Weymouth bit, which is at present in common use for draft horses of light work, as for carriages, coaches, \&c. It

$$
\text { c } 2
$$


consists of a strong plain mouth piece, of uniform thickness throughout, without any upset or jeive, but is simply curved forwards to give liberty to the tongue. This kind of construction is the simplest perhaps that the curb admits of.

The easier, simpler, and lighter a bit is in all its parts, provided it produces the desired effect, the better and more agreeable it will be.

The thicker and more fleshy, and the wider or broader the bars of the horse, the rougher may be the mouth piece. For the leaner and more delicate, consequently, the bits should be less severe. Care should also be taken that the mouth piece be well suited to the size and width of the mouth, and be not too narrow, as this would give pain, by squeezing the bars together: if, on the contrary, it is very wide, it rests with more force on the bars, without the interposition of the lips, as is most usually the case. Where the tongue is large and prominent, the upset 
should also be in proportion, otherwise the bit could not rest upon the bars, but would press upon the tongue.

3. As to the Reins, we need only observe, that their centres should be accurately marked; but when, by both reins being held in one hand, the near or left rein has to pass under the little finger and on the outside of the right rein over the forefinger, this should cause the right rein to be held from half to three quarters of an inch shorter, and the centre to come proportionably toward the left.

4. It remains for us to notice the proper application and adjustment of these to the horse's mouth.

In adjusting the bridle on the horse, the headstall, parallel to the projecting cheek bone, and immediately above it, must be of such length as to admit the mouth piece of the curb to rest on the bars, an inch above 
P. I.

the lower tushes, but clearing the under ones: Mares having no tushes, the mouth piece must be placed in their mouths about two inches above the corner tooth. The nose band must be buckled beneath the snaffle headstall, and so that a finger can pass freely under it in front of the horse's nose. The bit of the snaffle must be a little higher, but not so high as to wrinkle the corner of the mouth. The throat-lash should be buckled rather loose, to admit the horse when going to bridle his head. The mane is usually cut close where the headstall comes, and the finger should clear any part of the mane or foretop that may interfere with it. The foretop, when combed smooth, may be put over or under the front. The curb is the last thing adjusted, and though a trifling variation may be proper, according to the manner in which the horse carries his head, we set down that which suits the generality of horses.

The curb chain is to pass under the snaffle: therefore put your right hand under the 
snaffle reins to take hold of the curb chain; with the left, put two fingers within the cheek of the bit; and with your thumb take hold of the curb hook. The end links of the curb chain being in your right hand, turn the chain to the right, or as you would turn a screw, till every link lies smooth and flat, as though it were a strap, and then without losing a half turn, put that link on the hook which appears to be most appropriate, i. e. neither tight nor slack, and examine how the branch operates. If the branch has liberty to move forty-five degrees and no more, it is the action which is most proper; but a few degrees more or less are not to be regarded. Nevertheless, if one link of the chain confines it to thirty-five degrees, and putting one link lower gives it liberty to fifty-five degrees, the manner your horse carries his head must determine which of the links is most proper. If the horse naturally carries his nose high, let the branch have fifty-five degrees: if he brings his nose in, thirty-five will be best. We should be able to pass the finger between the horse's jaw and the curb. 
P. I.

If there is a chain-strap, the strap must be placed so high on the branch, that when passed through the ring in the curb-chain, it must be buckled to such tightness as to preclude the possibility of the horse lodging the branch on his teeth. Unnecessary tightness should be avoided, as it renders the bit less comfortable to the horse.

When a horse can stop readily and with ease, when his head is constant and steady, and he is light and firm in the hand, and so supple as to be able to obey it in all its motions with ease and readiness, he gives ample proof that the bit is properly adjusted and fitted to his mouth, and that he is reconciled and even pleased with the power it exercises over him: on the contrary, if he open his mouth as if he was gagged, if he writhe and twist his jaws, if he draw up his tongue above the mouth piece, or thrust it out of his mouth sideways, if he retain himself or run backward, if he carry his head very low, and endeavour to force the hand, if he fear the impression of the bit, have no appuy, toss his 
head up and down, or refuse to advance and go forward, interrupting his manege with various disorders, he gives evident reason to suspect that the bit is not properly adapted to his mouth, and offends or hurts it, either within side or without. 


\section{CHAP. III.}

OF THE MODES OF RIDING.

MANEGE riding is the art which teaches us command over the horse. For this purpose, it shows the effect and power produced by every variation of situation and aids. These are its means of rendering the horse obedient to the most delicate touches, of riding him with the greatest ease and exactness either forward, backward, or sideways, and of making him display himself in the most elegant attitudes.

By this method we ride with perfect security; for though we do so with the highest animation, and occasional rapidity, we never suffer the ascendency of the hand to be transferred to the horse. 
By this continual restraint, the horse is of course in general prevented from making the speed his capacity would admit: and the more he exerts himself to that purpose without the rider's permission the sooner he is exhausted.

It is evident that to those who ride fast long distances, or who hunt, the manege style is not calculated, either as regards their own ease or that of the horse.

Nevertheless, besides the fundamental and indispensable knowledge which it imparts, the study of the manege has many advantages.

We are not confined to riding in the manege style when we find it more convenient to ride in any other; but whenever we adopt the proper style for more extended paces, and suffer the horse to take a support and ascendency of the hand, we can, when necessary, more readily recover the superiority of the hand than those who are ignorant of the art. 
There are many persons who have been in the habit of riding from their infancy, who ride boldly in hunting, or on other occasions, and who yet, if by chance their horses happen to be restive, stop short, turn round, and refuse to obey the bridle or answer the spurs, are very awkward, destitute of knowledge to act effectively, and really in danger of being thrown. This may arise not from any extraordinary effort of the horse, but from defect in the seat; which, though sufficient to keep them in the saddle in the common paces of the horse, exposes them to danger on the most trifling occasions.

From ignorance of the principles of riding, such persons, moreover, are continually exposed to innumerable hazards, which they do not see, nor will attribute to the true causes when they happen.

A horse trips, for instance, and the rider tumbles over his head. He then ascribes that to the horse's falling, which is really ascribable to his bad riding; as he ought not 
to have fallen with his horse, but should have assisted him, and prevented the accident. The general cause of horses falling is more the fault of the rider than the horse, namely, bad sitting, and heavy hands.

We are often told that a horse reared, and the person fell off behind, in order that the horse might not fall backwards on him; but we are not told the occasion of the horse's rearing, which was perhaps only the severity of the rider's hand.

Another's horse is said to have shyed to the other side of the road, and the rider is thereby said to have lost his stirrup and fallen into the ditch. The rider of course never says, he fell because he could not ride, but because the horse shyed.

We have all heard also of persons, who, riding against other horses, or meeting carriages in narrow places, could not stop the horse, but ran against the shafts, killed the horse on the spot, or providentially escaped 
with only a few contusions and bruises. No prudent horseman ever met with such disasters.

The reason of such accidents is obvious.

A person may sit prepared for a horse's rearing; yet, if the horse were only to stumble on his knees he would tumble over his head.

The rider who, on the contrary, should guard only against kicking and stumbling, would be exposed to danger if the horse reared.

The rules of manege riding place every member in a situation to act on every emergency.

Other modes of riding will be explained in the sequel. 


\title{
PRINCIPLES
}

\author{
OF \\ MODER N RIDING.
}

PART II.

of

MOUNTING, DISMOUNTING, ETC. 


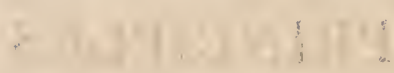

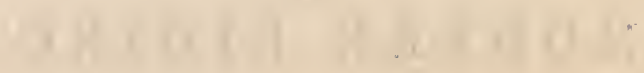
-11 + +1

- 


\section{PART II.}

OF MOUNTING, DISMOUNTING, ETC.

\section{CHAP. I.}

OF MOUNTING BY DISTINCT STEPS.

\section{Section I.-Preliminary.}

The pupil should be brought forward by degrees, and with due preparation. His lessons should be short and gentle, as well with a view to his gradual progress, as to prevent injury from too great exertion.

Some teachers so much regard this progression that before they place a man on horseback they make him execute, and that with facility, lessons with the bridle and sad- 
dle alone; and these occupy his attention several days.

The early lessons are given with a snaffle bridle, on a well trained and steady horse.

The first instructions are those of Mounting and Dismounting.

Section II.-Of Mounting by distinct Steps.

Whatever the disposition of a horse may be, he should be approached apparently in good temper. Horses know by appearance whether the rider is angry or pleased, bold or timid, handy or awkward. A soothing tone of voice and caresses are pleasing; and to such as are unsteady, or have a dislike to be mounted, it helps to dispel their fears. Young horses especially should therefore be thus gently treated and much encouraged.

Before mounting, it is proper to observe whether the saddle is rightly placed, the girths 


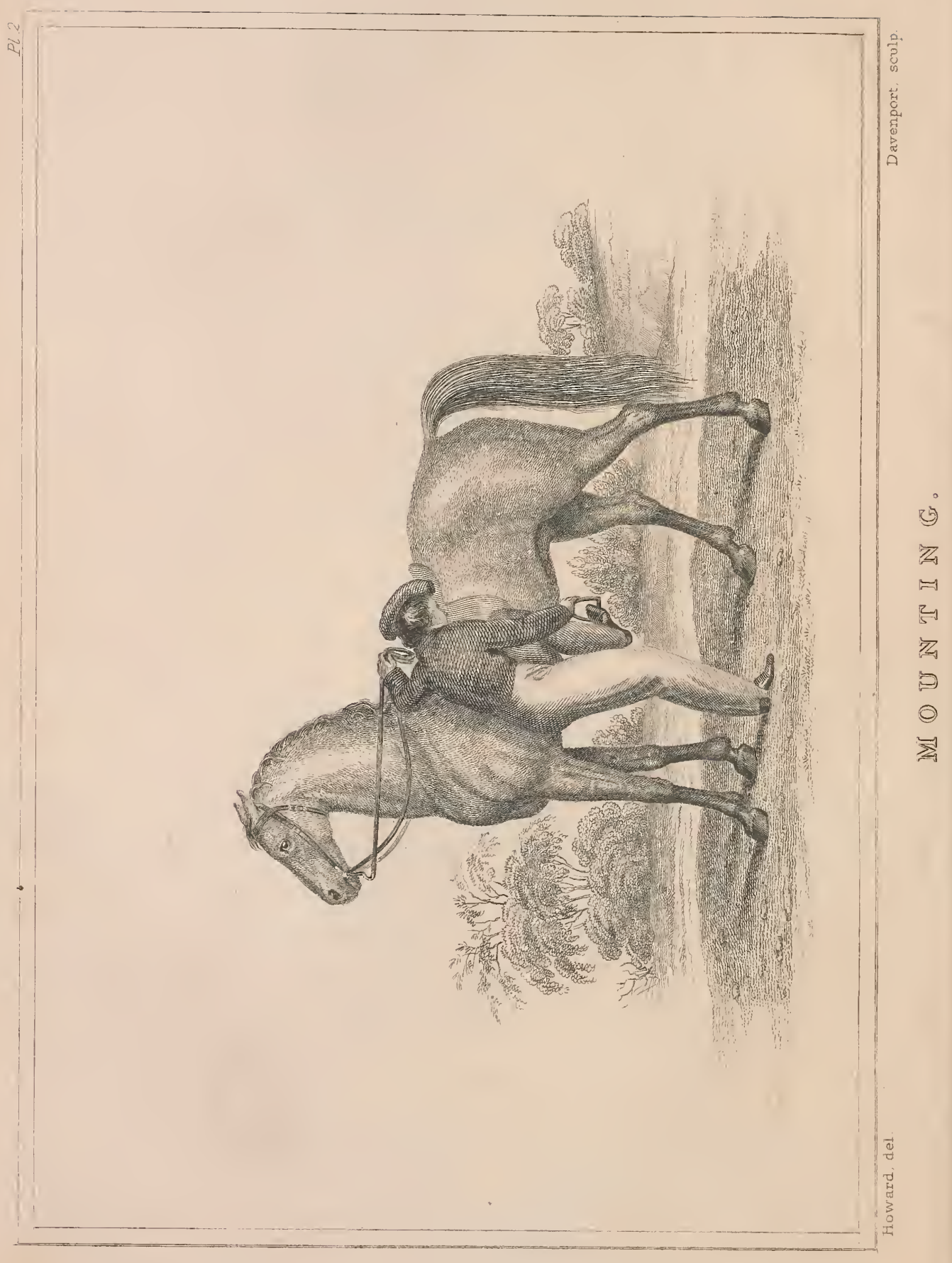


secure and not too tight (for many horses are apt to plunge when they are), the bridle fitly on, and the curb when used smoothly placed.

It is customary to mount a horse on the near or left side.

The rider presents himself rather before the horse's shoulder, with his left breast towards that shoulder, and with his whip or switch in his left hand.

He then takes the snaffle reins in the centre with the right hand, introduces the little finger of the left hand between them from before, the back of that hand being towards the 'horse's head, and places the left hand below the right on the neck of the horse, about twelve inches from the saddle.

The right hand draws the reins through the left and shortens them, so that the left has a light and equal feeling of both reins on

$$
\text { D } 2
$$


the horse's mouth; the right hand remaining for an instant over the left.

The right hand, after throwing the reins to the off side, takes a lock of the mane, brings it through the left hand, and turns it round the left thumb. The left hand closes firmly on the mane and reins.

The right hand, after quitting the mane, lays hold of the left stirrup; the fingers behind, and the thumb in front of it. Plate II. 



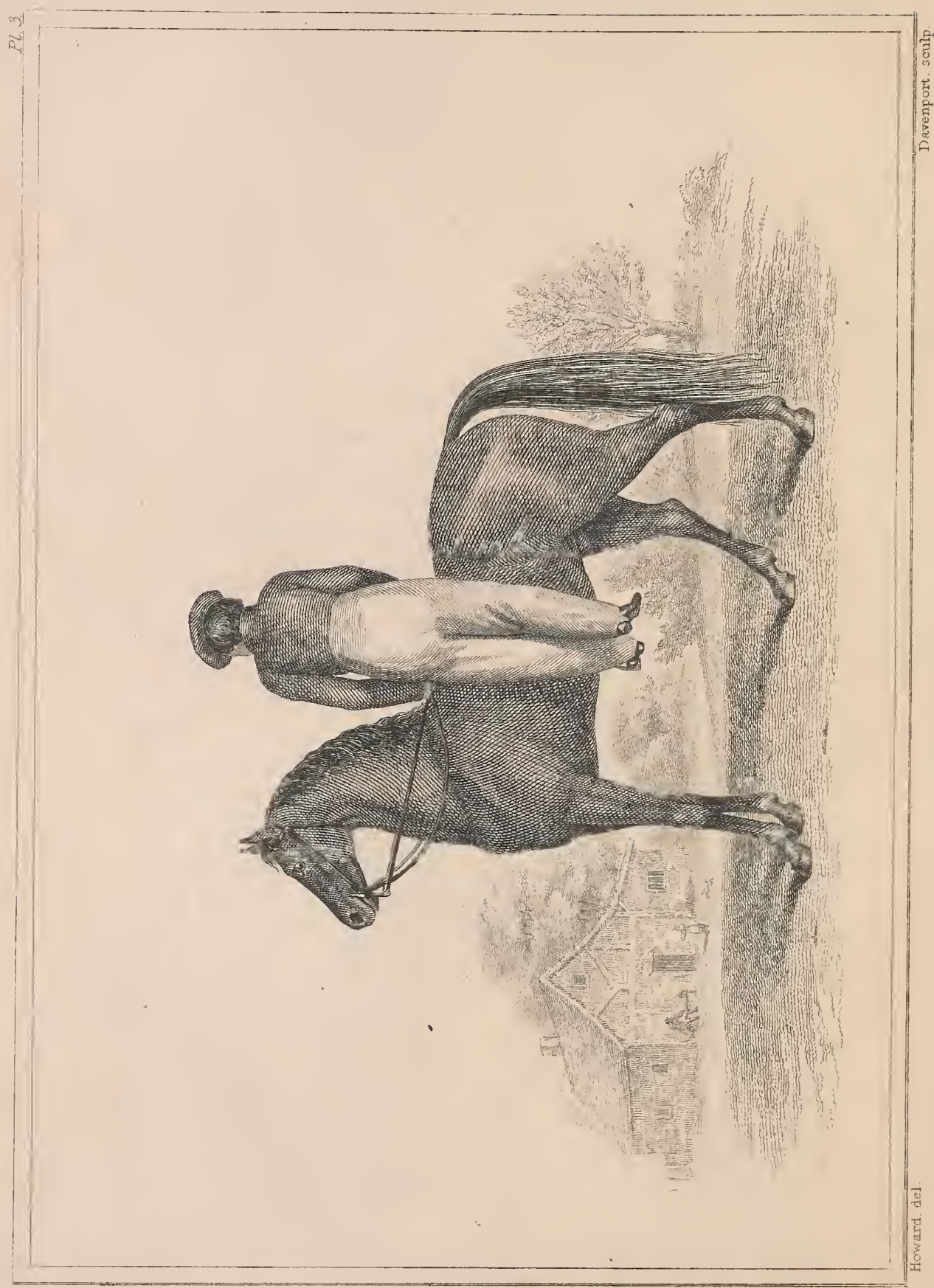

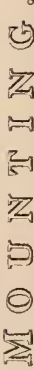


The left foot is raised, and put into, the stirrup as far as the ball of it; and, while the right hand is placed on the cantle, or back part of the saddle, the left knee is placed against the saddle on the surcingle, and the left heel is drawn back, in order to avoid touching the horse's side with the toe.

By a spring of the right foot from the instep, the rider raises himself in the stirrup*, bringing both heels together, the knees firm against the saddle, and the heels drawn back a little, the body erect, and partially supported by the right hand. Plate III.

* In this motion, the learner should be cautioned not to attempt to raise himself by pulling with his right hand, which would tend to displace the saddle: he must depend chiefly on the spring of the right foot. 
The right hand moves from the cantle to the pummel of the saddle, and supports the body while the right leg passes clearly over the horse's quarters to the off side. The right knee closes on the saddle, and the body comes gently into it.

The left hand quits the mane, and the right the pummel. 'The left or bridle hand, with the wrist rounded outwards, is placed opposite the centre of the body, and at three inches distance from it. The right arm is dropped, extended without constraint, the hand by the side of the thigh. The stirrup is taken instantly with the right foot, without the help of hand or eye. Plate IV.

The clothes are adjusted, and the whip exchanged from the left hand to the right, being held with the lash upwards, but inclining a little towards the left ear of the horse, and never departing from the right hand, except while mounting or dismounting.

The horse is to be accustomed to stand till you request him to move. 


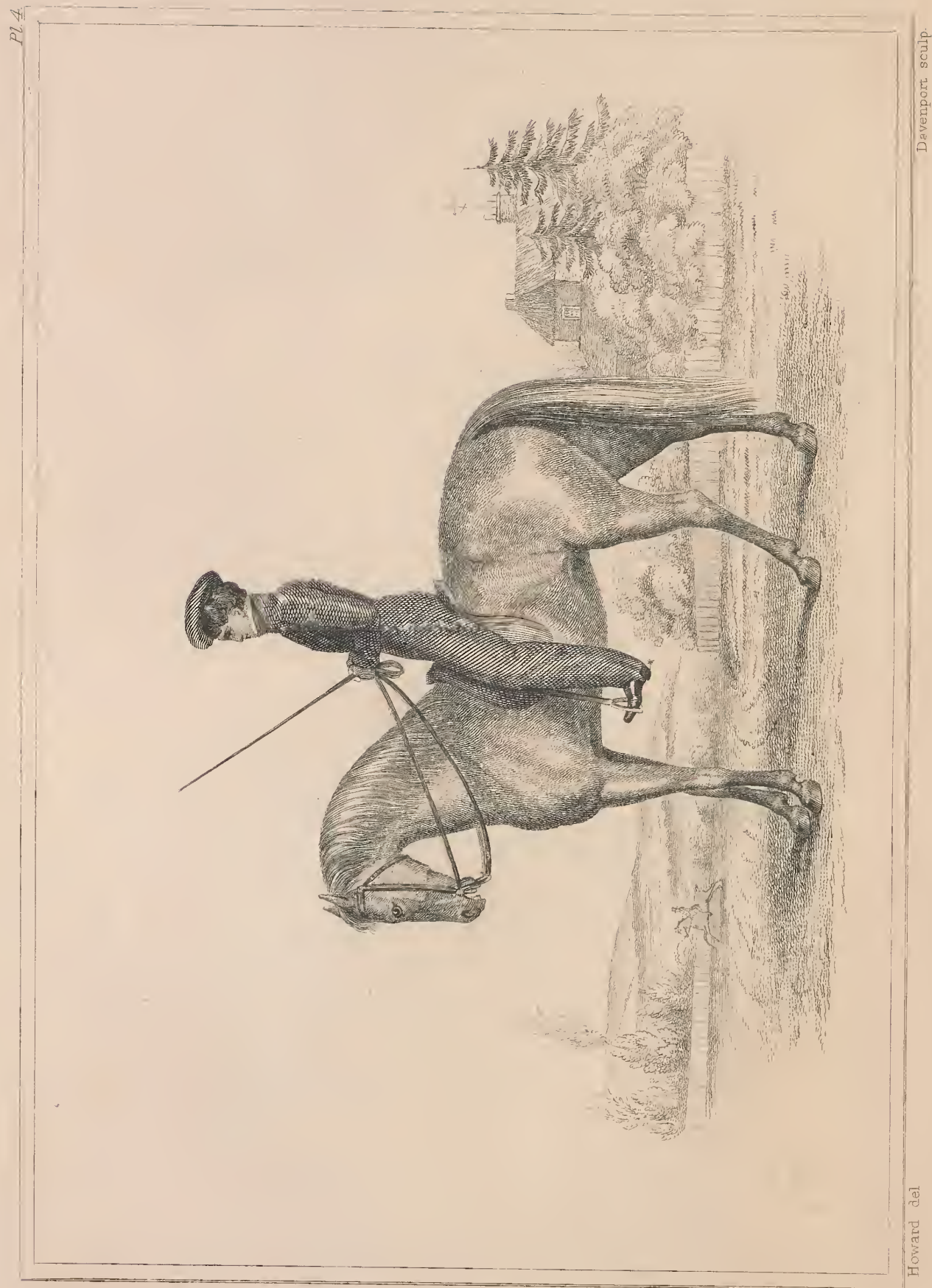




\section{CHAP. II.}

OF DISMOUNTING BY DISTINCT STEPS.

Dismountrag is to disengage oneself from the horse in like manner.

First, the whip is to be returned into the left hand.

The right hand takes hold of the rein above the left. The right foot quits the stirrup.

The right hand holding the rein, the left slides forward on it, about twelve inches from the saddle, feeling the horse's mouth very lightly.

Whe right hand dropping the reins to the off side, takes a lock of the mane, brings it through the left, twists it round the left thumb. The fingers of the left hand close on it. 
The right hand is placed on the pummel. The body is kept erect.

Supporting the body with the right hand and left foot, the right leg is brought gently (without touching the horse's hind quarters or the saddle) to the near side, the heels close; the right hand passing at the same time to the cantle of the saddle to preserve the balance of the body, as in the act of mounting.

The body is gently lowered until the right toe touches the ground.

Resting on the right foot the left stirrup is quitted, and the left foot is placed in line with the horse's hoofs; the hands remaining as in the former motion.

Both hands quit their hold of the mane and cantle, and the right hand lays hold of the snaffle rein near the ring of the bit. 


\section{CHAP. III.}

OF OTHER MODES OF MOUNTING, ETC.

Section I.-Of Mounting and Dismounting without Pauses-On the Off Side-Taking up the Stirrups.

As soon as the learner is perfect in these detailed motions, he should be practised in mounting and dismounting at once, without pausing between the several motions.

At all riding lessons, learners should go once through the detailed motions of Mounting and Dismounting.

Learners should also be occasionally practised in Mounting and Dismounting on the Off Side.

It is good to be expert at mounting on either side. The instructions given for the 
one will answer for the other, taking only the right hand for the left, and the left for the right, and when mounted, shifting the bridle instead of the whip.

When the learner has been practised a few times in the motions of Mounting and Dismounting, he should, when mounted, be taught to take up the stirrups, and to fasten them in front of the saddle, over the horse's neck.

Section II.-Of Mounting and Dismounting without Stirrups.

IN mounting without stirrups-After taking up the reins, instead of seizing the mane, the pupil is to lay hold of the pummel and cantle of the saddle, and mount by a spring of both legs from the insteps, by which means the body is raised to the centre of the saddle. By a second spring of both arms, the leg is carried over the horse, and the man enters his proper seat by closing the knees on the saddle, and sliding gently into it. 
The pupil is to be taught to dismount without stirrups on either side of the horse, by throwing the weight of the body on the hands, which must be placed on the pummel, and by a spring, raising the body out of the saddle before the leg is brought over the horse.

Section III._Of Disposing the Reins.

THe pupil should then divide the reins, placing them between the third and fourth fingers of each hand, the end of the reins being thrown over the fore fingers, the thumb closed on them, and the fingers shut.

When afterwards further advanced, he holds the reins in the left hand as they are at first taken up. 


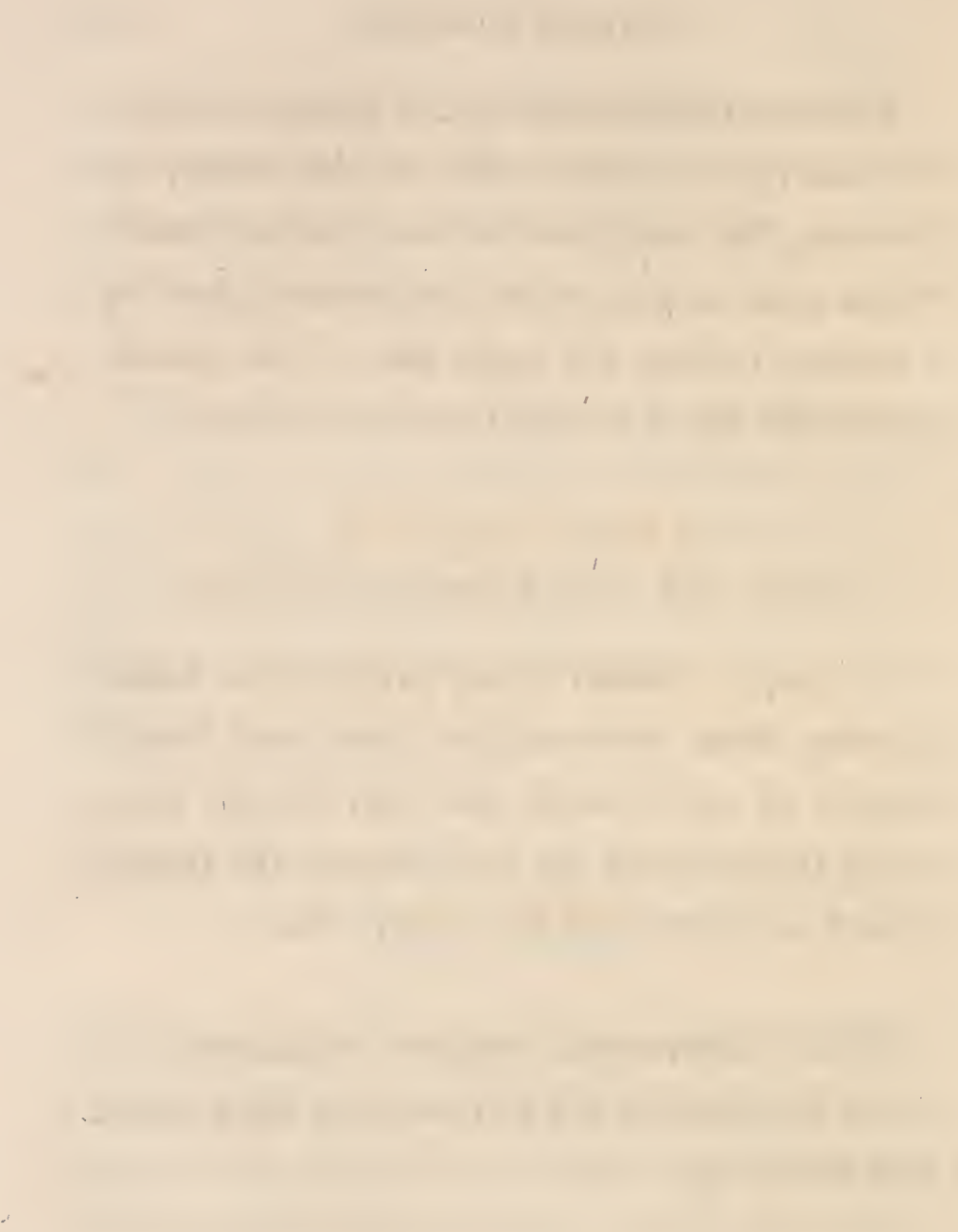




\title{
PRINCIPLES
}

\section{OF M O D E R R I D N G.}

\author{
PART III. \\ or
}

THE SEAT, THE BALANCE, AND THE HAND. 


\section{PART III.}

OF THE SEAT, THE BALANCE, AND THE HAND.

\section{CHAP. I.}

OF THE MANEGE SEAT.

\section{Section I.-Preliminary.}

The Seat is the Disposition of the several parts of the horseman's body, agreeably to the manner in which the horse works.

The immediate result of this is the keeping firm in the saddle at such times as the body is liable to be thrown on the horse's neck, if not over his head, or to tumble backward over the horse's tail. 
The fundamental Seat is that medium position from which all others proceed, and in which the rider sits when the horse is not only going straight forward, but without any bend in his position.

Section II.-General Division into Parts.

In describing this, it is usual to consider the horseman in three parts, and to explain their different functions.

I. The first are the thighs, from the fork to the knees.

These are commonly called the immovable parts; and upon them the whole attitude depends. They ought certainly to be so far without motion as not to wriggle and roll about so as to disturb the horse, or render the seat weak and loose; but the thighs may be relaxed, and even opened to a certain degree with propriety and advantage, when the horse hesitates, and doubts whether he shall advance or not. 
II. The next are the legs, from the knee downwards. These are auxiliaries, and occasionally strengthen the hold of the thighs by a grasp with the calves. They likewise aid, support, and chastise the horse.

III. The last is the body, from the fork upwards, which must always be in a situation to preserve the balance, and take the corresponding motion.

Section III.-Position of particular Parts.

I. LET the horseman then place himself at once upon his fork, sitting exactly in the middle of the saddle, and let him support this posture in which the fork alone seems to sustain the weight of the whole body, by very moderately leaning upon his buttock.

Let the thighs be turned inward, and rest flat upon the sides of the saddle; and, in order to do this, let the turn of the thighs proceed directly from the hips, and let him 
employ no force or strength to keep himself in the saddle, but trust to his weight.

The horseman never avails himself of the strength of his thighs, because, besides that they would then be less steady, the closer he pressed them to the saddle, the more would he be lifted above it.

The muscles of the thighs however act as springs, taking a moderate and pleasant hold, and by practice they act involuntarily in preserving the seat. Thus, when the body is a little thrown to one side, the next motion the body receives, the muscles in the opposite thigh recover the seat again, and by this nice action of the muscles the seat is continually preserved.

The knees must be stretched down and kept back, so as to place the thighs about twenty-five or thirty degrees short of a perpendicular. This will cause the rider to sit on his fork. 
The rider is never to gripe the horse with his knees, unless there be danger of losing all other hold. If the knees be forced or closely pressed against the saddle, the proper action of the body with that of the horse will be lost.

II. If the thighs are upon their flat side in the saddle, the legs will by a necessary consequence be turned just as they ought to be, and will infallibly give the same turn to the feet, because the feet depend upon them as they depend upon the thighs.

The legs then are to be in a line with the rider's body, and they are to hang near the horse's sides, but not to touch.

The legs are also to give an additional hold to the seat when necessary; and the calves are to act in support of the aids of the hand. Being near the part of the horse's body where his feeling is most delicate, they are ready to do their office the instant they are wanted.

E 2 
The heels are to be sunk as low as possible, and the toes to be raised from the insteps; and to be as near the horse as the heels.

This will give firmness and strength to the muscles of the legs and thighs, and prevent the heel touching the horse; for the lower the toe is as well as the more outward, the nearer the heel will be to the sides of the horse, and the more in danger of touching his flank.

III. The head should be free, firm, and easy. It should be firm, that is to say, straight, without leaning to the right or left, neither advanced nor thrown back, in order to be ready for all the natural motions that the horseman may make in turning it to one side or the other. Otherwise it would occasion a stiffness ; and that stiffness affecting the different parts of the body, especially the spine, they would be constrained.

The shoulders should be thrown back. 
The chest should be advanced.

The small of the back should be bent a little forward.

IV. The upper parts of the arms should hang perpendicularly from the shoulders.

The lower parts should beat right angles with the upper.

The elbows should be lightly closed to the hips, but without stiffness.

If the elbows are not kept steady, they will give an uncertainty and fickleness to the hand, sufficient to ruin it for ever.

The wrist should be rounded a little outwards.

The hands should be placed so that the little fingers may be on a level with the elbows, about four, and never more than six inches 
apart; the thumbs and knuckles pointing towards each other.

When at rest, the hands are to be in line with each other, and about three inches from the body. When in motion round the manege or the circle, the inward hand (which is the hand on which he turns), is to be a little lower than the outward one.

When the rider is in the proper position on horseback without stirrups, his nose, breast, knee, and instep, will be nearly in a line. With stirrups, the nose, breast, knee, and toe will form a perpendicular line.

The manege seat in these respects corresponds with the advice of Xenophon:- "We would not have him sit in the attitude of one who drives a chariot, but as if he were standing erect with his legs somewhat astride, for thus his thighs will cling closer to the horse, and, being upright, he will be better able to wield his lance, and strike with more force." 



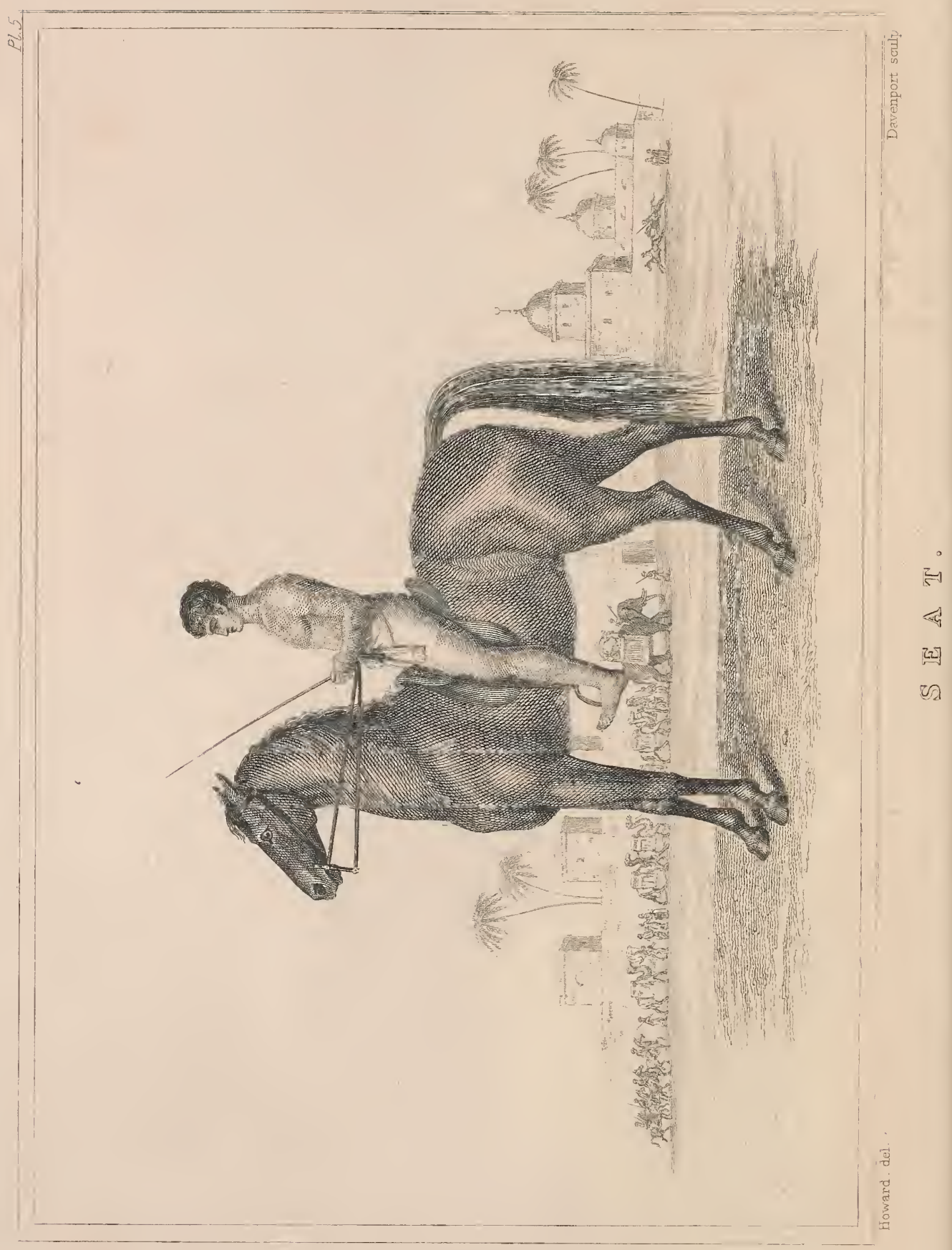




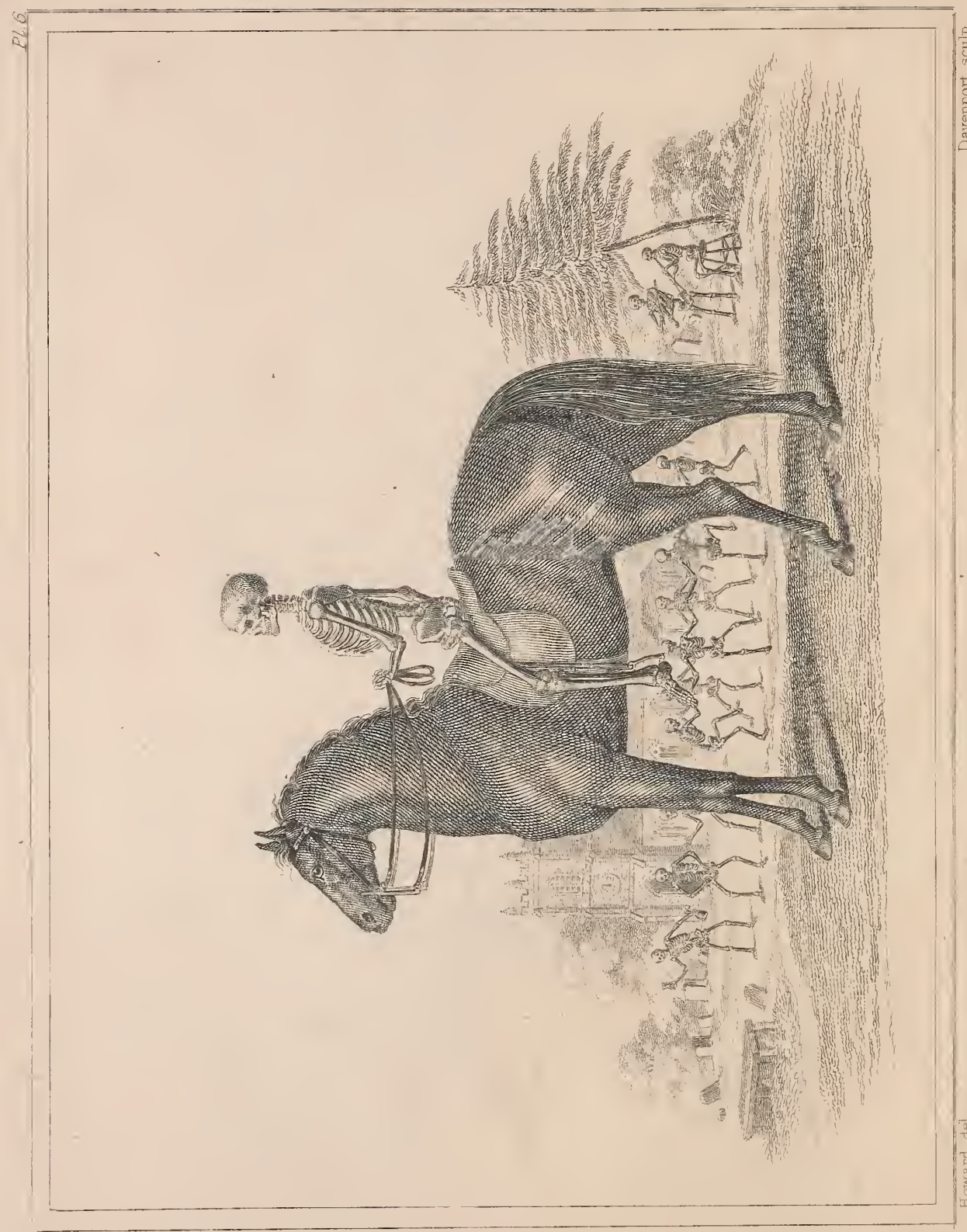


This, then, is the general position on horseback, when the horse stands still or is moving at a walk.

\section{Section IV.-Concluding Remarks.}

IT is ever to be understood, that the man and the horse are to be of a piece. In other words, when the horse is at liberty and disunited, then the rider, in like manner, sits at his ease, and may be said to be disunited; and as he begins to collect and unite his horse, so. he collects and unites himself. When the rider is pressing a horse to the union, and drawing from him the most elegant attitude and lofty action, the rider's attitude must likewise be in the extreme of elegance, and his exertions in the same proportion as that of the horse.

We may conclude by observing with $\mathrm{Be}$ renger, that the seat alone may be cultivated: for some time; and when the scholar is arrived at a certain degree of firmness and confidence, if the horse can be trusted, let 
the master hold the longe, and the pupil, abandoning the government of him to the master, ride him to both sides with his hands behind him. This will very soon settle him with firmness in the saddle, will advance his waist, will place his head, will stretch him down in the saddle, will teach him to lean gently to the side to which he turns, so as to unite himself to his horse, and go with him, and will give that firmness, ease, and just poise of the body which constitute a perfect seat, founded in truth and nature, and upon principles so certain, that whoever shall think fit to reduce them to practice, will find them confirmed and justified by it.

Plates V. VI. and IV. examined in succession illustrate the Seat.

The seat of the eastern people appears to have been nearly the same in ancient as in modern times. Plate VII. is supposed to represent Darius, saluted King of Persia, when he had gained the empire by the neighing of his horse. 'These nations have, in all 


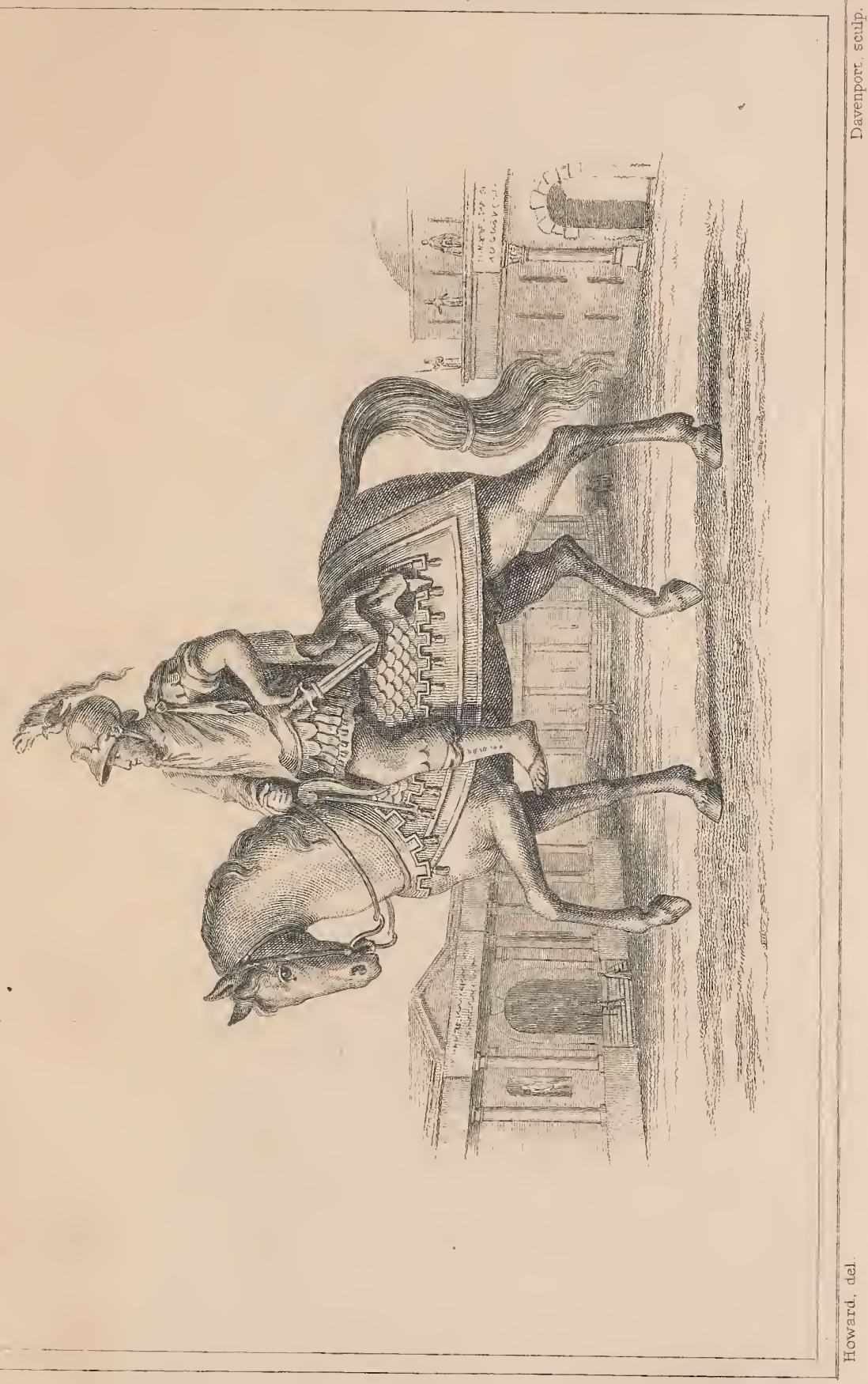





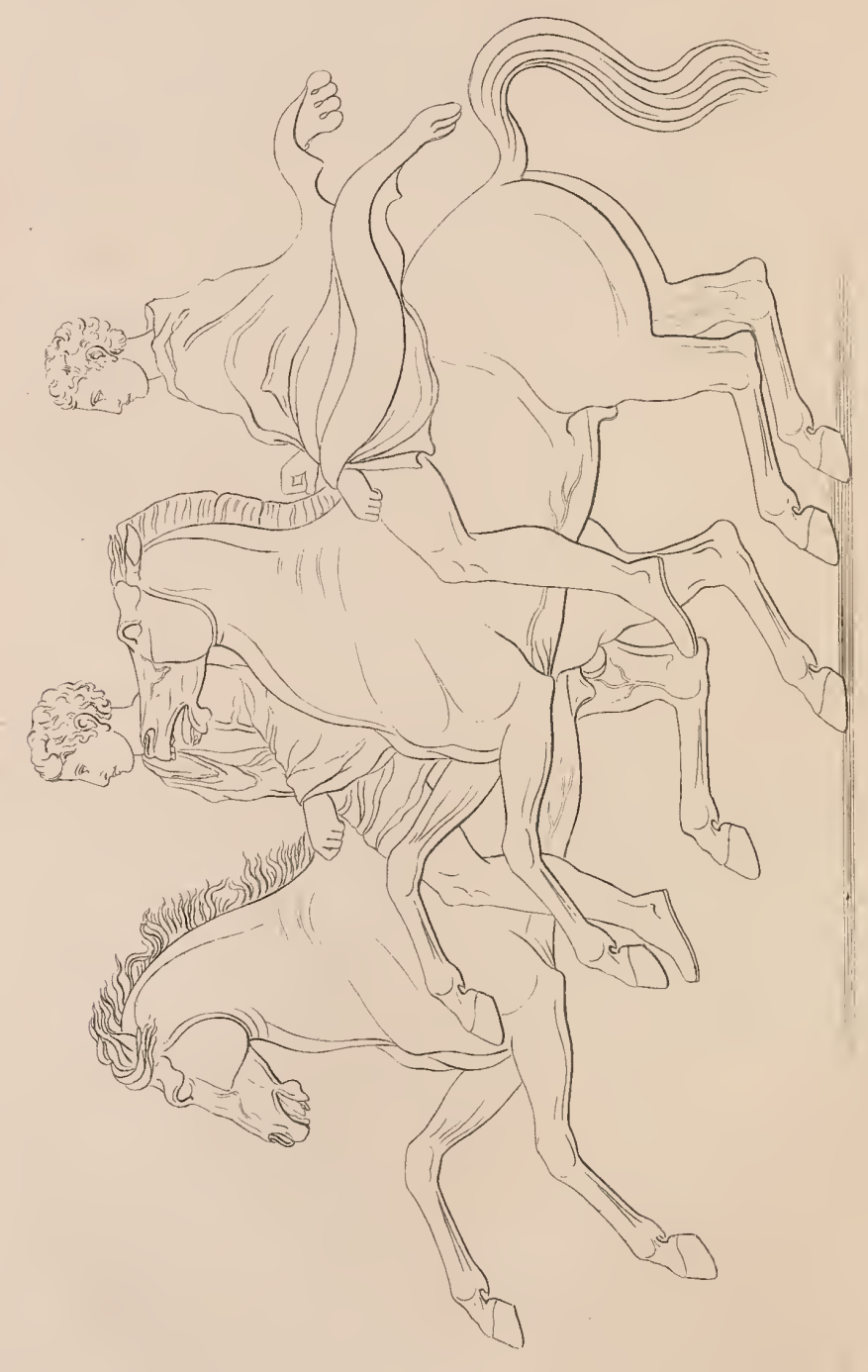

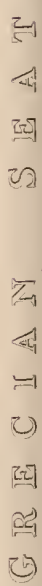





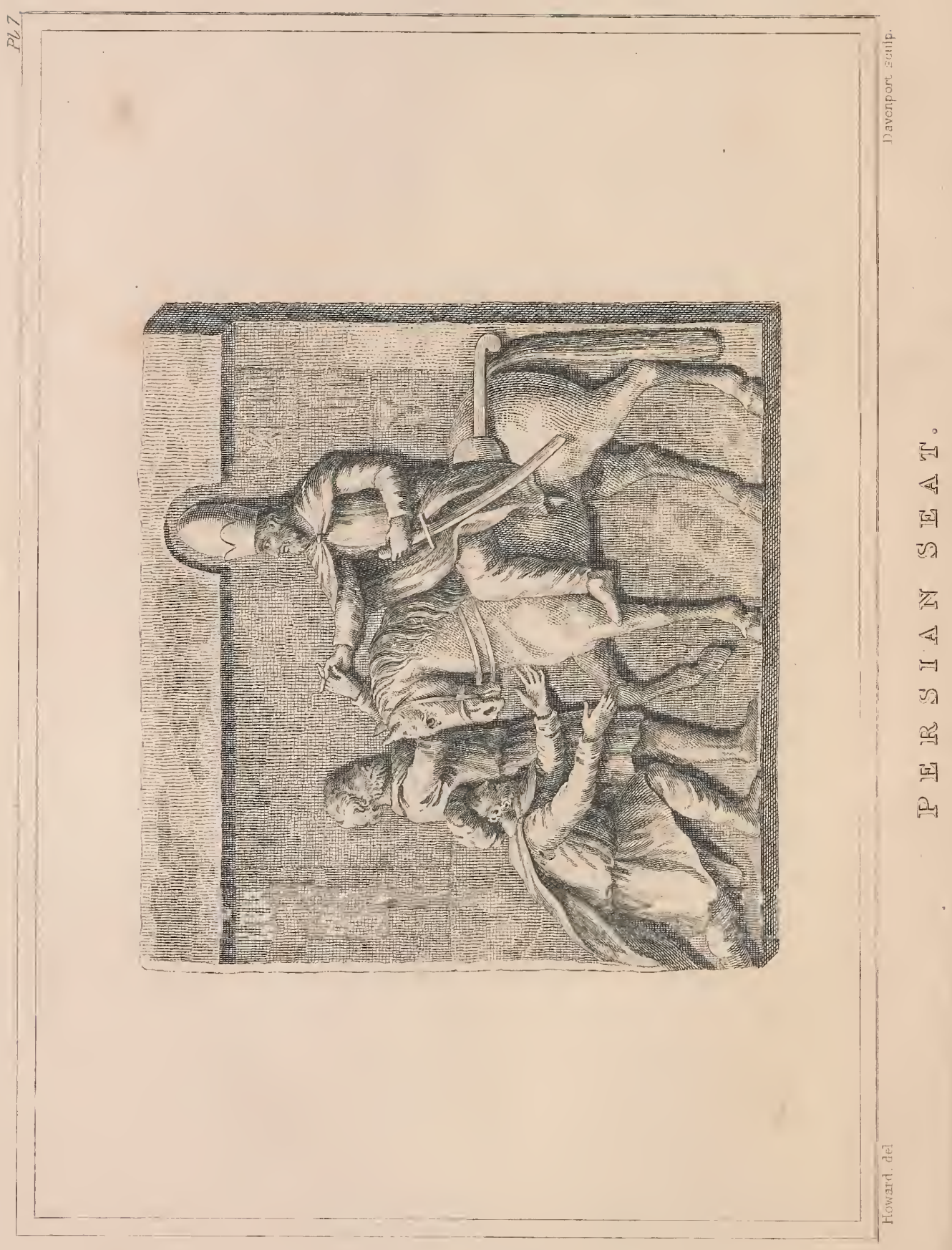


ages, been much accustomed to ride; and their seat, nearly resembling our racing seat, is adapted for speed.

The Roman seat is shown in the following Sketch of the Emperor Theodosius, Plate VIII. which, as the Romans were a more military people, approaches nearer to our manege seat, and indeed is nearly the same with our road or hunting seat.

The Greek seat, shown in Plate IX. two horsemen from the frieze of the Parthenon, is, like every thing relating to that transcendent people, perfectly beautiful; but it is a parade or promenade seat, in which the rider is rather disunited, and as such is at present imitated by our fashionable horsemen. 


\section{CHAP. II. \\ OF THE BALANCE.}

Tre balance in riding is the preserving the body from that inclination to one side or the other, which even the ordinary paces of the horse in the trot or gallop will occasion.

The balance is preserved when the horseman sits upon his fork directly down upon the saddle, and so firmly that nothing can loosen his seat. But the firmness here necessary is that hold with which he keeps himself on horseback, without employing strength, trusting entirely to the natural balance of his body to accompany all the motions of the horse.

Nothing but practice can give this balance, and consequently this hold upon the horse. 
Let us illustrate this balance.

If the horse work straight and upright on his legs, the body must be in the same upright direction.

As the horse moves into a trot, the body must be inclined a little more back; while the whole figure must be pliant, and accompany all the movements of the horse; the elbows and lower limbs being kept steady. So also in the gallop, in leaping, or in any violent movements of the horse, the body must chiefly be kept back, and accompany the various actions of the horse with an easy pliancy.

When the horse bends or leans, as he does when he works on a circle or trots briskly. round a corner, then the body must lean in the same direction and proportion, or the balance will be lost.

To preserve the balance, it is evident that the body must keep in the same direction as 
the horse's legs; and thus the balance is maintained by as many different positions as the horse has capacity to work in.

The pupil must take no assistance from the reins to support the balance. The hand must be fixed, and the reins of such a length as to feel and support the horse, but never to hold on.

To acquire the balance the practice on circles, or what is called the longe, is recommended. Here it is right to begin on large circles, and at an easy gentle trot, by which the horse will be so little bent as scarcely to make a perceptible alteration in the fundamental position; but as the circles are contracted, and the face extended, it is necessary not only for the body to lean with the horse, but likewise to bend or be turned in the same direction as the horse's head, which, of course, is a little within the circle. In doing this it is useful to work equally to both hands, and not to use stirrups till the pupil has acquired the balance without them. 
Experience proves, that the body, if in the manege seat and fundamental position, almost involuntarily takes the corresponding motion, whether the horse rears, springs forward, kicks, stumbles, \&c. 


\section{CHAP. III.}

OF THE HAND.

\section{Section I.-Preliminary.}

$\mathrm{ON}_{\mathrm{N}}$ the hand depends all excellence in horsemanship The hand directs the action and time, raises the horse's forehand, lightens the mouth, and supports the position. In violent contentions with the horse, the hand deprives the horse of half of his power to throw the rider, and it would otherwise be impossible to keep on the back of some horses.

\section{Section II._Of Holding the Reins.}

BEFORE the operation and effects of the hand can be attained, an expertness at holding the reins must be acquired.

There are various methods of holding the reins, according to the style of riding, the 
design of the rider, and the propensities or defences of the horse.

Here we consider bridles which have but one rein attached to each end of the bit, such as snaffles.

I. In these as well as in other cases, the reins ought generally to be separated, passing into the hand between the third and fourth fingers, and out of it over the forefinger, where they are held down by the thumb.

II. When the snaffle is held in the common way, both reins are placed in the left hand. The left rein passes under the little finger, and the right. under the third finger, both lying smooth through the hand, the superfluous quantity of rein hanging over the first joint of the fore finger, and the thumb placed upon them.

Section III.-Of the Correspondence and Appui. To convey to the pupil an idea of the manner in which the hand operates on the horse's 
mouth, he should be placed on a horse whose mouth is perfectly formed and obedient, but not too delicate; the reins being held as described, the hand placed so that the ends of the fingers are opposite to the centre of the body, and about the height of the elbow; the reins collected to such determined length, that, bracing the muscles of the hand, would rein the horse back, and easing them permit the horse freely to advance. The hand, for preserving a medium effect on the mouth, should be only half shut; the knuckles next the wrist being nearly open.

I. The hand being connected to the reins, the reins to the bit, the bit operating in the curb on the bars in the horse's mouth, and in the snaffle on the lip, the rider cannot move the hand, nor scarce a finger, but the horse's mouth is more or less effected. This is called the correspondence.

II. If then the hand be held steady, as the horse advances in the trot, the fingers will feel, by the contraction of the reins, a slight tug, occasioned by the cadence of every step. 
This tug, which is reciprocally felt in the horse's mouth, by means of the above described correspondence, is called the appui.

While this appui is preserved between the hand and mouth, the horse is in perfect obedience to the rider, the hand directing him with such ease that the horse seems to work by the will of the rider, rather than the compulsion of the hand.

Now the correspondence, as it is termed when we speak of the effective communication between the hand and mouth,- - the appui, when we speak of the quality or strength of the operation in the mouth,- the support, when we speak of the effect the hand produces in the position or action-are always to be maintained in the manege and all united paces; and, without these, a horse is under no immediate control, as we find in the extended gallop or full speed, where it may require a hundred yards to pull before you can stop. 
The strength or degree of this appui (allowing for the different qualities of horses' mouths), depends on the relative situation of the hand and position of the horse.

The raising of the rider's hand increases his power; and this, raising the horse's head, diminishes his power.

If a garter were placed across the pupil's forehead, and a person behind him held the two ends in a horizontal direction, if the pupil stood quite upright, he could not pull at the person's hand, nor endure the person's hand to pull at him without falling or running backwards. This is the situation of a horse when united.

Accordingly, when the pupil felt the hand severe, or expected it to pull, he would guard against it by bending the body, projecting the head, and planting one foot behind. This is the situation of the horse when disunited, or defending himself against the heaviness of the hand. 
Hence a heavy insensible hand cannot unite a horse, because the horse cannot bear its severity when united. And hence heavy hands make hard-mouthed horses.

If then the appui be heavy, from the head being carried too low, and the horse not sufficiently united, raise the hand, and let the fingers, by moving, rather invite than compel the head to rise; the legs at the same time pressing the haunches under. By this means, the horse will become more united, and the appui will be lightened.

Should the hand be too straight or confining to the horse (which it may be, though it does not pull half an ounce), by the rider collecting the reins to unite the horse, and the horse freely uniting himself, he may become so balanced on his haunches, that, while the hand supports him thus, though it do not pull in the least, he cannot disunite himself, nor advance one step; and, should the rider then press him without yielding or dropping the hand, he would compel him to rear. 
By these two extremes may be understood, first, where the horse is disunited; and last, where he is too much united. The intermediate consequence and effect of the hand and heel must be acquired by practice.

Section IV._Of the Qualities of the Hand.

There are many properties requisite to constitute a masterly hand. 'That is called a masterly hand, which is not only well formed in itself by tuition, and riding manege horses, but can make the untutor' $d$ mouth partake of the sensibility of the hand, which, in other terms, is dressing the horse.

Three qualities are essentially necessary to such a hand. It ought, to be firm, gentle, and light.

I. That may be called a firm or steady hand whose feeling corresponds exactly with the feeling in the horse's mouth. This demands a certain degree of steadiness, and constitutes that just correspondence between 
the hand and the horse's mouth, which every horseman wishes to find.

Such a hand will not yield to the solicitation or craving of the horse to get the ascendency of the hand; for an ascendency of the hand is obtained when the horse abandons that delicate correspondence producing the appui, and keeping him under the strictest obedience, and makes a dull or insensible pull on the hand. And horses, though they have been ever so well broke, after being rode a few times by an untutored hand, will fall into this, if permitted.

To frustrate the little efforts of the horse to obtain his purpose, the hand is kept firm, and the fingers braced, by which their operation becomes severe, and is a proper punishment. Should the horse disregard this, and plant his head low, to endure the severity of the hand, the hand must act by moving the fingers, shaking the reins, \&c. to raise the head and divert him from his purpose; and lastly, the correction of the hand must be 
given severely, if necessary, to deter him from further attempts. This correction is given by first yielding the hand that the reins may become slack, then giving them a smart or violent snatch in an upward direction, which will make the horse raise his head; and the apprehension of a repetition of it will deter him from putting it down again.

II. An easy or gentle hand is that which, by relaxing a little of its strength and firmness, eases and mitigates the degree of feeling between the hand and the horse's mouth.

It is a rule in this respect not to pass, at once, from one extreme to another, as from a firm hand to a slack one, or to jump over that degree of sensation which is derived from the easy or gentle hand. Were the rider at once to go from a firm hand to a slack one, he would entirely abandon his horse, he would surprise him, deprive him of the support he trusted to, and precipitate him on his shoulders. On the contrary, were he to pass from the slack to the tight rein all at 
once, he must jerk his hand, and give a violent shock to the horse's mouth:-rough and irregular motions which would be sufficient to falsify the firmest appui, and to ruin a good mouth.

The hand, moreover, must be sensible and discriminating whether the horse wishes to disengage himself from its restrictions, or whether he wants a momentary liberty for his accommodation and ease. He will remove the rider's hand if he wants to cough; he will move his head if cramped by too long confinement, or to dislodge a fly, and the like. The rider, discovering the cause of such removal, will not correct (unless the horse, presuming on his compliance, takes too much liberty), but rather allow a reasonable accommodation, and be gentle and pleasant while the horse is united and obedient.

III. A light hand is that which lessens still more the feeling between the rider's hand and the horse's mouth, which was before moderated by the gentle hand. 
The appui being always in the same degree, would heat the mouth, would dull the sense of feeling, would deaden the horse's bars, and render them insensible and callous. Lightness of hand consists, then, in an almost imperceptible alternate feeling and easing of the bridle, regulated by the motion of the horse.

By proper attention to this practice, the natural delicacy and feeling of the horse's mouth will be preserved,-the rider's hand will be gradually formed,-and a constant correspondence between the horse and the rider will be established. On the contrary, any dead or continued pull will produce effects directly opposite to those desired,

It is indispensably necessary, therefore, that all the operations of the hand should be firm, gentle, and light; and, in order to this, it is necessary that the wrist alone should direct all its motions, by steering it, if we may so say, through every motion which it is to make. 
It is, nevertheless, true, that with horses that are well dressed, one may take liberties. Such are those motions which are called descents of the hand. These are made three different ways, either by dropping the knuckles directly and at once upon the horse's neck, or by taking the reins in the right hand, about four finger's breadth above the left, and letting them slide through the left, dropping the right hand at the same time upon the horse's neck; or else by taking the end of the reins in the right hand, quitting them entirely with the left hand, and letting the end of them fall upon the horse's neck. These motions, however, which give a grace to the horseman, never should be made but with great caution, and exactly at the time when the horse is quite together, and in the hand; and the rider must take care, by throwing back his body, to counterbalance the weight of the horse upon his haunches.

Besides these rules, there are others not less just and certain; but the niceness of which every rider is not able to understand. 
Both reins being in one hand, and that being in the first position, if I open the two middle fingers, I slacken my right rein. If I shut my hand, the right rein operates again, and resumes the appui. If I open my little finger, carrying the end of it upon the right rein, I thereby slacken the left and shorten the right. If I shut my hand entirely and open it immediately again, I thereby lessen the degree of tension and force of the two reins at the same time. Again I may close my hand not quite so much, but still close it. It is by these methods, and by the vibration of the reins, that we may unite the feeling in the hand with that in the horse's mouth; and it is thus that we may play with a fine and made mouth, and freshen and relieve the two bars in which the feeling or appui resides.

It is the same with respect to the second descent of the hand. The right hand holds the reins, and we pass and slide the left hand upon the reins, up and down, and in that degree of appui of the easy and slack hand; 
by means of which the horse endeavours of himself to preserve that mutual sensation between his mouth and the rider's hand, which alone can make him submit with pleasure to the constraint of the bit. 



\section{PRINCIPLES}

\section{OF M O D R N R I I N G.}

PART IV.

oF

THE AIDS. 



\section{PART IV. \\ OF THE AIDS.}

\section{CHAP. I.}

OF THE AIDS OF THE HAND.

\section{Section 1.-Preliminary.}

AIDs are the indication of the horseman's will to the horse, and are so called, because they not only require, but assist, the horse to execute. They, at the same time, check or obstruct him from acting contrarily.

These aids are certain positions of the hand, body, legs, and sometimes of the switch or whip; the hand being the principal. The others are sometimes called accompaniments, 
as they give greater power and efficacy to the hand.

A horse can move four different ways. He can advance, turn to the right, to the left, and stop or go back, but he cannot make these different motions, unless the hand of the rider permits him, by making four corresponding motions which answer to them. Thus there are five different positions for the hand.

The first is that general position from which proceed the other four.

Section II.-The Five Positions when the Reins are separate.

WHEN the reins are separate and one held in each hand, the first position is that which has been already given; viz. the reins passing up between the third and fourth fingers of each hand, their ends being thrown over the fore fingers, the thumbs closed on them, and the 
fingers shut, the hands in line with each other, about three inches from the body, and the little fingers as high as the elbows.

The second position consists of a slight relaxation of the preceding, and permits the horse to advance.

The third position shortens the right rein rather upward, and turns the horse to the right.

The fourth position shortens the left rein rather upward, and turns the horse to the left.

The fifth position shortens both reins, and stops or reins the horse backward.

In all these cases, the hands are kept near the body. 
Section III.-The Five Positions wehen the Reins are not separate.

WHEN both reins are held in one hand, these rules are modified as follows :-

First, let the hand be held three fingers breadth from the body, as high as the elbow, in such a manner that the joint of the little finger is upon a right line with the tip of the elbow; - let the wrist be sufficiently rounded, so that the knuckles may be kept directly above the neck of the horse;-let the nails be exactly opposite the body, the little finger nearer to it than the others, the thumb quite flat upon the reins, which must be separated by putting the little finger between them, the right rein lying upon it. This is the first and general position.

Would you have your horse go forward? Yield to him your hand; and for that purpose turn your nails downwards, in such a 
manner as to bring your thumb near your body, to remove your little finger from it, and to bring the thumb into the place where the knuckles were in the first position, keeping your nails directly above your horse's neck. This is the second position.

Would you turn your horse to the right? Leave the first position, and carry your nails to the right, turning your hand upside down, in such a manner, that your thumb be carried out to the left, and the little finger brought in the right. This position of the hand will carry the operation of the reins nearly three inches more to the right, by which the left reins will press the neck, and the right reins will be slack. This is the third position.

Would you turn your horse to the left? Leave the first position, turn the little finger to the left, the thumb to the right, the back of the hand upwards. This will carry the operation of the reins to the left, the right reins will press the neck, and the left reins will be slack. This is the fourth position.

G 2 
Would you make your horse stop or go backward? Quit the first position, let the wrist be quite round; turn the nails quite upwards, and the knuckles towards the horse's neck. This is the fifth position.

These different positions, however, are not alone sufficient; we must be able to pass from one to another with readiness and order.

These aids where the reins are held in one hand are not so effective as those where the reins are separate; which have already been described.

They may be more simply given by a little extending or bending the wrist to make the horse advance or go backward, and by slightly carrying the hand to the right or left, and rather upward, to make the horse turn in these directions. 


\section{CHAP. II.}

OF THE AIDS OF THE BODY.

II. To cause the horse to advance, while the hand is relaxed, throw the body a little forward, but do not press the horse's fore parts with your weight; and at the same time approach your legs to his sides.

If your horse rise up, bend your body more stronger forward.

If he kick, leap, or jerk out behind, throw your body back also.

If he gallop when he should not, oppose all his motions; and, for this purpose, push your waist forward towards the pummel of the saddle, making a bend or hollow at the same time in your loins. 
III. and IV. In order to make the horse go into the corner of the manege, you must begin by opening it.

To open a corner is to turn the shoulder before you come to it, in order to make it cover the ground; and then the croupe, which is turned in, will not follow the line of the shoulders till they are turned and brought upon a straight line, in order to come out of the corner. In order to turn the shoulder to the corner, you must carry your hand to the side to which you are to go; and to throw in the croupe, you must support it with the leg on that side to which you carry your hand.

To make the shoulders turn, and come out of the corner, you must carry your hand on the side opposite to that to which you turned it, in order to go into the corner; and that the croupe may pass over the same ground as the shoulders, you must support with the leg of the same side to which you now carry your hand. 
The horse never can perform any of these actions without an entire agreement of all these aids, and one single motion of the body will be sufficient to unite them all with the utmost exactness. In effect, instead of carrying your hand out, and seconding that aid with the leg, turn your body, but imperceptibly, towards the corner, just as if you intended to go into it yourself; your body then turning to the right or left, your hand, which is one of its appurtenances, must necessarily turn likewise, and the leg of the side on which you turn will infallibly press against the horse and aid him. If you would come out of the corner, turn your body again, your hand will follow it, and your other leg approaching the horse, will put his croupe into the corner, in such a manner, that it will follow the shoulders, and be upon the same line.

It is by these means that you will be enabled to time the aids of the hand and legs with greater exactness than you could do, were you not to move your body; for how 
dexterous and readily soever you may be, yet when you only use your hand and leg, without letting their aids proceed from, and be guarded by, your body, they never can operate so effectually, and their action is infinitely less smooth, and not so measured and proportioned, as when it proceeds only from the motion of the body.

The same motion of the body is likewise necessary to turn entirely to the right or left, to make your horse go sideways on one line, or to make the changes.

V. If you would make the horse go backward, throw gently back your own body, your hand will go with it, and you will make the horse obey by a single turn of the wrist, 


\section{CHAP. III.}

OF THE AIDS OF THE LEGS.

II. If you want to make the horse go forward, while you yield your hand to him, at the same time close your legs. The hand ceasing to confine, and the legs driving his hinder parts, the horse obeys.

III. If you want to go to the right, while you carry your left hand to the right, and support him with your right hand, your right leg determines his croupe to the left, and facilitates the action of the shoulder, which your hand had turned to the right.

IV. If you want to turn him to the left, while you carry your right hand to the left, and support him with your left hand, you approach your left leg. 
When you would make a change to the right, your left leg confines the croupe, so that it cannot escape, but must follow the shoulders. If you would change hands again to the left, your right leg acts as your left did in going to the right.

V. When you wish to stop him, hold him in, and approach your legs gently to his sides.

The aids of the legs have their progressive strength and effect, thus given:-The leg being brought nearer the side, is the first degree, or lightest aid; placing the leg further back, with the toe turned out, is the next; the lightest possible touch with the calf of the leg, is the third; and so on, increasing the degree of pressure according to the strength of aid required, with the toe kept up firmly, that the muscles of the leg may be hard and operative. The strongest aid is the scratch, which is thus given:- when the leg is laid on hard without effect, drop the toe; and if the spur is placed in a horsemanlike 
manner on the heel, the rowel of the spur will thereby pinch or scratch the horse's side: to this let a correction succeed by giving the spur sharply.

Aids with the whip are sometimes used to give greater effect to the heel. These are gentle taps with the whip on the hind quarters, and sometimes on the shoulders.

When given on the near side, the hand is either applied behind the back, with the whip held by the fingers as you would a pen, with the lash downwards; or crossing the bridle hand before, the whip being held with the lash upwards.

When the aids are properly displayed, they discover the taste and judgment of the horseman, and have a pleasing appearance. 


\section{CHAP. IV. \\ OF ANIMATIONS, SOOTHINGS, AND COR- RECTIONS.}

\section{Section I.-Of Animations.}

Antmations are requisitions of more exertion, life, and spirit, and proceed from the hand, the leg, the whip, or the tongue.

Those of the hand and of the legs have been already described among the aids.

Animations of the whip are mild taps to quicken the horse; or, if the lash is upwards, switching it in the air. This has a gay appearance, as well as effect, if not too often repeated, or continued too long.

The animations of the legs and whip, are menaces which indicate a punishment, if not attended to. 
The animation of the tongue seems to operate by surprise. It is a sound which letters cannot easily express, and is produced by placing the tongue flat against the roof of the the mouth, and suddenly displacing the posterior part of it by drawing the air laterally between it and the palate. This noise is the most animating sound to the horse, and, when judiciously applied, has its proper effect; but if too much continued, or too frequent, its design is done away, for it no longer alarms or surprises.

Thus the rider may use his animations alternately to keep up an effect; and with sluggish horses, he may be necessitated to use the whip and spurs.

Section II._Of Soothings.

SoothINGS are the reverse of animations, and are used to pacify horses that are alarmed, or have too much fire in their constitutions. 
Of all the means we use in dressing horses, soothings and caresses are the most salutary. These dispel their fears, reconcile them to new operations, and give them confidence in their master.

The voice sooths by the soft and mild tones with which we accompany such expressions, as-So, so, so! poor fellow! and the like: the hand, by gentle patting, stroking, \&c.: the body and legs, by a stillness, and relinquishment of all unnecessary firmness, sitting easy, and not moving a muscle.

From this it will appear, that a horseman should have perfect command of temper, in order that the horse may not irritate and provoke him to anger, as well as invincible patience and perseverance, to make the horse comprehend and perform. Mildness and perseverance will overcome all difficulties. Demand but little the first time, and you will be more readily obeyed the next; and increase your demands as the horse becomes accustomed and has temper to submit to it. 
Section III.-Of Corrections.

Corrections are of two sorts. You may punish a horse with the spurs, the switch, or chambriere; you may punish him by keeping him in a greater degree of subjection. In all cases, a real horseman will endeavour rather to work upon the understanding of the creature, than upon the different parts of his body.

In reality, the corrections which reduce a horse to the greatest obedience, and which yet dishearten him the least, are such as are not severe; but such as oppose him in what he wants to do, by restraining and putting him to do directly the contrary. If your horse do not advance, or go off readily, or if he be sluggish, make him go sideways, sometimes to one hand, sometimes to the other; drive him forward, and so alter alternately. If he go forward too fast, being extremely quick of feeling, moderate your aids, and 
make him go backward some steps: if he press forward with hurry and violence, make him go backward a great deal. If he is disorderly and turbulent, walk him straight forward, with his head in and croupe out. These sorts of correction have great influence upon most horses.

When you do correct with the whip, it should be given with strength. For this purpose, let the lash be upwards, lift the arm high, and apply it behind the girths round the belly. Sometimes correction is also given forward over the shoulders, between the fore legs.

Should your horse kick at the application of the whip to his flank or quarter, you must, at that instant, apply the correction as smart and determined as possible, and must repeat it sharper, if possible, should he kick at that. By this the horse is made sensible of his fault, and is punished for it. Indeed without such punishment the horse might be ignorant of doing amiss. 
To give a horse both spurs properly the rider must change the posture of his legs, and, bending his knee, strike him with them at once, as quick and firmly as he can.

When, however, the whip or spurs are applied two or three times sharply to restive horses without effect, desist, and try other methods.

Some horses disregard the whip, but fly at the spurs: others disregard the spurs, and are terrified at the whip: the rider consequently will apply that which is most likely to produce the desired effect. 
1) Int

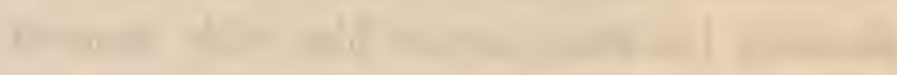
.

nin

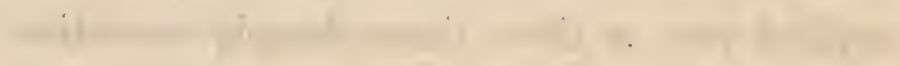

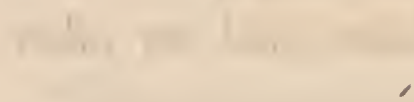

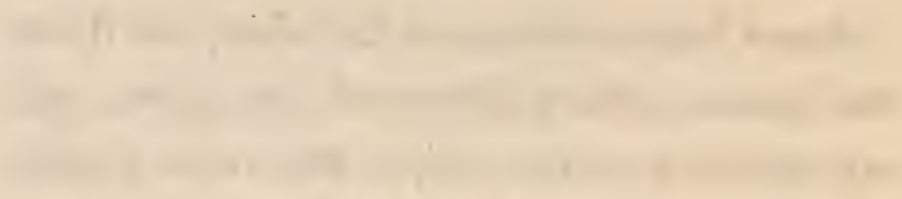
I t $+\frac{1}{2}+1$ 


\title{
PRINCIPLES
}

\author{
OF \\ M O D E N R I I N G.
}

PART V.

of

THE DIRECT PACES.

H 2 


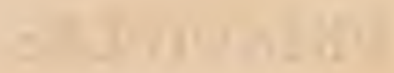




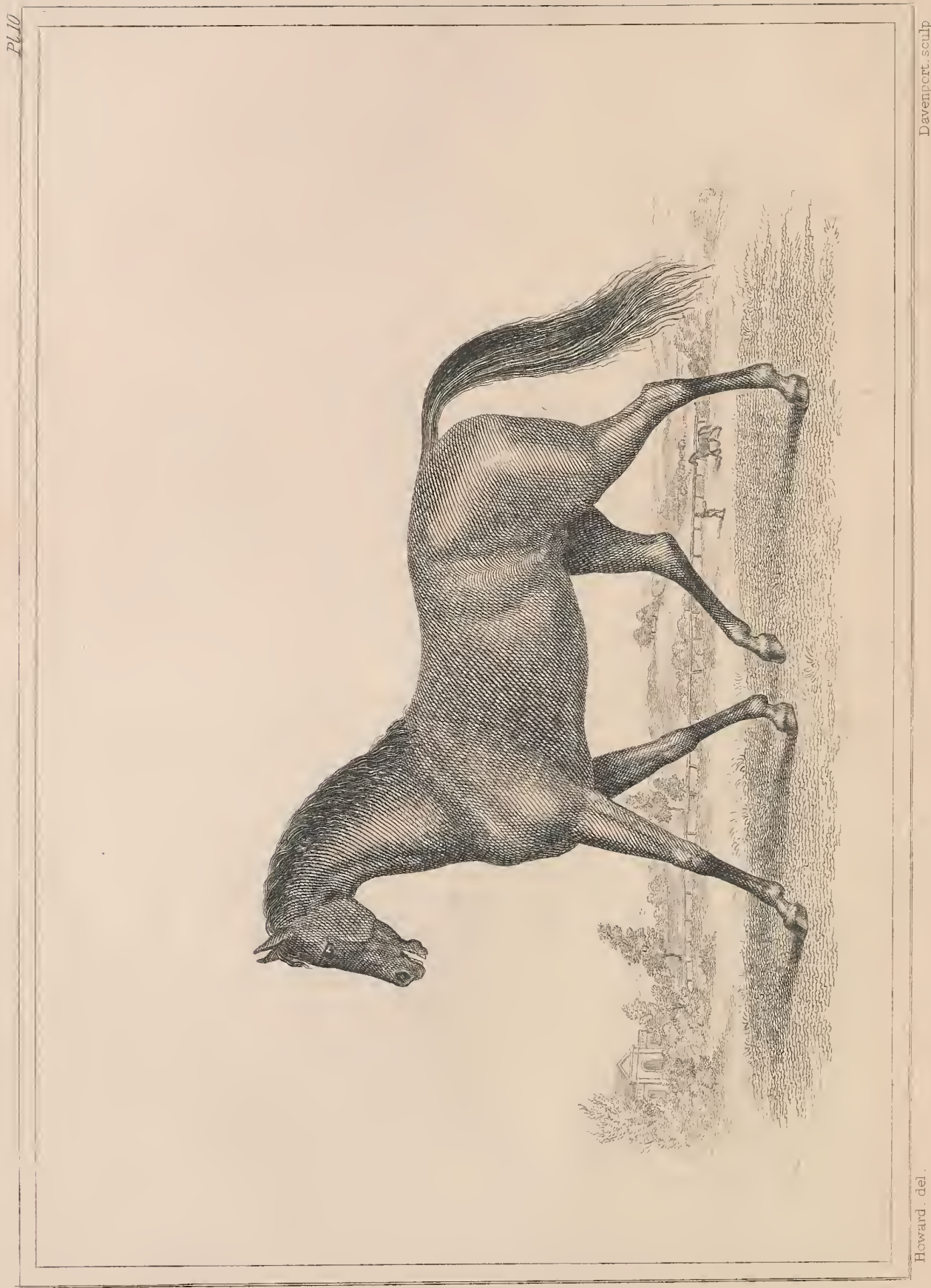




\section{PART V.}

OF THE DIRECT PACES.

\section{CHAP. I. \\ OF THE WALK.}

Section I._Of the Walk generally and particularly.

For the lessons of a few days, the pupil should ride quietly at a walk round the manege, in order to have an opportunity of becoming, in some degree, accustomed to the movements of the horse, of extending his limbs, and of preserving the proper position and balance while he is in motion.

He should not suffer the horse to move, if he can help it, till his clothes are adjusted, 
and his whip shifted. Then collecting his reins and taking one rein in the right hand, he must close his legs to request the horse to move forward in the walk, and till he makes this request the horse should not be permitted to advance.

As soon as the horse begins to move, the legs are to resume their former position,--the hands are to remain perfectly steady,-the body is to yield to the movements of the horse. The walk is begun at a slow rate, as this prevents confusion, and by the eliquette of the riding house it is directed to the right hand first.

The excellence of the walk depends on that degree of union which supports the horse's head, and raises his feet without shortening or retarding the step; and that degree of animation which quickens the step, and sharpens the beats, without falsifying the time or altering the action. The perfection of the walk therefore is, an animated quick step, measuring exact distances, and mark 
ing a regular time, by putting the foot flat to the ground.

If the horse's head is not supported, he not only carries himself slovenly, but does not raise the foot sufficiently to put it out flat, and he therefore shortens his step, and is liable to touch with his toe. If, on the contrary, the head is supported too high, he cannot put his foot out, and the step will also be shortened and retarded. In this situation, should the rider animate the horse to quicken his step, or put out his foot, he would break time, and go into the trot.

Thus if you do not support the horse sufficiently, his head will be low, and his walk slovenly. If you support him too much, you will shorten his step so that he cannot walk freely. If you do not animate him, he will not exert himself. If you animate him too much, he will trot.

If the horse trots when you design him to walk, check him immediately, and examine 
the cause. You will find your animation somewhere above the walk; for, though you do not animate with whip, legs, or tongue, yet your hand, or even your body, may be too animating, when added to the natural spirits and vivacity of the horse. The hand, if too high or confining, is too animating for the walk: the body, if braced too firm, or as might be necessary in the trot, would also be too animating in the walk; for as the horse is, so must the rider be.

'I'he rider must practise the walk to both hands, by crossing over in the long change. Let us therefore consider that and turns in general.

Plate X. illustrates the Walk. 
Section II.-Of Turns in the Walk.

AlL Turns are, at first, to be made very slowly.

The inward hand (which is the hand on which we turn to the right or left), is to be a little below the outward hand, and the inward rein leads, and is to be held with double power or pressure, in comparison-with the outward rein. This aid is to be given by the little finger pulling gently upwards and towards the body-never downwards to the knee. The outward hand is to retain a steady hold of the outward rein.

The horse is to be supported, and kept up to the bridle, by an occasional slight pressure of the calves of both legs. He will thus be made to obey the leading rein, and to bring his haunches under him. The pressure of the inward leg only would occasion the horse to throw his haunches too much outwards. 
P. V.

The aids are to be proportionately applied, according to the effect you mean to produce. The greatest exactness, uniformity, and delicacy is required in the execution.

To give an idea of this, suppose a circle of thirty yards diameter, and the number of circles that can be described within so large a circumference. Just so many degrees of operation have those aids to perform. Even in the centre, these aids, judiciously managed, can turn the horse on three distinct and separate pivots :-first, on his centre, or the point directly under the seat of the horseman, in which the fore feet take place of the hind, and the hind of the fore:-secondly, on the fore feet, in which the fore feet keep their ground, and the hind feet move round them : -lastly, on the hind feet, which keep the centre, while the fore feet describe the circle.

In walking a horse upon a circle of thirty yards diameter, the delicacy of these aids is not perceivable; and yet, if there were none, the horse would certainly work on a straight 
line. This shows how susceptible and obedient a horse is to the most imperceptible touch ; for while a proper correspondence is maintained, and the appui delicate and true, a hair's breadth alteration of position affects the horse's mouth.

This proportionate degree of aids proceeds from, and is directed by, the eye. Thus: the eye traverses about three or four yards before the horse on the ground intended to be gone over; the body presents itself to the direction of the eye ; the hand, in its proper situation, moves with it; and the hand being moved off the line, though but half an inch, directs the horse off the line in that proportionate degree. The more the circles are contracted, the eye, of course, in traversing the ground, will be the more directed to the hand you are working to, and, consequently, the body and hand, presenting themselves in that direction, give the proportionate degree of aid required. 
Section III._Of Wheels in the Walk.

A HoRse may wheel or turn on his own ground, on three pivots. The first two are in continual use in the army-the first, by the centre man of three-and the second, by the standing flank man in all wheels-the third is rarely wanted, but all should be practised, to give a thorough knowledge of the power and efficacy of the hand and heel.

I. Here it is to be observed, that the aids of the hand direct all before the horseman, and the aids of the heel all behind him: hence, in wheeling on centres, the hand and heel operate together-the hand leading the shoulders round-the leg directing the croupe. Thus, in going about, the fore feet describe half a circle, and the hind feet another half circle; by which means the fore and hind feet change situations.

The great attention of the hand is to support that degree of appui which will carry its 
aids into effect, and not suffer the horse to move off his ground; for if the appui is too weak, the horse will advance over his ground, and, if too strong, he will retire from his ground. But whether you wheel to the right or left, let the aids of the hand, body, and leg, exactly correspond, and practise, slowly at first, as much to the one hand as the other.

As the horse arrives at the situation you intend him to halt, whether it is a wheel, which is a quarter circle-about, which is half a circle-or about and about, which is a whole circle-the hand, body, and leg must resume their proper straight position; the hand being dropped, and the fingers eased, that the horse may stand quiet.

II. In wheeling the horse on his fore feet, the hand has to support and confine the fore part, while the heel directs the croupe round.

The aiding with the leg will induce the horse to advance, if a proper restriction be not put in the fingers. The hand, therefore, 
keeps its proper centrical situation, putting so much restriction in the fingers as is necessary to prevent the horse from advancing; while the leg, by a proportionate strength of aid or pressure, directs the croupe round.

The further attention of the hand is to correct any propensity of the shoulders to move, and that in the most delicate manner, lest you create a greater disorder than you meant to prevent.

III. The wheeling a horse on his hind feet is by far more difficult than the preceding.

The hand possessing a greater power than the heel, if it act too precipitately or confiningly, will force the croupe off its ground: the hand therefore must act with the greatest caution and delicacy, allowing sufficient scope for the shoulders not to force the croupe to shift.

Both legs are to be attentive to the croupe. The inner leg, which is that to which hand 


you are turning the horse, is to be placed back, but not to touch, lest you should throw the croupe out. The outer leg must be ready to stay the croupe, if it has such a propensity.

Section IV.-Of Changes and Demivolts in the

\section{Walk.}

I. A CHANGE is no more than the altering the hand to which you were going, or the foot with which you were leading; but this being done by different tracks or modes, and in several actions, gives corresponding names to them.

The long change is crossing the riding house in a diagonal line, the whole length of the house. In this, when you are working to the right, you quit the wall at Figure 1, and cross to Figure 3; or quit the wall at Figure 3 , and cross to Figure 1; by which you change the hand to which you were going.Plate XI. Figure 1. In like manner when working to the left, and you would change to 
the right, you depart from the wall at Figure 2, and cross over to Figure $4 ;$ or at Figure 4 , and cross over to Figure 2 ; which effects the change.

When working on circles of a large diameter, and you would effect a change, you form another circle of the same dimensions, making a Figure 8; in the intersection of which circles, you change your own and horse's position, and work to the contrary hand. These are called Large Changes.Figure 2.

When you change on circles which are so circumscribed that the two do not exceed the width of the riding house, they are called Narrow Changes.-Figure 3.

If, when you make a change, you perceive the croupe to be too much in, by turning your body in, you will drive it out; and the hand following the body, determines the shoulder by means of the outward rein, which is shortened. If the croupe is too much out, 

turn your body out, and this posture, carrying the hand out, shortens the inner rein, and confines the croupe. This aid is so much better, because, if executed with delicacy, it is imperceptible, and never alarms the horse. In order to make the hand and leg work together, it is necessary that the motion should proceed from the horseman's hip, which, in turning, carries with it the rest of the body insensibly: without this, very far from being assisted by the balance of your body in the saddle, you would lose it entirely, and, together with it, the gracefulness of your seat.

II. An air performed on a circle is called a Volt; and consequently the half circle is a Demi-Volt.

The change by the Demi-Volt is effected, when working to the right, as from $A$ to $B$,Plate XII. Figure 2. At B you quit the line, and work on a Demi-Volt, which brings you to the point $\mathrm{C}$, at which place you change and work to the left. In changing again from 
the left to the right, you quit the line at the point D,-Figure 3, work on a Demi-Volt to the point $\mathrm{E}$, change and work to the right.

The changes on the Volt are confined to particular airs. When the Volt is complete, make a half stop, change the leg, and work the Volt round to the contrary hand, on the same ground as before.

The change reverse is worked on traversing lines, and confined to the same airs as the Volt. It is done by reversing your hands, position, \&c. and consequently the horse's position and foot at every angle.-Figure 4 .

Section V.-Of the Stop in the Walk.

The Stop in horsemanship is an instantaneous prevention of action at the height of animation, without the least previous notice or indication by which the horse could be aware of your intent: otherwise the effect and intention would be lost. 
The generality of horses and horsemen are not capable of stopping at the word, and are content to effect this by a gradual cessation of action in an uncertain distance, depending on the degree of animation and speed, disunion of the horse, or inefficacy of the rider's hand, which may require the space of from one to one hundred yards.

The Stop properly performed shows the great superiority of the rider's hand over the horse, thereby gives him confidence, confirms the horse in obedience, unites him, supples the haunches, and bends the houghs.

Though its effects are beautiful and salutary, mischief may occur from a too frequent or injudicious practice of it; for, should we act too powerfully on a horse weak behind, or in his loins, we may spring his sinews, or sprain his back.

The perfection of the Stop consists in the action ceasing at the finish of a cadence, with- 
out breaking the previous time; the horse being so balanced on his haunches, and the animation still alive, that, with liberty given, he can advance with the same rapidity as before.

'The Stop is performed by the rider putting a proportionate strength in the muscles of the hand, bracing his arms to his body, feeling both reins equally and firmly, drawing the fingers toward the body, closing for an instant both legs in order to press the horse up to the bridle, and throwing the body back. All this must be done at one and the same instant, making but a single motion; for, if the rider omit to close his legs, the horse may not bring his haunches under, and consequently the Stop will be on the shoulders, and spoil the effect.

The time must be seized when the first part of the cadence is coming to the ground; so that the finish of that cadence completes the Stop. If this time is not seized by the horse- 


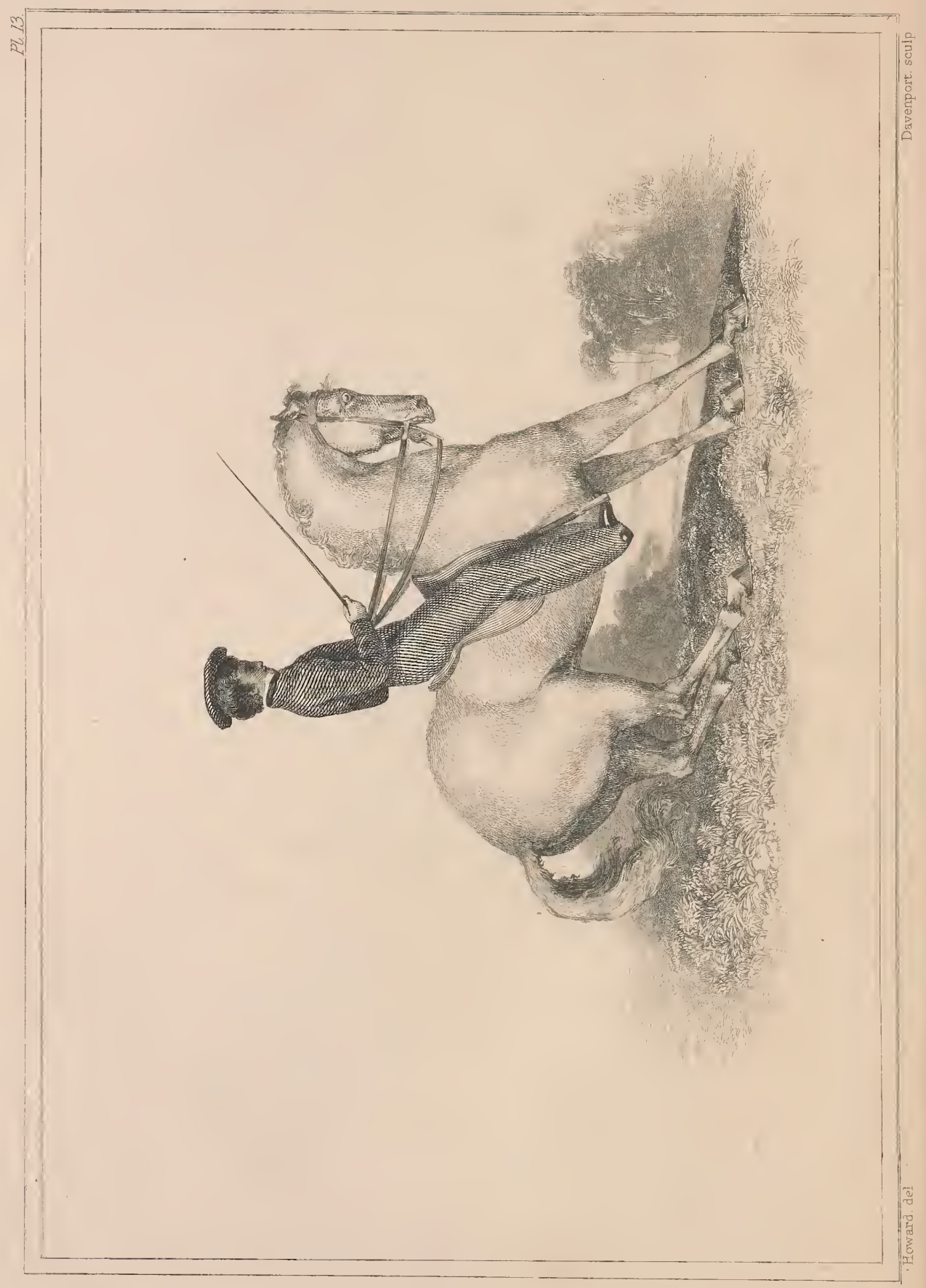

다
ज]
4
4
4 
man, the cadence will be broken, and the Stop irregular.

If your horse has not readily obeyed in making his Stop, make him go backwards; it is a proper punishment for the fault. If in stopping, he tosses up his nose, or forces the hand, keep your bridle hand low and firm, and your reins quite equal, give him no liberty, press upon his neck with your right hand, till he has brought down his nose, and then immediately give him all his bridle; this is the surest method to bring him into the hand.

\section{Plate XIII. illustrates the Stop.}

Section VI._Of Going Backward in the Walk.

Tн $\mathrm{E}$ action of a horse when he goes backward is, to have always one of his hinder legs under his belly, to push his croupe backward, to bend his haunches, and to rest and balance 
himself one time on one leg, and then on the other.

Care must be taken that this action of going backward be just; and that in performing it the horse keep his head steady, fixed, and in a right place, that his body be trussed or gathered up as it were under him, that he be not upon his shoulders, but, on the contrary, on his haunches, and that his feet be even.

It is by an equal and steady feeling of both reins of the bridle, that the horse is made thus to step back; and to give greater efficacy to this, the hand should be kept from rising, the knuckles a little down, and the belly drawn in. The body should no longer be thrown back as in the stop, but rather bend forward, which gives the hand greater effect without provoking the horse to rear-a circumstance that might occur with horses which do not readily obey the hand, particularly if you leaned back to give power to the hand. If you attempt to compel the horse 
back by the power or weight of the body, and he should rear, the body cannot be brought forward, you hang on by the bridle, and should you happen to have the preponderance, you pull the horse backwards on yourself. The horse must at the same time be gently felt with both legs, in order to keep him up to the bridle, and to prevent him from swerving.

The operation of the hand in reining back is a kind of invitation. Should the horse not readily obey, play with the mouth by moving the fingers : this will induce the horse to raise his head.

The instant the horse is constrained to back, the body, if in a proper position, will incline forward, and the fingers must be eased. A horse that is properly broke, obeys the slightest pressure of the fingers, and backs without throwing himself off his balance, but the horse that is constrained to back, is overbalanced, and, if the body did not come for- 
ward, or the hand relinquish its severity, he must back till he fell : therefore, the instant the horse yields to the hand, the body and hand yield to the horse, that he may recover his balance. He should then be gently invited or pressed to back again.

In reining back, the hand must preserve its centrical situation, so that it may not compel the croupe to traverse off the line. If the hand is from the centre to the left, the croupe will traverse to the right; and if to the right, the croupe will traverse to the left.

With the greatest exactness of the hand, however, some horses' croupes will traverse, and require the particular attention of the heel to support and direct them on the line. The hand and heel are always to support and assist each other. Thus: should the croupe traverse to the right, you must, of course, lay the right leg on; then to give assistance or cooperation, the hand must be carried a little to the right; but this must be done with the 
greatest delicacy, lest you should throw the croupe too much to the left, and reverse the disorder instead of correcting it.

It is to be observed, that, in reining back, the hand and the heel change their functions; that is, the hand compels the action, and the heel directs it.

This operation ought to be performed very slowly at first, and only two or three steps at a time. 


\section{CHAP. II.}

OF THE TROT.

\section{Section I.-Of the Trot in general.}

WIIEN the pupil has been sufficiently practised in the turnings, \&c. at a walk, he is to be instructed to urge his horse into a gentle trot.

This pace is the foundation of excellence in all others. By its alternate action, we supple every joint-the shoulders, the elbow, the knee, the loins, the haunches, the houghs: we raise the head and foot, and make the mouth, without which the faculties of the horse are confined, and all his actions stiff and uneven. 
The perfection of the Trot consists ; first, in its suppleness, which gives the horse a free use and extension of his limbs, either on straight lines or circles; next in its union, by which the labour is more equally distributed, for a little observation points out, that the horse's fore legs have a greater portion to sustain than the hind, especially when the horse is disunited, or, what is termed, on the shoulders; then in its action, which should be true and equal, the liberty of the fore quarters not exceeding the hind, nor the hind the fore,-the knee up, the haunches bent, springy and pliant, the step measuring exact distances, marking a regular time of one, two, the measure of which depends on the animation, restriction, or rapidity of the action. By these qualities, the horse is capacitated to work freely to right or left, on circles, without falsifying his step, or breaking his time.

In the trot, as in the gallop, the horse leads with a foot, either right or left, by which the leading side is a little more advanced than 
P.

the other. This nice discrimination is observed only by those much acquainted with horses. The suppling to both hands, capacitates him to work to one hand as well as the other; and in horses that have not been so suppled, if chance or fatigue make them change their leg for that which they are not accustomed to, their action is stiff, confined, irregular, and unpleasant.

\section{Section II.-Of the Kinds of Trot.}

There are three kinds of Trot-the extended, the supple, and the even. These depend upon each other. In effect, you cannot pass a horse to the supple trot, without having first worked him upon the extended trot; and you can never arrive at the even and equal trot, without having practised the supple.

I. By the extended, is meant that trot in which the horse steps out without retaining himself, being quite straight, and going directly forwards. 'This, consequently, is the 
kind of trot with which the pupil may begin; for before any thing else ought to be meditated, the horse should be taught to cover his ground readily, and without fear.

II. 'The trot, however, may be extended without being supple; for the horse may go directly forward, and yet not have that ease and suppleness of limb which distinguishes and characterizes the supple trot. The supple trot is that in which the horse, at every motion that he makes, bends and plays the joints of his shoulders, knees, and feet. This no colts or raw horses, who have not had their limbs suppled by exercise, can execute: on the contrary, they always trot with surprising stiffness and awkwardness, and without the least spring or play in their joints.

III. The even or equal trot is that wherein the horse makes all his limbs and joints move so equally and exactly, that his legs never cover more ground one than the other, nor at one time more than at another. To do this, 
the horse must of necessity unite and collect all his strength, and, if we may be allowed the expression, distribute it equally through all his joints.

To go from the extended trot to the supple, you must gently, and by degrees, hold in your horse; and when by exercise he has attained sufficient ease and suppleness to manage his limbs readily, you must insensibly hold him in still more and more, and by degrees you will lead him to the equal trot.

Section III.-Of the Trot in particular.

BEGIN each pace conformably with etiquette, by going first to the right. Therefore, from the walk cross over from the left by the long change, and put your horse to the trot.

To make the horse trot, apply, for an instant, both legs to his sides: at the same time raise the fore hand by a light feeling of the bridle, drawing the little finger of each hand 
rather upwards, and towards the body. This, as well as all other aids of the hands, must be done smoothly, avoiding all jerks or sudden motions.

The instant the action commences, the hand receives and regulates it. If too rapid, it is checked by strengthening the hand;-if too slow, by easing the fingers, and more animation;-if not sufficiently united, by collecting the reins, and raising the head.

The beginning is always moderate. 'The rider sits close to the saddle, not rising nor standing in the stirrups; and he keeps the hands up in their proper situation, steady and pliant, preserving a due correspondence, and just appui.

As the horse moves on in the trot, the body of the rider should incline a little backwards, and the whole figure must be pliant, partaking of, and accompanying, the movements of the horse. 
'The seat must chiefly be preserved, by the balance of the body, and not by the pressure of the knees; for all attempts to hold on by the gripe of the legs and thighs would tend to derange the balance, and destroy that easy and unconstrained position of the limbs, which is essential to a firm and graceful seat.

These things attained, the rider may proceed as rapidly as the firmness of his seat and balance will admit,-being mindful not to exceed that, lest his seat should be thrown into disorder, and he contract a habit of applying the calves before he attains the complete balance with the thighs.

When the pupil is confirmed, in some degree, in his seat at a trot, he should be taught to collect his horse, and to bring his haunches under him. This is effected by pressing the horse up to the bridle by the aid of the legs; but care must be taken that this is not done too hastily or violently, as the horse might thereby be injured. 
It is of importance to remark, that the rider ought at no time, neither in the extended, supple, nor equal trot, to confine his horse in the hand, in expectation of raising him, and fixing his head in a proper place. If the appui be full in the hand, and the action of his trot should be checked and restrained by the power of the bridle, his bars would very soon grow callous, and his mouth be hardened. and dead: if, on the contrary, he has a fine and sensible mouth, this very restraint would offend and make him uneasy. The rider must endeavour, then, to give him by degrees, the true and just appui, to place his head, and form his mouth by stops and half stops,-by sometimes moderating and restraining him with a gentle and light hand, and yielding it to him immediately again,-and by sometimes letting him trot without feeling the bridle at all.

The only proof, or rather the most certain sign of a horse's trotting well, is, that when he is in his trot, and the rider begins to press him a little, he offers to gallop. 
As the rider improves, he will encourage his horse to put his foot out freely, supporting his fore hand up, and his haunches under. For this purpose he must keep up a sufficient degree of animation; and the instant he perceives a languor, which may be felt before any visible abatement in the action takes place, he must throw in his animation in time - a touch of the finger, the animation of the tongue, the switch of the whip, or the application of the legs, whichever comes the most ready, so that it is not too frequently used to lose its effect.

Section IV.-Of Turns, Stops, \&c. in the Trot.

The operations, directed in the preceding Chapter to be performed at the Walk, are now to be practised at a Trot.

On Turns and Changes in the Trot there is nothing to be added; but as stops were required to coincide with cadences, it is necessary to observe that the first cadence in the 
trot is performed by the two feet that lead, and mark the time, one; and that the feet that mark the time, two, finish the cadence, and should complete the stop.

To give variety and information, the rider should occasionally alter the cadence or measure of the action, by strengthening the hand, and keeping up a sufficient degree of animation, to prevent the horse from stopping. Then again he should give him liberty, and proceed with the same spirit as before. Now he may make a stop: then rein him back two or three steps, keeping the horse so united and animated, that the instant the hand may give him liberty, he advances as rapidly again.

The pupil by thus exerting himself, and progressively aiming from one degree of excellence to another, till he can ride a spirited horse to the height of his animation, will strengthen his seat, get the true balance of body, and learn the operation, effect, and power of the hand. 
When the pupil rides with this animation and spirit, which cannot be expected for some time, the lessons must be proportionably short. If we ride a horse to the height of his animation, though he were in regular exercise and the best condition, he would be so heated in ten minutes, that humanity would say"Stop; let the horse take breath, and recover himself."

This, in horsemanship, is called a reprise ; and two such breathings is sufficient for any horse to do in one day; for the moderate riding of a horse twenty miles on the road would not be more distressing, nor reduce his condition so much, as riding two such reprises.

Plate XIV: illustrates the Trot. 



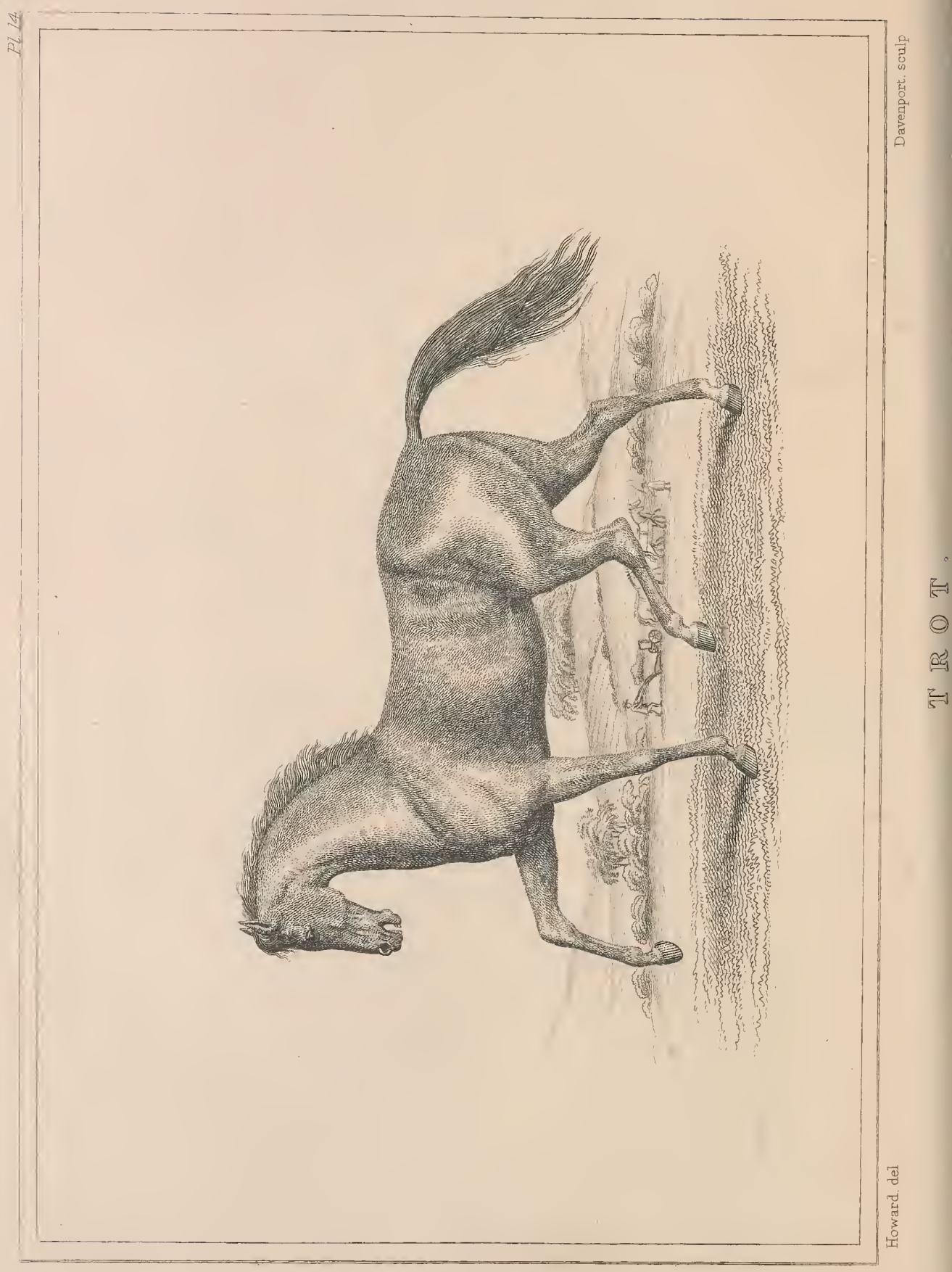


CHAP. III.

OF THE GALLOP.

Section I.-Of the Gallop in general, and of its Kinds.

$\mathrm{W}_{\mathrm{E}}$ do not recommend the Gallop to be begun soon, because the Trot is the foundation of good riding. The young horseman, however, being duly prepared by the practice of the foregoing lessons, may proceed to that of the Gallop.

The Gallop may be considered under three distinct heads, namely:-That of the Racer, on the course at Newmarket; that of the Hunter, under moderate animation, on the plain ; and that of the Lady's or Pleasure Horse, on the road, which is commonly called the Canter. Each of these actions has its peculiar excellence; but the last is the most difficult 
to accomplish, as it requires the skill of an able rider to foreshorten and throw the horse on his haunches, sufficiently to complete it.

In Cantering or Galloping on a straight line, it is immaterial whether the horse leads with the off leg before, or with the near leg before, provided the hind leg of the same side follows the fore leg. Indeed it has been found, on trial, that by strictly adhering to the rule of never suffering a horse to gallop but with his right fore leg, he has been quite worn out on one side, when he was quite sound on the other. It is, however, proper that the horse should be determined by the rider as to the leg with which he should lead.

In Cantering round the circle, or the manege to the right, it is necessary the horse should lead with the inward, or off fore leg; followed by the off hind leg. 'T'his action is termed true or united.-Plate XV.

In Cantering to the right, if the horse lead with the off fore leg, and near hind leg, he is 



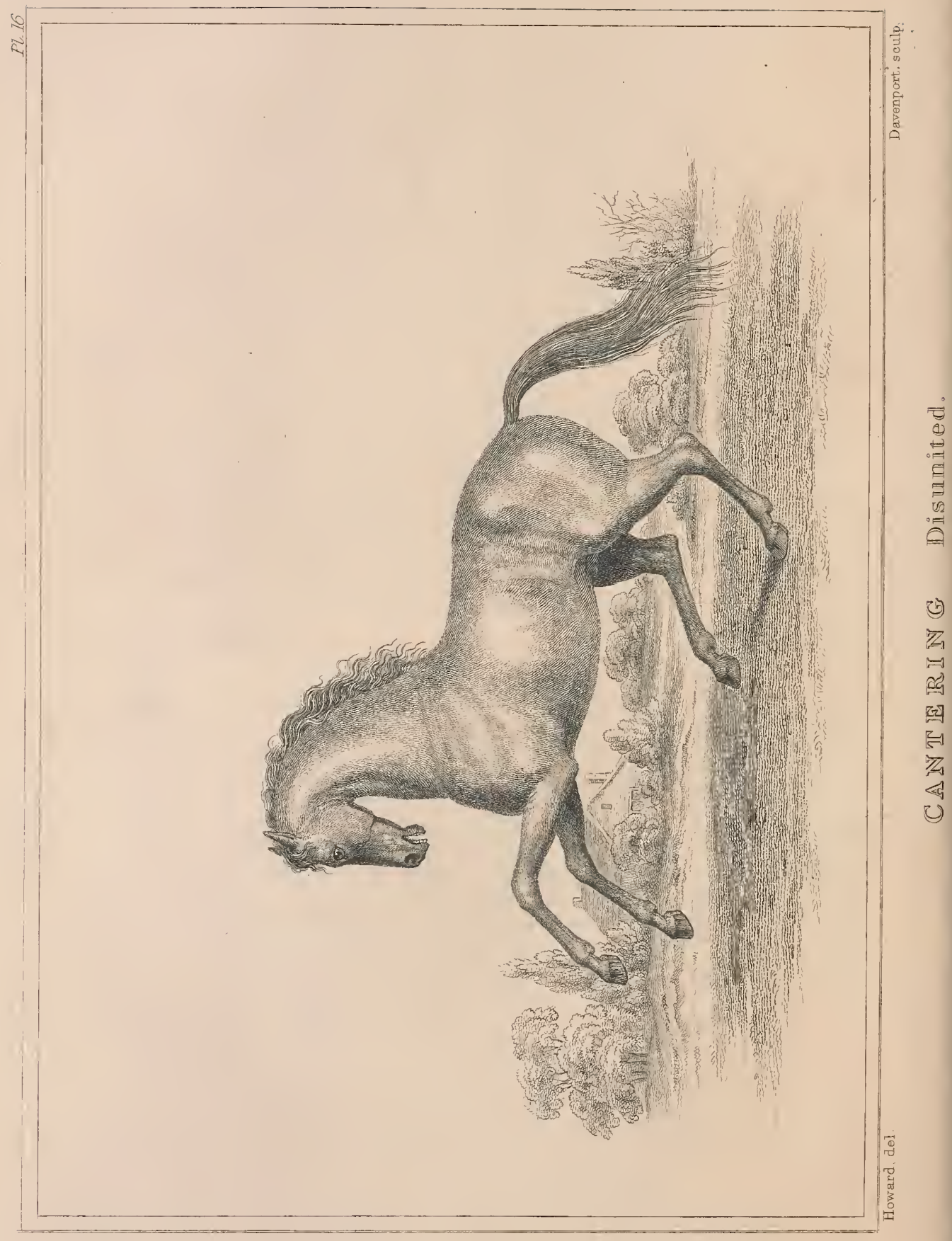





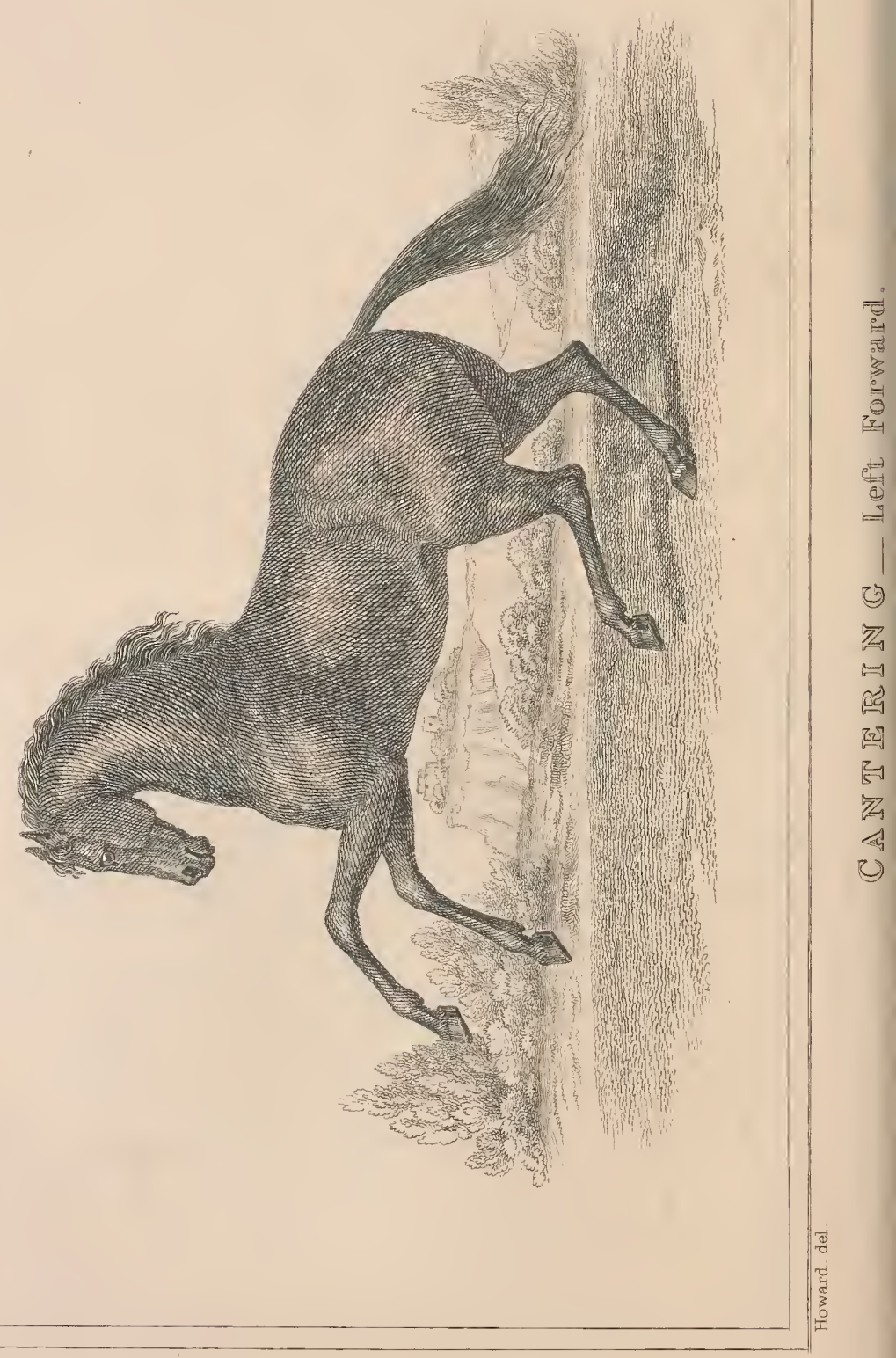


said to be disunited : it is a rocking motion, the legs interfere, and he cannot sustain it. Or if he lead with the near fore leg, and off hind leg, he is equally disunited.=-Plate XVI.

In Cantering to the right, if the horse lead with both near legs, he is said to gallop false.

In Cantering round the circle, or the manege, to the left, it is necessary the horse should lead with the inward, or near fore leg, followed by the near hind leg. This is termed true or united.-Plate XVII.

In Cantering to the left, if the horse lead with the near fore leg and off hind leg, he is said to be disunited. Or if he lead with the off fore leg and near hind leg, he is equally disunited.

In Cantering to the left, if the horse lead with both off legs, he is said to be false. 
P. $r$.

Section II.-Of the Canter in particular.

In the early practice of the Canter, it should be commenced from a short, animated, and collected Trot. After some practice it may be done from the Walk; and finally from the Halt.

'The first thing to learn is, how, in a proper and horsemanlike manner, to put the horse into a Canter ; for to begin the Canter well, and to finish it well, displays more the skill of the horseman than any part of it:

To put the horse immediately to the Canter from the spot where you may be standing, or from any pace you may be riding, the hands and heel must collect and press the horse together: in other words, press the horse with the legs, or animate with the tongue; and at the same time, with a quickening sensation in the fingers, and a little raising of the hand, invite the fore legs to rise in the action of the Canter. 
If the horse do not readily obey this, you must increase your animation, and keep the hand more firm, to prevent the horse trotting. By this means, you will constrain him to raise his fore legs together, which commences the action.

Besides raising the action to the Canter, you are likewise to direct the horse which foot he is to lead with. The foot the horse should lead with is the inner; and horses that have been equally suppled to Canter with either leg, readily take the foot, by putting the croupe in. This will be understood by what follows.

In the Canter, the horse leads with one side, and that side is advanced somewhat more forward than the other, which is increased as a horse may canter more or less with his croupe in. The position of the horse makes a corresponding position of the horseman necessary, whereby the balance is kept more steady, and the position of the horse better supported. 
P. V.

It may, then, be taken as a general rule, that whichever side the horse leads with, the rider's thigh on that side must be rather more turned in towards the saddle. This brings the hip on that side more forward, and consequently turns the other thigh a little out, and the hip back.

This turn of the hip effects a turn of the body; and the hands being fixed, and considered a part of the body, are carried with it.

The rider's head, by a like general rule, is always to be directed to the horse's nose, his eye glancing on the ground the horse's fore feet go over. In the Canter the horse's nose is directed to the ground: the rider's face is " consequently the same.

This position of the rider must be proportioned to the position of the horse; that is, as the horse Canters more or less with his croupe in. 
Let the pupil then attempt to put his horse to the Canter, we will say to the right: that is, leading with the right foot foremost. At the instant he makes the disposition with his hands and animations to raise the action to the canter, let him take the corresponding position, by turning the right thigh in, advancing the right hip, \&c. and the effect will be this: the hands will be carried more to the left, which will determine the shoulders out and support the horse's head in a proper position; while the left, which is the outer thigh, being turned a little out, will bring the left leg farther back, and nearer to the horse's side, and that will support the croupe to the right, that is, in.

In this position, the animation and union raising the action to the Canter, the horse cannot but take the right leg; unless he has never been suppled, or accustomed to gallop with any other than the left.

In military riding this turn of the body for obvious reasons is not admitted. The soldier, 
to begin the Canter or Gallop (for they are the same), round the manege draws both the reins a little towards himself, feeling the inward rein with double power, and at the same time closes his outward leg, which disposes the horse to advance, and strike off with the inward leg.

If the horse strike off with the wrong leg, false or disunited, the rider must endeavour, at the first corner at which he arrives, by an additional feeling of the inward rein, and application of the outward leg (without using the spur), to make him change, and lead with the proper leg.

It is extremely necessary that a horse should be suppled, and accustomed to change and gallop with either leg; for then, even if the rider is inattentive, when the horse finds himself insecure by leading with the wrong leg, he can readily change, and will do so of his own accord; but horses that have not been suppled and united cannot change without a great risk of falling. 
When the horse leads with the proper leg, the hand should resume its usual position, the rider observing to make the horse bend a little inwards, by shortening the inward rein. The fingers should be softened, if necessary, to let the horse advance, but the hand kept up, and every cadence felt of the fore feet coming to the ground.

Beginners cannot be expected at first to know when the horse takes the proper leg: practice alone must give them that know ledge. If the rider, however, take the proper position, and if the horse goes off smoothly, and continue the croupe in, he may reasonably suppose him right; but on the contrary, if the horse appear to resist these aids, and the croupe be out and the shoulders in, he will, most likely, be false.

It is natural with beginners, to suppose that the faster they ride, the better they ride; but, however, gratifying the riding fast may be, there is more skill displayed in keeping up 
an animated action in the Gallop, at the rate even of but three miles an hour, than at that of twelve or fifteen miles an hour. The attention of the pupil should therefore be, to keep up the animation and action of the Gallop, without going fast. If the animation fail, or the action be not supported by the hand, the horse will break into the trot, particularly as the Gallop is shortened or united.

The perfection of the Gallop consists in the suppleness of the limbs, the union of the horse, the justness of the action, and the regularity of the time.

The Gallop when disunited and when extended to speed, even though the horse is supple and just on his legs, loses its harmony and regularity of time. In these cases, the fore legs measure less space from each other, and so do the hind legs, which makes the beats quicker in each, and leaves a space between the beats of the fore legs, and the 
beats of the hind. In these Gallops, it would be highly imprudent to circle, or turn, but on a very large scale.

Begin, therefore, in a medium way, neither too rapid nor too slow. Be sure to keep the hands up, rather above than below the elbow, and quite steady, that you may feel the cadence of every step, and the support your hand gives. If you feel the action declining, correct it instantly, before worse disorder takes place, by an animating touch of the fingers, the leg, or the tongue. The hand first discovers any disorder or relinquishment going to take place, and consequently is the first to correct it.

Horses, when broke, in many instances, discover the inefficacy of the rider's hand, particularly in the gallop round the riding house. If the hand be not attentive, the horse will break his ground at the ends : he will not only evade filling the corners, but will circle without going to the extent of the 
house. To prevent this, keep the horse sufficiently united, and properly supported by the hand. Do not suffer him to depart from the side wall, till his nose arrives within five yards of the end wall. As you become proficient, you may ride him up to a yard. Then gradually turn or incline your body, to let the horse circle; but still keep the hands sufficiently operating outward, to keep the horse's fore legs on the outer extent of the ground, and close the outer leg, to support the croupe in, and haunches under; by which the horse will be properly balanced, and in no danger of slipping.

When you have sufficiently practised to the right, and find you can support the action in a united Gallop, in which the horse never breaks the time, or falls into the trot, which shows a defect in the rider, stop and practise the Gallop to the left.

In galloping to the left the position is reversed, which needs no farther explanation. 
The pupil must be trained by practice and instruction to retain his seat and balance, and to make his horse obey the aids, with as much ease and steadiness at a Canter as at the walk.

When the rider finds he can put his horse off to either hand with the proper leg, and support the action, he must particularly attend to the truth and union of the action, and try to raise it to the highest animation, riding sometimes rapidly, sometimes slowly, yet always united.

When capacitated to ride the Gallop in high animation, lofty action, united and true to both hands, he will proceed to make the Changes.

Section III.-Of Turns, Changes, Stops, \&c. in the Gallop.

I. WHEN the rider is familiar with the paces, easy in his seat, and has learned to apply the 
P. V.

proper aids, he should be taught how to turn his horse to the right and left, at a canter. This is to be done with the leading rein, by raising the horse's fore hand, and pressing the haunches forward and under him; at the same time the outward rein assists to steady the horse, and a pressure of the calf of the outward leg keeps the haunches from falling too much out.

If the man turn his horse suddenly with the inward rein only, without lifting the fore hand or applying the outward leg, the horse must turn on his shoulders, and lose all power to halt on his haunches, and being twisted round unprepared, he will change to the outward leg, to counteract the effect of this uncollected turn.

II. The Changes in the Gallop will be more easily and readily performed by the horse, if the rider be particularly careful to bring him properly to his ground where he is to change in such position, that, when the legs are changed, he will be as truly on the lines he 


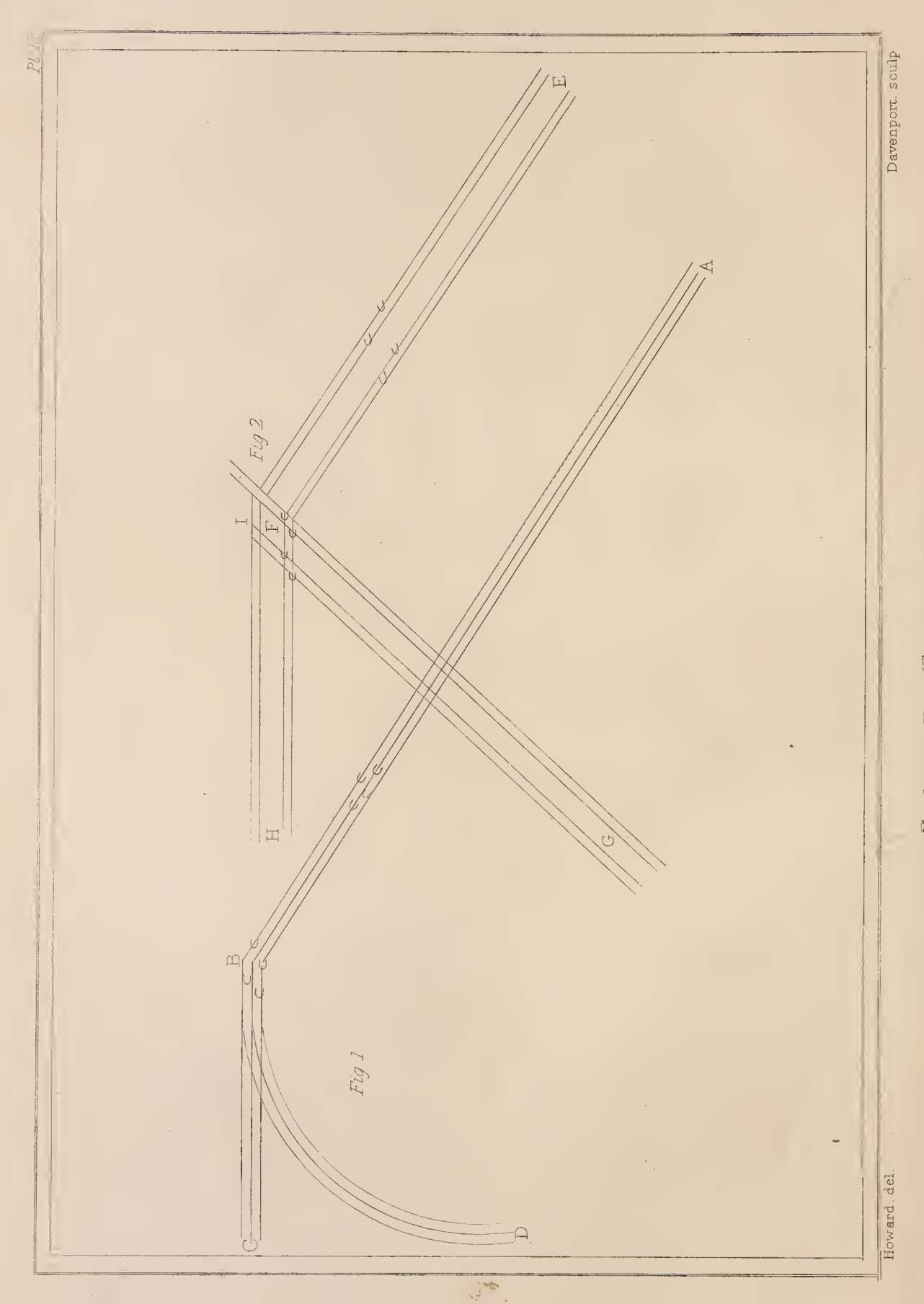


is to proceed on, as he was on those before he changed.

For example, if you make the long change, you cross the riding house from $A$ to $B$ (Plate XVIII. Figure 1); and at B you are to change and gallop, with the left leg towards C or D. Now, if you bring the horse properly across the house, the croupe not being too much in, when you arrive at $B$, the central line of your horse will be in the same direction on the new lines $\mathrm{B}, \mathrm{C}$, when the horse has changed his legs, as they were on the former lines $\mathrm{A}, \mathrm{B}$, as the Plate shows. The horse-shoes on the lines $A, B$, show the position of the horse's feet when galloping from A to $B$, leading with the right leg; the horse's shoes at B show the position of the horse's feet when changed to gallop with the left leg.

Were you to gallop across the riding house with the croupe so far in, as is described by the footmarks on the lines $\mathrm{E}, \mathrm{F}$, and to continue the position till you changed at $\mathrm{F}$, your

L 2 
horse, when changed, would be in a position to gallop to $\mathrm{G}$; and consequently, if you designed to gallop to $H$, you would be obliged to alter the position of your horse as you arrived at F, before you changed, that the horse might, when changed, be capacitated to work on the lines $\mathrm{F}, \mathrm{H}$.

For trial,-begin with the long change, and bring your horse properly to his ground, as has been explained. When you arrive at the place, seize the time the horse's fore feet are coming to the ground, and lean the body a little back, nearly as when you intend to make the half stop: then as the cadence finishes, bring your body upright, and change your position, and the horse will begin the next cadence with the other leg.

The inner hand always supports the position the horse works in, and must be fixed to the body. The outer hand must be accommodating to the inner: that is, it may be detached from the body, - placed forward to admit the little turn of the horse's nose to the 
lines he is to work on,-carried higher than the inner, to raise the action and animation without moving the hand that supports the position,- and if the outer elbow is raised, the hand, elbow, and shoulder must be of a parallel height, and form à graceful arch.

When you change, the whole must be performed smoothly and evenly at one and the same instant; so that, at the finish of the cadence, your body, hands, thighs, and legs are reversed, for the horse to commence his next cadence with the contrary leg.

The other Changes in the Gallop are done on a similar principle,-a due regard to the position of the horse before you change, that, when changed, he may be capacitated to proceed on the intended lines.

III. The pupil should also practise the Stop frequently, always changing the place where he stops, lest the horse should prepare himself to halt when he comes to the place at which he has been accustomed to stop. 
1. To avoid any unnecessary shock either to rider or horse (especially to the former when riding without stirrups), during the manege lessons, the halt should at first be preceded by the trot, and the pupil should stop his horse well on the haunches, by applying the flat of both legs as he feels the bridle, raising his horse's forehand, and suffering him to go a pace or two at the trot before he finally halts.

To stop skilfully in the gallop, you seize the time when the horse's fore feet are coming to the ground, which is the beginning of the cadence; and the hind feet coming up to their exact distance finish the cadence, and complete the stop; while the horse is so balanced, that he can readily set off again with the same rapidity as before.

The skill of the rider and obedience of the horse are happily displayed in the Stop, during the gallop; for, besides seizing the exact time, as above observed, a due proportion of power must be attended to, agree- 
able to the readiness, obedience, union, or rapidity of the action. Should your operation be too feeble, the Stop would not be effected, at least in a proper manner: if it be too powerful, you overbalance the horse on his haunches, and compel him to move his feet after the cadence is finished, to recover his balance. Besides, in these over violent operations of the body and hand, you risk the extension of the sinews behind, or hurting the back and loins; and therefore, till horses are ready and obedient to the Stop, it should not be attempted in too violent and rapid gallops; nor even then, if the horse is weak, or the rider heavy, in which case, the double arret is used, as being less liable to injure the horse or shake the rider.

2. The double Arret is, the Stop completed in two cadences of the gallop, which, in violent action, is far less distressing, both to man and horse. The horse, till practised and made obedient to the Stop, will not, however, be handy at the double Arret; for, in the first 
instance, he stops by compulsion; but, when practice has brought him to obedience, he readily stops at the easy throwing back of the body. In rapid action, the body being gently thrown back, will not make the action instantaneously cease; but the obedience of the horse makes the effort, which checks half his career in the first cadence, and the body still being kept back, he completes it in the second.

3. The half Stop is a pause in the gallop, or the action suspended for half a second, and then resumed again.

Now, the difference in performing the half Stop is throwing the aid of the body back, not so determinately, lest you should thereby so overbalance the horse that he cannot readily set off again without moving his legs after the finish of the cadence; for the cadence is no sooner finished than the body is to come forward, to permit the action to go on: so that the half Stop is only a pause in 
the gallop. It is mostly used to effect a change; that is, changing from the right leg to the left, \&c.

The cadence of the Stop, half Stop, and double Arret, are quicker than the gallop, because, when the aids are thrown in to effect the Stop, the hands check the fore legs, while the rider's legs drive in the haunches; and this occasions the feet to come to the ground quicker and nearer together. The cadence of the Stop should be no shorter than the readiness and obedience of the horse will admit: the half Stop not quite so short; and the two Arrets still more moderate, by which the horse stops with more ease to himself in two cadences.

As the Canter is a severe exercise both for men and horses, the duration of it should be short. 


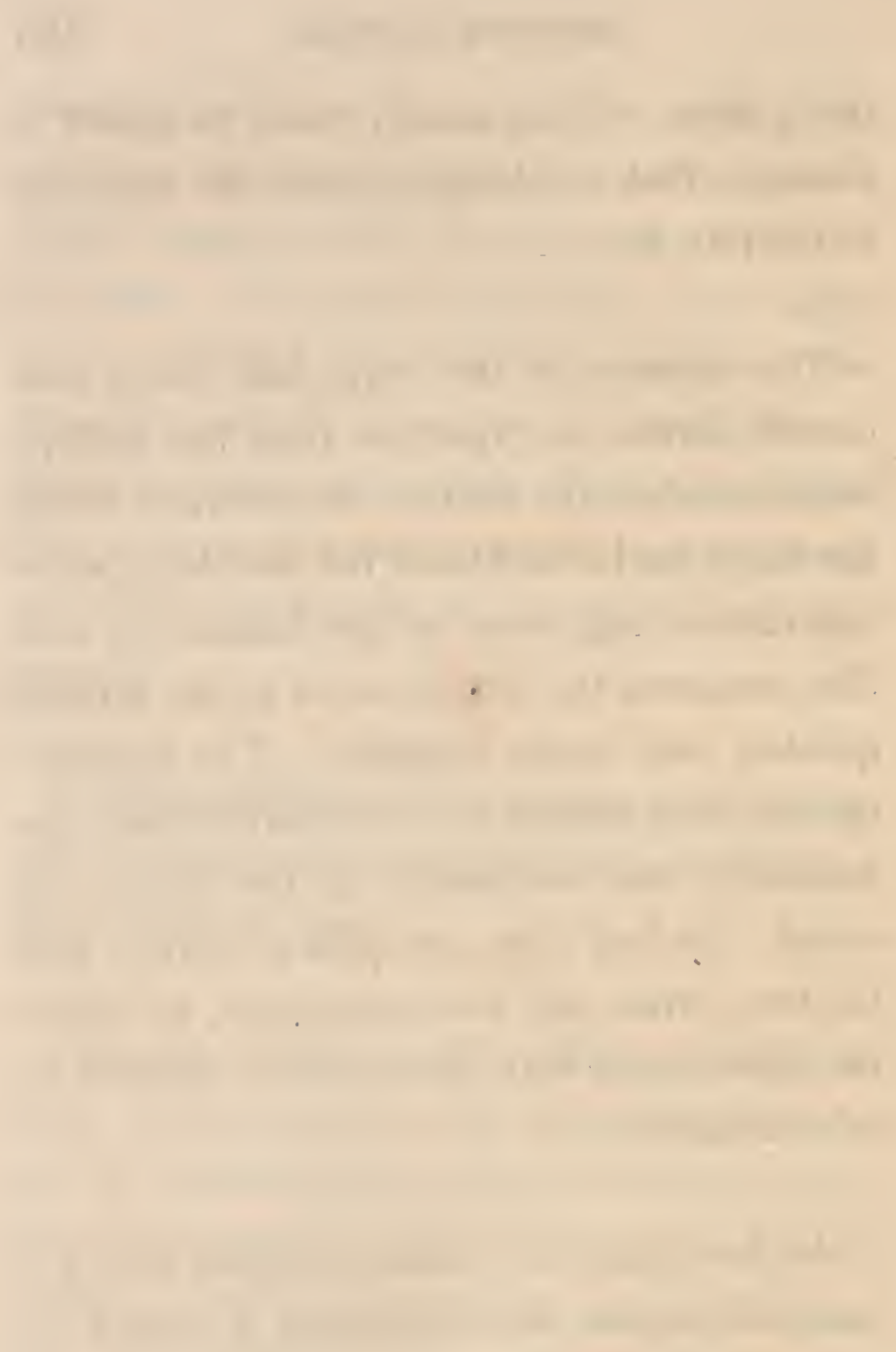




\title{
PRINCIPLES
}

\author{
OF \\ M O D R N R I I N G.
}

PART VI.

OF

THE LATERAL PACES. 


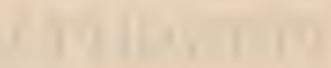

y

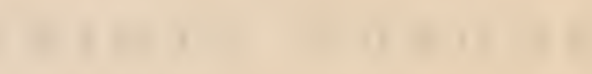




\section{PART VI.}

OF THE LATERAL PACES.

\section{CHAP. I.}

OF SHOULDER-IN, ETC.

\section{Section I.-Preliminary.}

WHEN the pupil has obtained a perfect knowledge of the Turnings, \&c. in the direct or straight forward paces, and of the Aids to be applied in those movements, he may proceed to the lateral paces of Bending or Shoulder-in, Passaging, and Terre-à-terre.

The pupil should be cautioned, that in these, as in other lessons, he must avoid all sudden and violent changes of the Aids, which would defeat the object in view-to teach the skilful management of the horse. 
Section II._-Of Bending.

To bend the horse's head to the right or to the left, the pupil shortens his inward rein, and holds it with a firm, but light hand ; supporting his horse at the same time with the outward leg and rein.

If these Aids be properly applied, the horse will readily yield to them, and bend in the degree required, which commences from the poll of the neck, and turns the head so that the rider can see the horse's inward eye.

Section III._-Of Shoulder-in.

Tre Shoulder-in is a greater degree of the Bend.

Till a proficiency in this, and in head and croupe to the wall, called the keys of the manege, are acquired, a person is but indif- 
ferently qualified to ride the Gallop with the Changes.

The particular intention of this operation is to bend, supple, and retain the horse's shoulders; and as the position of the rider varies according to the position the horse works in, it is equally indispensable, for the suppling the rider, retaining the hips and shoulders, giving freedom and ease in the seat, and a balance in side actions.

Here the position of the horse is nearly opposite to that in the gallop; the gallop having the croupe in, and this having the shoulders in.

As this lesson is sometimes taught both horse and man first on circles, it is more easily explained on them. The horse being bent with his head more or less towards the centre, agreeable to the suppleness he has acquired, retains the inner shoulder, and advances the outer, which is the reverse of 
P. VI.

the gallop, where the inner shoulder is the advanced, or leads. The croupe, by this, is thrown out; that is, the hind legs describe a circle without, or larger than the fore legs.

In the same manner, if you work the horse along the wall, though the horse bends his neck within the house, if the hind feet do not describe lines without the fore feet, the horse does not work the lesson true.

The position of the horse is bent, and he works to the convex side, while his head is turned in the opposite direction.-Plate XIX.

Hence not only the neck, but the shoulders, loins, and haunches, become suppled; and if worked equally to both hands, this gives a surprising capacity or ability to the horse.

In the following Plate XX. Figure 1, the dotted lines represent the outlines of a horse's body, without having regard to the head or 



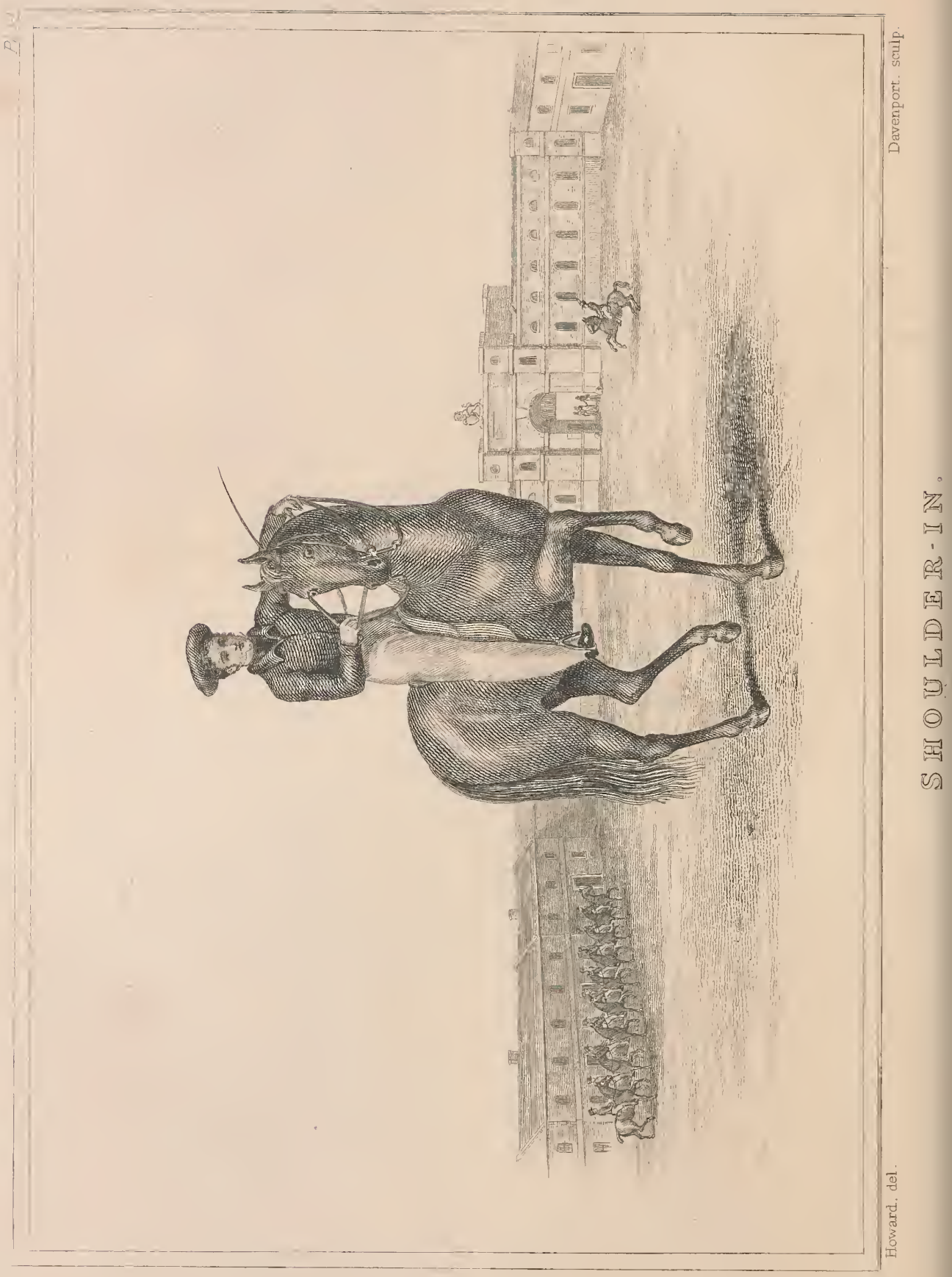





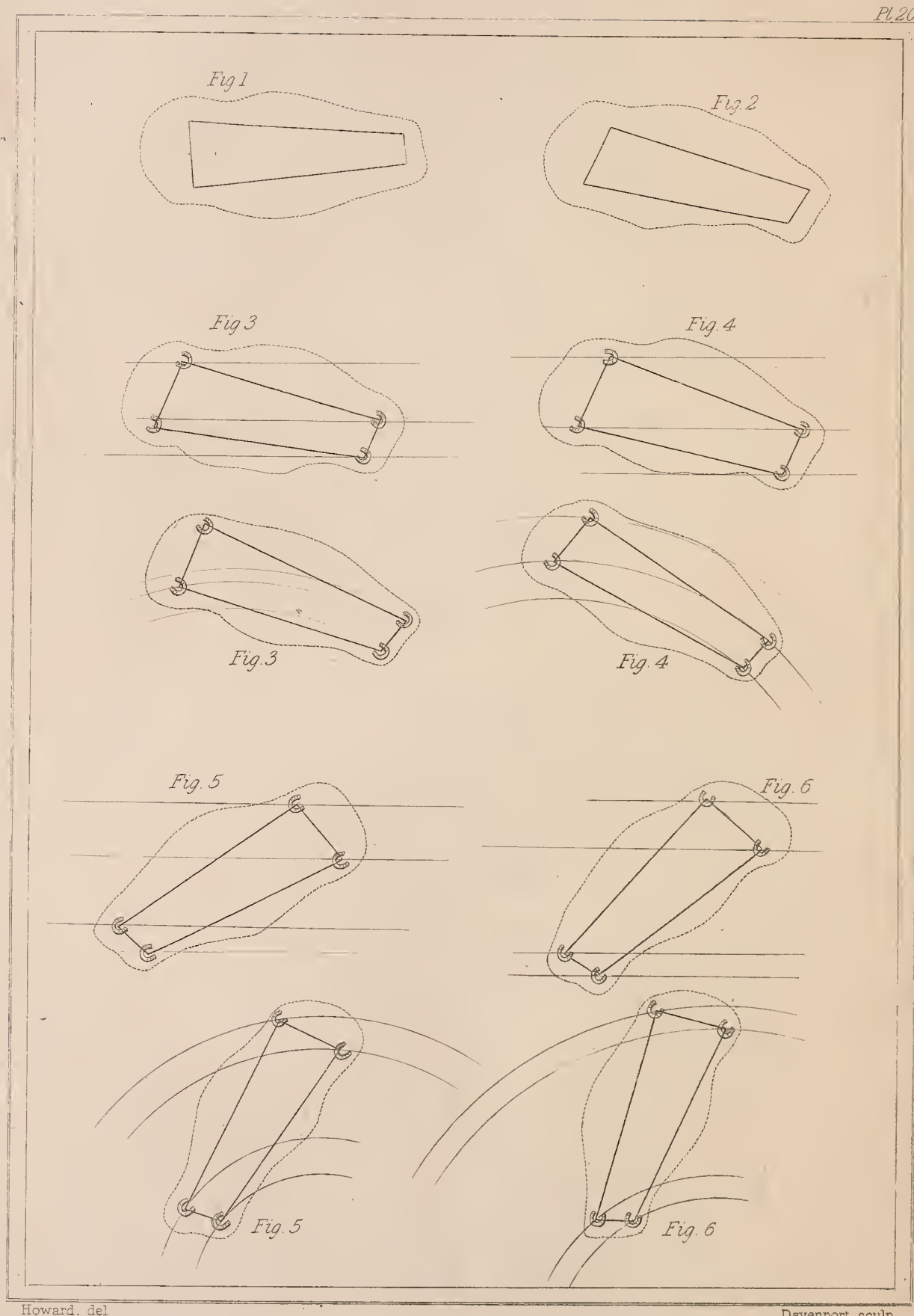

$\mathbb{P} \mathbb{C} \mathbb{S}$. 
neck, supposing you take your view from an eminence directly over the horse, where his body entirely obstructs the sight of his legs.

Now when a horse works straight, we may suppose that, if lines were drawn from each quarter to each shoulder, it would form a trapezium,-as represented in that figure. The intent of this lesson, however, is to retain the inner shoulder, and advance the outer; and therefore, by working the horse in a curved position, as Figure 2, if lines were drawn from the points, as before, it would form an oblique trapezium, and show the inner shoulder retained considerably behind the outer.

This position of the horse's body affecting the feet, if we draw lines through the angles they will show the treads the horse's feet work on, three or four in number according as the shoulder is worked more or less in. This may be seen by Figures 3, 4, 5, 6, which represent the horse on straight lines and circles, in different degrees of suppleness. 
The corresponding position of the rider to support the position and action of the horse, and maintain an undisturbed balance is next to be considered.

For this purpose, collect and separate the reins, or in other words take one in each hand. In doing this, let them be taken short enough, because, if too short, you can with ease slip them to a proper length; but if too long, you cannot shorten one hand without the assistance of the other. Bring your inner hand down, letting the wrist rest on, or just above, the hip. By this, if your rein is of a proper length, you will draw the horse's nose within the circle and support the position; and as this is your aim, be mindful not to prevent your own intentions by pulling with the outer hand. For this purpose, as you draw the inner hand towards you, advance the outer, to admit the horse freely bending. At the same time, present your own body (as the horse bends himself) towards the horse's nose. Whether the horse is bent much or little, your body having the like degree of 
inclination, will give the corresponding position, by which to support the attitude the horse is to work in, and maintain your balance undisturbed.

To make this more easy and effective, advance the outer hip, and retain the inner one. This will turn the inner thigh a little out, and the outer thigh more in. The inner leg, by this means, will be brought nearer the horse, to aid and drive the croupe out; and the outer thigh will be in a position to support the balance,--for the horse being bent, and working to the convex side, the rider's body is thereby impelled inward, till such time as he acquires the method of supporting his balance by the muscles in the outer thigh.

The outer hand, as already said, is to be placed forward, to admit the horse bending himself to the inner hand. It is likewise to be placed so high, that the shoulder, elbow, and wrist, are in a horizontal situation,-the arm forming a graceful arch,--and the fingers being soft and pliant, that the operations 
P. VI.

may be the more delicate. The inner hand, however, being fixed and determinate, no operation of the outer hand must be so strong as to destroy the effect of the inner. In this situation, the operation of the outer hand may assist the inner, by occasional touches inward or outward, as the circumstances may require. The animating touches of the fingers, in an upward direction, will likewise rouse the apathy, raise the action, and unite the horse.

In the practice of this, the pupil should clearly understand that it is the outward rein which leads the horse, the inward rein which preserves the bend; the inward leg which presses the horse to cross his legs; and the feeling of the outward leg which keeps him up to the hand.

These constraints keep the horse together, and prevent his taking too long a side step which might strain him.

In this and in all side movements, a certain freedom of action must be allowed for the 
horse, to enable him to cross his legs. If the hand should pull at the moment when he is crossing his legs, it would prevent his action, and he would rein back. On the contrary, if the horse be allowed too much liberty when stepping sideways, he will be disposed to advance.

The horse will yield to these aids (if they be properly applied and timed to his pace), so that his whole figure will be bent; the fore and hind legs moving on two lines parallel to the sides of the manege; the shoulders leading; and the inward crossing over the outward legs,

The ground you intend to work on must be particularly attended to ; and this the aids of the body and leg, if properly applied, will regulate, without the motion of the inner hand, or the interference of the outer. Not that the outer hand is not to be used : the one hand is always to be assisting to the other; but the inner hand and heel constitute the principal support of the position, action, 
time, \&c. as well as direct the ground the horse is to work on.

Thus, should the horse traverse within the intended lines you meant to work on, examine the cause. It may be from your inner hip and shoulder being turned beyond a due proportion, or the body too much bent, or inclined inwards. Correct your own error, and as you assume a more straight or upright position of the body, which will carry the shoulders out, you must proportionately apply the inner leg to keep the croupe out; by which you will support the position as before, and only enlarge your ground.

On the other hand, should the horse break his ground, by going without the lines, let the body be more turned or inclined inward, which will bring the shoulders to work on a less circle. Should an unwilling obedience of the horse occasion the croupe to be too far out, keep off your inner leg, and it will come to its proper situation. 
The eye glancing on the ground your horse is to work on, the aids of the body and hand will naturally operate to that direction.

On the arrival of the rider at any corner of the manege, he should feel the inward rein twice as strongly as the outward one in order to stop the fore hand of the horse, and at the same time press with the inward leg, with double strength, to bring his quarters gradually on the new line in a circular direction. $\mathrm{He}$ should then lead the horse off with the outward rein, and preserve the bend by carefully applying both hands and legs, as before directed.

Section IV.-Of Changes, \&c. in Shoulder-in.

The usual Changes in this lesson are, by the long change and demi-volt.

As a trial of proficiency, occasionally work from the wall towards the middle of the riding house, as though you were going to make the 
long change; but when arrived at the middle of the house, work back to the other end of the wall from which you came. This is no change, but only tries the obedience of the horse, and the proficiency of your hand and aids.

It is in these lessons that the pupil acquires an accurate knowledge of the use and effect of the aids necessary in more confined movements.

This pace should be performed with great care at a walk.

This and all constrained lessons, being particularly distressing to the horse, and rendered more so, frequently, by the awkwardness of beginners, they should not be continued too long at a time, and in that short time should be frequently changed. The working twice round the riding house to one hand--changing and working to the contrary hand, is sufficient. 


\section{CHAP. II.}

OF THE PASSAGE.

Section I.-Of the Passage in General.

WHEN the pupil has arrived at some degree of dexterity in the use of the Aids necessary in Shoulder-in, he should be taught the Passage.

The Passage is the key which opens all the justness of the art of riding, and is the only means of regulating horses in all sorts of airs; because, in this action, we may work them slowly, and teach them all the knowledge of the leg and hand, as it were insensibly, and without running any risk of disgusting them, or making them rebel. 
In the Passage, the action of the horse's legs is the same as in the Shoulder-in; but the horse is supported in a different and more graceful attitude; the small but elegant bend is on the side he moves to; so that he works to the concave side, which is more brilliant in appearance, as well as more difficult to execute. In the Shoulder-in, the horse looks the contrary way to that in which he moves; but in the Passage, he looks the way he is going and follows the leading rein; his shoulders preceding his haunches, and the body being placed obliquely to the lines on which his legs are made to move. The action is grand, and the time as regular as the beats of a clock.

Section II.-Of the Kinds of Passage.

There are several sorts of the Passage.

In that which is derived from the trot; the action of the horse's legs is the same as in the trot. The Passage is distinguished from the 
trot, which is the foundation of it, only by the extreme union of the horse, by the action being raised before and lowered behind, by his keeping his legs longer in the air, and lifting them both equally high, and by being neither so quick nor violent as in the action of the trot.

In the Passage which is founded on the walk, the action of the horse is nevertheless the same as in the trot, and consequently the same as in the walk, with this difference, that the horse lifts his fore feet a good deal higher than his hinder, and that he marks a certain time or interval sufficiently long between the motion of each leg; his action being much more together and shortened, more distinct and slow than the ordinary walk, and not so extended as in the trot, in such a manner, that he is, as it were, kept together and supported under himself.

There is another sort of Passage to which the trot likewise gives birth, and in which the action is so quick, so diligent, and so sup- 
ported, that the horse seems not to advance, but to work upon the same spot of ground. The horses which take this sort of Passage have not their action so high and strong as the other, it being too quick and sudden; but almost all horses which are inclined to this, are endowed with a great share of gentleness and activity.

Section III._. Of the Passage in particular.

$I_{N}$ the Passage, the forehand is raised,-the shoulders out,-the croupe in,-and the neck partakes of a two-fold bend,-that is, the neck bends a little inward, and the nose is a little turned from the perpendicular, and this bend and turn put the forehand into an elegant form. The inner side of the horse, which is that to which he is working, is advanced or leads, the same as in the gallop; but the feet are lifted as in the trot, only raised higher before and less behind, the consequence of a closer union. The fore feet 
being raised higher and retained in hand, make a shorter step and slower time, and the action not being so rapid as the trot, the beats are not so sharp.

Let the pupil try this first to the right. For this purpose, collect and separate the reins, bring your right hand down to your body, letting your wrist steadily rest against it, the little finger being of a parallel height with the elbow. This hand supports the position or attitude of the horse, and is never to move but with the body, while you work the horse to the right. The left hand having the rein of equal length will be somewhat advanced, to admit the small bend of the neck and turn of the nose, as described. The right hand being fixed to the body to support the position, the left may be detached, the hand and elbow being raised to a parallel with the shoulder, and the elbow so bent as to form a graceful arch. In this situation, it operates in the same direction from the horse's mouth as the right, only higher, for the purpose of raising the forehand, and by 
those delicate sensations of the fingers, inseparable from a good hand, it enlivens the mouth, lightens the appui, animates the horse, and raises the action.

The corresponding position of the body (as has been described in the gallop with the croupe in), is the right hip advanced, the thigh turned inward, \&c. But as the side action of the horse is more liable to disturb the balance than the gallop, be sure to keep the body upright, steady, square to the same front as the horse, and dressing to the right.

As to the legs, press with the calf of the left leg to make the horse place his haunches in the proper direction, cross his legs, and answer the leading rein. Stretch also the right leg down, and brace the muscles firm.

The eye must always traverse the ground the horse is to work on.

In this movement, then, the right rein leads, and the left leg presses, and obliges the horse 
to place his left foot before the right; the left rein keeps the horse's head up, assists and balances the power of the right, and the right leg presses the horse up to the hand, prevents the croupe from coming too much to the right, and retains the horse in the oblique direction on two diagonal lines.

In all this, the pupil begins cautiously, and gently presses and collects his horse into his hands, till he feels that he has him completely united and balanced there. The arms are firm and steady, and the fingers as soft and pliant as the obedience and working of the horse will admit,--supporting the appui as lightly and delicately as possible, leading the shoulders off first, and letting the croupe accompany them.

The pupil is now to observe, that the horse does not advance over his lines; that he does not retreat from his lines; that the shoulders work no faster than the croupe, by which the horse would become straight on his lines; 
P. VI.

that the croupe does not work faster than the shoulders, by which the horse would not be able to advance ; and that the balance is preserved without leaning the body outward.

If the horse advance over his line (if the reins are of a proper length), the operation of the hand is not sufficiently strong, therefore brace the tendons of the fingers, which will cause the sensation or appui to be stronger.

Should the horse retreat from his lines, the hand may be too strong, therefore ease the fingers, and close both legs, to bring him to his ground.

Should you perceive the shoulders gain on the croupe, you need not move your hands, if they are properly placed, but keeping them perfectly steady, turn your body a little outward, which is the contrary way to which the horse is working. This will stay the shoulders while the croupe comes up. 
The right hip, however, being much advanced, to preserve the balance and support the position, to prevent any unseemly distortion which the body would have by thus turning beyond a certain medium, the shoulders may be stayed by carrying the left hand a little outward, or letting the hand operate outward by the turn or motion of the wrist.

Observe, when the body and hands are placed straight with your horse, an imperceptible turn of the body will remove the hands an inch, which is about a fifth part of the power the aid of the body possesses, independent of any removal of the hand.

The leg, always remember, is to assist the hands, by putting the croupe forward, while you stay the shoulders; and when both are right, let them proceed together.

Should the croupe advance too forward, as mostly happens from a defective balance, the body by leaning to the outward stoping the shoulders, -if so, correct your seat; otherwise 
aid less with the leg, or turn the body a little more inward. Either or both will correct the error.

Should you find your balance disturbed, stretch down your inward leg, brace the muscles strong, and press the inner part close to the saddle.

But you must not be satisfied while you suffer those disorders to take place; for they are generally more from the defect of the rider than of the horse.

Plate XXI. illustrates this pace.

When you have worked the length of the riding house to the right, work back again.

For this purpose reverse your position, i. e. bring your left hand down to your body, to support the position, advance and raise your right hand to support the action,-advance your left hip to maintain the balance, - direct your face to your horse's nose, and 


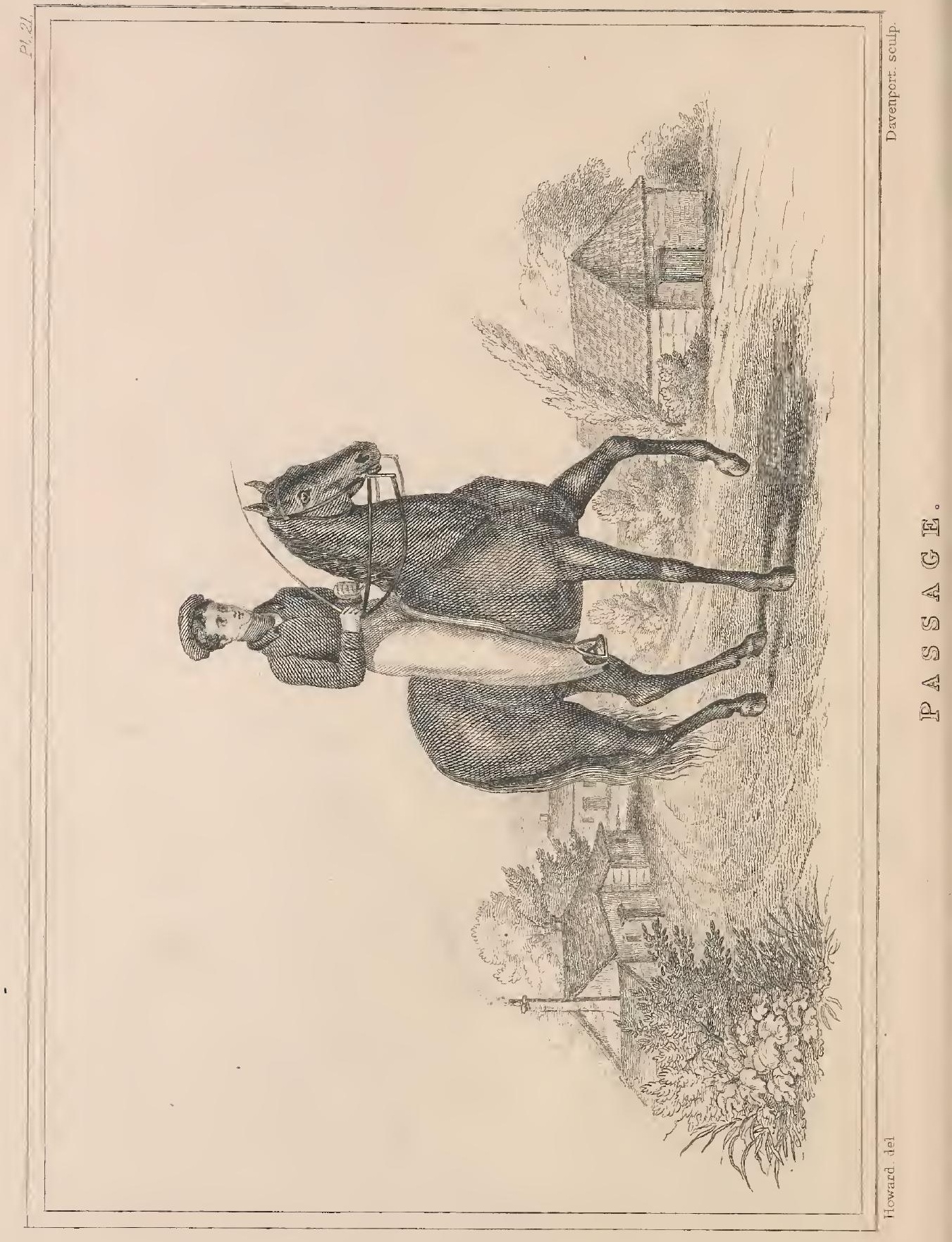





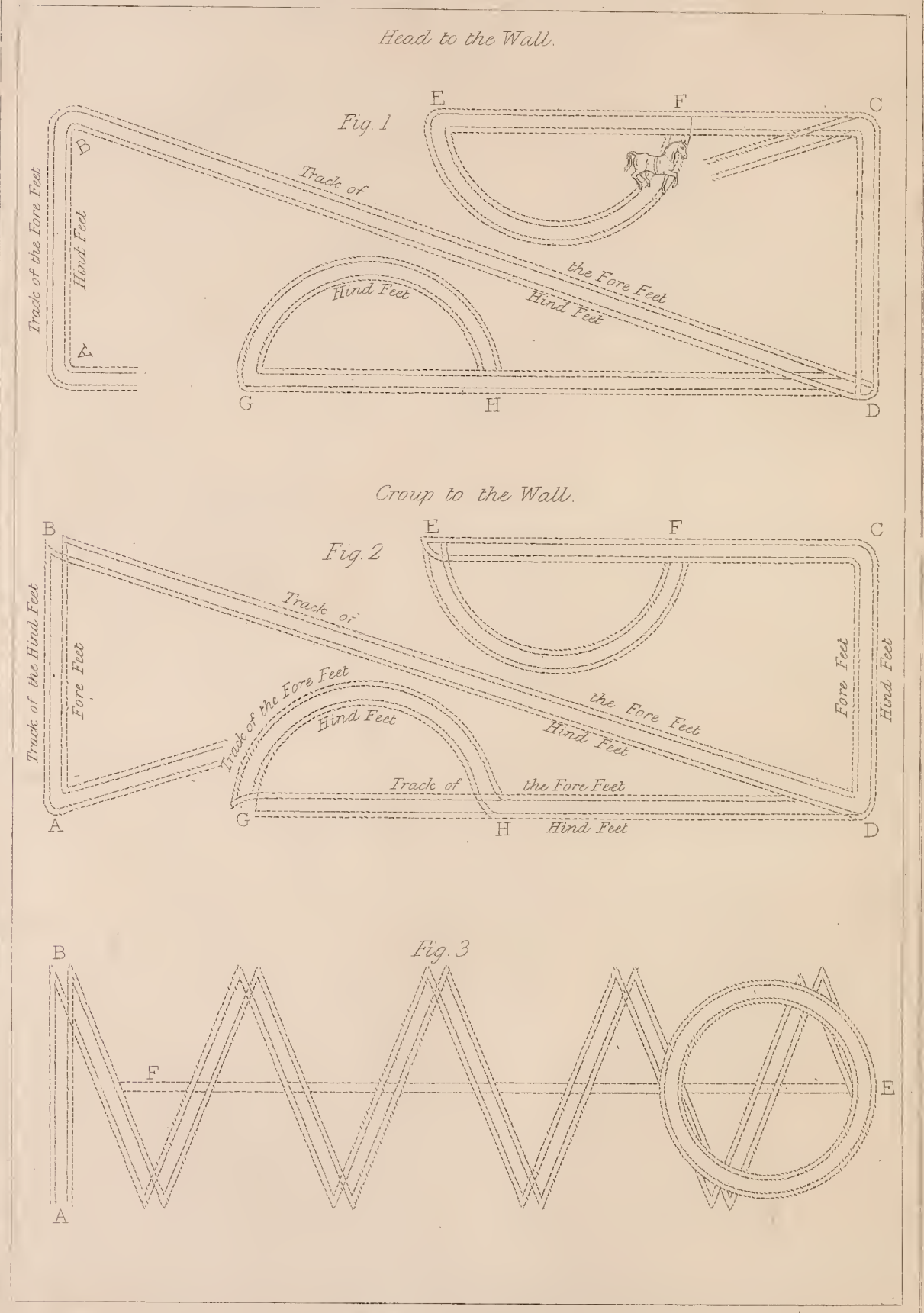

Howard de!

Davenport. sculp.

IESSON ON TCET TASSAG 
your eye along the line his fore feet are to work on.-In this manner you work to the left.

From perfecting yourself in this lesson with both hands, proceed to work it with one hand. The reins properly adjusted, and the hand in its usual situation, the same aids of the body and hands will produce the same effects.

Section IV.-Lesson on the Passage.

To give practice in this operation, the following method may be adopted.

Begin to work the head to the wall to the right, and when you arrive at the corner A, Figure 1, Plate XXII. observe the turning of the corner.

If you lead, or suffer, the shoulders to go round too soon, the corner would not be filled, 
P. VI.

and it would be seen that the hand permitted the horse to break ground, which all horses will do with inattentive hands.

On the other hand, if you worked too close, the shoulders would not have room to turn, and you would be what is termed locked up. Attending to this, stop the haunches in time, that the shoulders may have just room to turn.

If you have your horse properly united, and, as it were, balanced in your hands, the gradual turn of your body,-desisting at the same time from aiding with the leg, will lead the shoulders round; and, as the shoulders advance to their proper situation on the new lines, the body and leg should resume their former position, and work both shoulders and croupe together.

Remember that the beauty of this lesson consists in working the ground truly, supporting the proper position, high animation, elegant action, and regular time. 
When arrived at the corner $\mathrm{B}$, in like manner, lead the shoulders round till they are properly situate to work on the diagonal lines which cross the house to the corner D.

If you bring the horse properly to this corner, he will be situate, by only the change of your position, to work on the described lines to the left. Carefully observe, then, to turn and fill the corner $\mathrm{C}$, and work to the point E.

Here stay the croupe while you lead the shoulders round to station them on the intended demi-volt; then, forming with your eye as true a half circle as you can, correctly work thereon; keeping the croupe. all the way towards the centre, as the situation of the marks on the lines more clearly express.

Here lead the shoulders from the wall, work the volt correct, keep the horse in a true position and situation in every part of the volt, turn the croupe at the finish, for the 
purpose of changing and working to the right, in high animation, close union, and without breaking time.

Having arrived at the point F, turn the croupe sufficiently in, and work to the right, round by the wall, observing properly to fill your corners till you arrive at $\mathrm{G}$.

There, in like manner, work on a demivolt to the point $\mathrm{H}$, where you change and work to the left, filling your corners.

Work to the corner $\mathrm{C}$, then cross the house in a diagonal line to the corner A, Figure 2, where instead of changing, turn the croupe round, and work croupe to the wall, to the corner B.

Here you may change and work to the right hand across the house to the corner D,

There you may stay the shoulders while you turn the croupe, till your horse is properly stationed to work croupe to the wall, to 
the corner $\mathrm{C}$, and then turning the croupe, continue to work to the point $\mathbf{E}$.

At $\mathrm{E}$ stay the shoulders, turn the croupe in, make the change, and work the demi-volt, which brings you to the point $\mathrm{F}$.

From F, carefully turning the horse's croupe to the wall, work to the corner $\mathrm{C}$, and from thence to $\mathrm{D}$, observing to turn the croupe round at each corner, and continue working to the point $\mathrm{G}$.

At $\mathrm{G}$ make the change, and turn the croupe round, so that the the horse may be properly stationed to work on the demi-volt, to the point $\mathrm{H}$. Then turning the croupe to the wall, work to the corner $\mathrm{D}$, and from thence to $\mathrm{C}$.

At $\mathrm{C}$, change and work across the house to the corner A, Figure 3.

Now turn the croupe round in the corner; and work to the corner $B$. 
Here change and work the traversing lines up the riding house, reversing your hand at every angle, which is called the Change Reverse, till you arrive at the point $\mathrm{E}$, where you halt for a moment.

Now work upon the volt to either or both hands, terminating at $\mathrm{E}$, where the volt began.

Here the principal object is, to station the horse properly at the commencement, turning the croupe toward the centre, in the exact position on the lines, as the horse is to preserve throughout the volt; and, the volt being determined by the eye, the hand and heel must aim to work to it, observing that the shoulders here, as well as in straight lines, rather take the lead. The more contracted or narrow the volts are, the body must have a proportionate turn, and likewise a backward inclination to assist and facilitate the shoulders, which have a larger circle or space to work over than the haunches. Care must be taken that this inclination of the 
body does not affect or cause the horse to retire from his ground. The hand, therefore, must preserve its exact situation and operation; letting the body, as it inclines, depart from the hand; that, while you are assisting the one part, you may not disorder the whole.

Then rein the horse back to the point $F$, and work the horse forward to the point $\mathrm{E}$, in a straight position, lofty action, slow time, and as much united as possible.

Observe, that when working the croupe to: the wall round the riding house to the right, you are working to your left hand; and when working round the riding house to the left, you are working to your right hand. Observe likewise, that the changes in the croupe: to the wall are made both previous to crossing the riding house, and at the commencement of the demi-volt, contrary to the head to the wall, where the changes are made at the termination of each. If this is not at- 
tended to, you may confuse and bewilder yourself.

At the finish of the demi-volt, you have carefully to turn the croupe on the lines you intend to proceed on, when working croupe to the wall; and the shoulders on their respective lines, when working head to the wall; before you make the change. In croupe to the wall, the change was made at the commencement of the volt.

This lesson is the test of horsemanship; and it is therefore recommended for continual practice.

In the half passage, the horse should only half cross his legs, placing one foot before the other. 


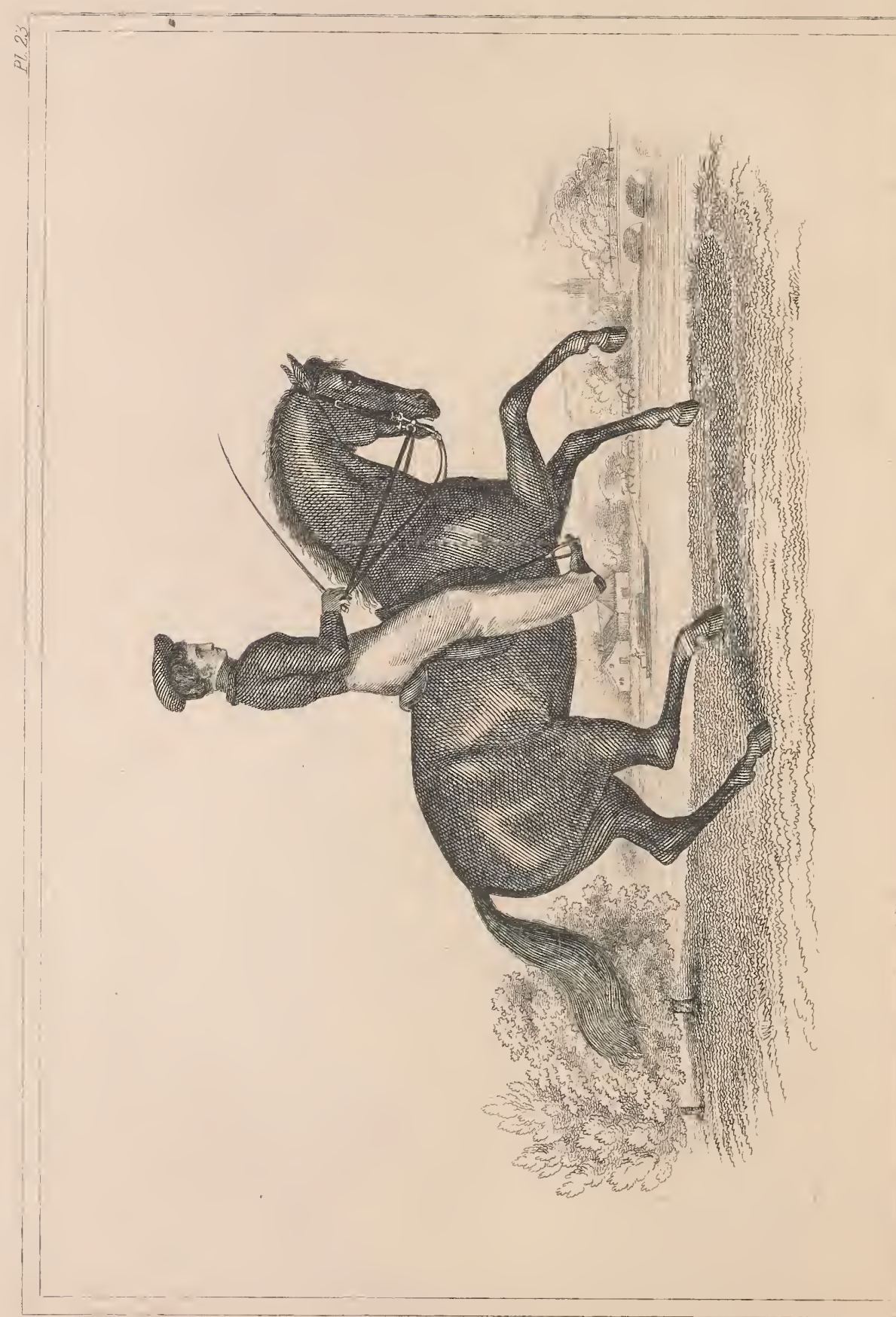




\section{CHAP. III.}

OF THE TERRE-À-TERRE.

Section I.-Of the Terre-d-terre in general.

Galloping a Terre-à-terre, is the galloping sideways, with the head to the wall or otherwise.

The position of the horse in galloping a Terre-à-terre, is the same as working the lesson of head to the wall; and the only difference is, that the legs are lifted in the action of the gallop, and mark four beats, rather quicker than the gallop; because the horse is more together, the feet measure less space, and the hind legs follow the fore more rapidly. 
The gallop, however, is the foundation of the Terre-à-terre, for in these two motions, the principle of the action is the same, since the Terre-à-terre is only a shortened gallop, with the croupe in, and the haunches following in a close and quick time.

When a horse works Terre-à-terre, he always ought, the same as in the gallop, to lead with the legs that are within the volte, his two fore feet being in the air, and the moment that they are coming down, his two hind feet following.

The action of the gallop is always one, two, three, and four: the Terre-à-terre is performed upon two lines, and in two times.

Section II.-Of the Terre-à-terre in particular.

To. work a horse Terre-à-terre upon large: circles, take care to keep your body straight, steady, and true in the saddle, without leaning to one side or the other. Lean upon the: 
outward stirrup, and keep your outward leg nearer the side of the horse than the other leg, taking care to do it so as not to be perceived. If you go to the right, keep your bridle hand a little on the outside of the horse's neck, turning your little finger up without turning your nails at the same time; although, if need be, you must turn them, in order to make the inner rein work, which passes over the little finger. Keep your arms and elbows to your hips; for, by this means, you will assure and confine your hand, which ought to accompany, and, if I may so say, run along the line of the circle with the horse.

Plate XXIII. illustrates this pace.

The like changes and airs, which are wrought in the last lesson, may be performed in this ; namely, the long change, demi-volts, change reversed, volts, \&c. 



\title{
PRINCIPLES
}

\author{
oF \\ M O D E R N R I I N G.
}

PART VII.

of

CIRCLING, LEAPING, AND CRITICAL SITUATIONS. 


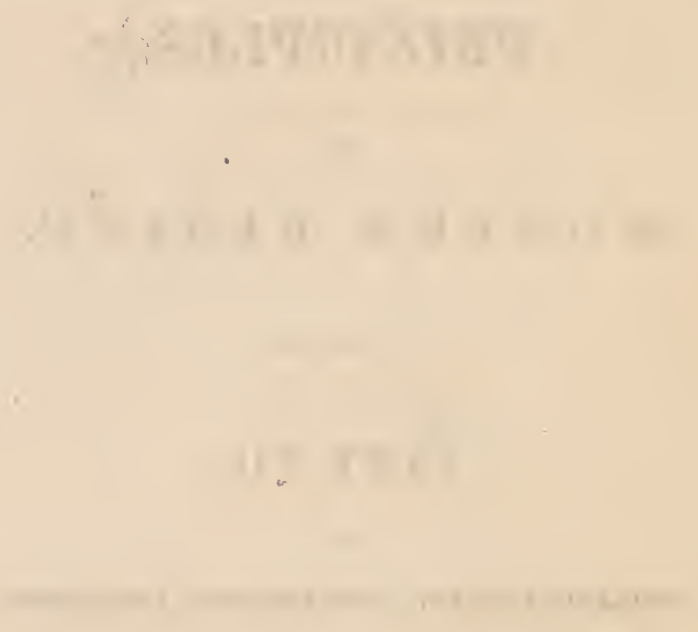




\section{PAR'T VII.}

OF OIRCLING, LEAPING, AND CRITICAL SITUATIONS.

\section{CHAP. I.}

OF THE CIRCLE.

Tне Circle should, at first, be from twelve to twenty yards in diameter, and the horse be made to move on it for some days at a walk.

In moving round a Circle, in order to preserve the poise of his body, the horse must necessarily lean inwards in proportion to the size of the Circle, and to the speed at which he is made to move upon it. The rider must of course conform to, and partake of, that 
inclination, or the equilibrium of both will be disturbed, and the man will lose the power to retain his seat.

This exercise of the Circle confirms the equilibrium and unity of the man and horse.

Commence the Circle to the right, by leading off the horse with the inward rein, so that you can see the inward eye; and support the horse with the outward leg, to keep his haunches under him.

The direction already given, that the inward rein is to be lower than the outward one, should be particularly attended to, when riding with the snaffle.

Here, besides keeping up a proper correspondence in the hand, supporting the action, and regulating the time, your eye is to mark the ground your horse is to work on; and your aids for that purpose are to be smooth and delicate, that the action or time may not be interrupted. 



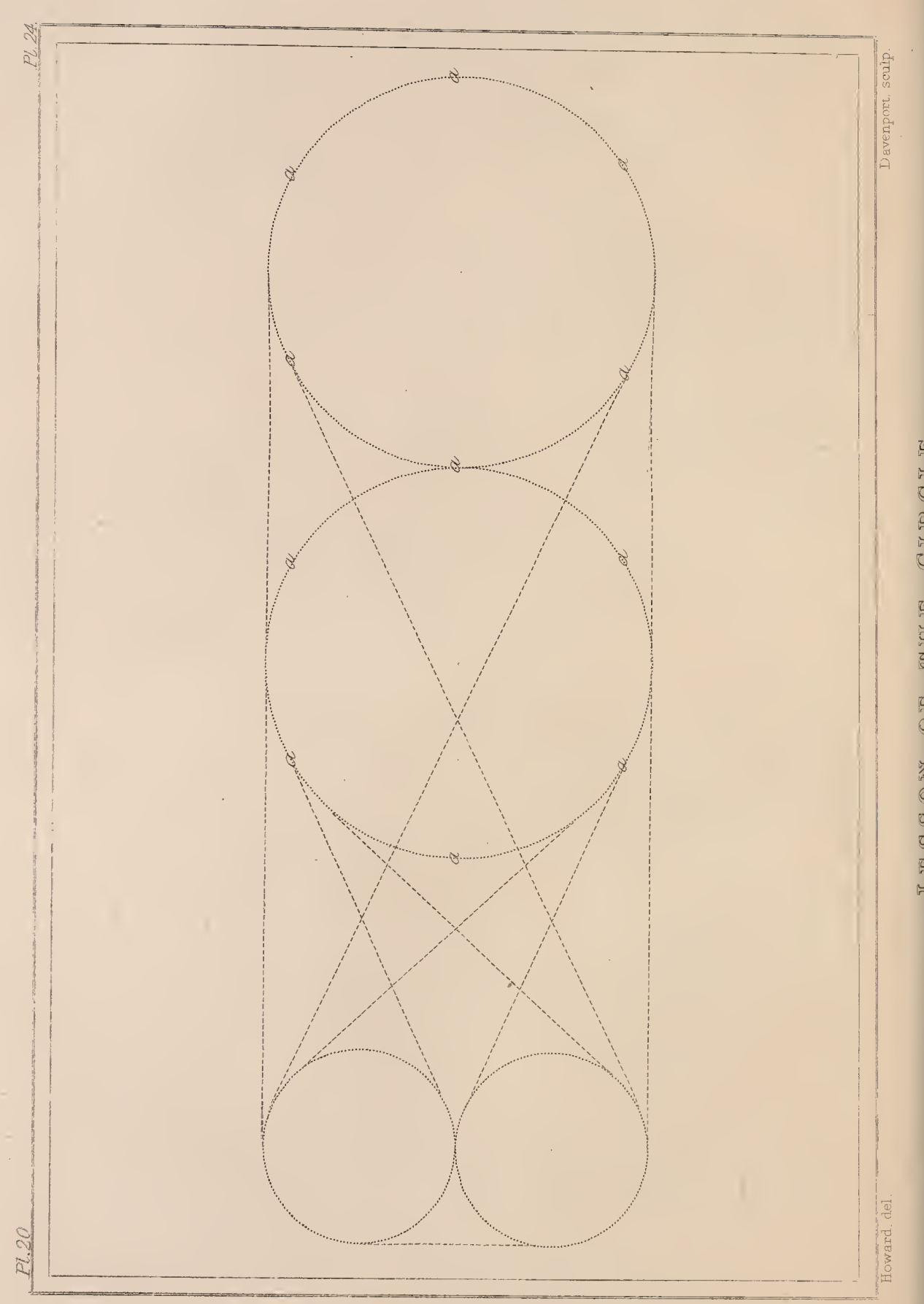


To be certain that your hand and aids are correct, you may at first have some mark to direct your eye, which the horse would not be directed by; for if your Circles were trodden on a green sod, your horse would of himself follow the beaten path, and you would not be able to discover the truth of your aids. Having, therefore, ground which is not marked, if you place four or five marks on each Circle, endeavour to pass directly over each mark. You will then discover how near you can work.

Do not confine yourself to work the whole time on two Circles, because that would not only become irksome, but the horse might work it by rote. After some continuance at it, therefore, diversify your track, and change your ground as often as you please, that the horse may never be aware of your intention, except by the correctness of your aids.

Plate XXIV. will more clearly describe the lines to work on. The intersection of o 2 
the Circles, and the termination of the diagonal lines, are the points where you change your ground from one Circle to another. The letters $a$ are where you may drop your marks to direct you to your ground, and discover the correctness of your performance.

Begin, then, with a slow cadence, and moderate animation, till you can keep your ground, and change smoothly without breaking time or pace. Then attempt a brisker action, and higher animation, always attending to the accuracy of the performance. As you attain perfection in the large changes, occasionally attempt the narrow, which still makes a greater diversity, always aiming at exactness in working your ground true, and changing without breaking time.

As the rider is confirmed in his balance and seat, the Circle may be gradually diminished, and he may urge his horse into a gentle trot; and finally, when properly prepared, into a short, collected canter. 
This lesson, after being practised with both hands, must be accomplished with one.

This occasioning great exertion to the horse must be of short duration, and relieved by frequent halts.

After due preparation, the Circle should be the concluding part of each day's lesson, and should, at first, be done without stirrups, and afterwards with them. 


\section{CHAP. II. \\ OF LEAPING.}

Section I.-Of Leaping in general.

For the practice of Leaping in the manege, the moveable bar is preferable to fixed posts, as by being easily removed, it leaves the place free for other purposes of exercise when the bar is not wanted. The bar should be ten feet in length, which will admit of two horses leaping abreast. It should be low at first (from one to two feet); and never very high.

Stirrups are no security to the seat in any situation on horseback; and those who cannot forbear pressing a weight in them, had better, when learning to leap, have none. 
It is true that many leap entirely by the help of their stirrups, but they leap very badly; they sometimes with great difficulty save themselves from coming to the ground; and, when a horse makes a rough or awkward Leap, they generally do fall. Let it be observed that any disturbance of the seat, whether you are thrown up from the saddle, or your body falls forward, or you get out of balance, is as disgraceful as falling to the ground. A person should sit so close as to carry a shilling under each thigh, just above the knee, one in each stirrup under each toe, and one under his breech,-and this, when practised on steady leaping horses, should seldom fail.

It is evident, that when any action of the horse tends to lift you from the saddle, stirrups cannot keep you down. Nothing but the gravity of the body presses to the saddle. The pressure of the thighs indeed holds it down; and when the action is so violent that the hold with the thighs is not sufficient, then the legs are applied, which is a deeper and 
stronger hold. Bearing in the stirrup, however, must operate to the lifting you from the saddle, and must loosen any hold you may take with the thighs or legs.

Hence, those who bear in the stirrups when leaping, are thrown high from the saddle, and the use they make of the stirrups is to catch them on their return. They plant their legs forward to keep them from being thrown upon the horse's neck; and, while they keep the body back, the reins hold them from tumbling backward; but a rough or irregular Leap so disconcerts the best practitioners in that way, that if they do not come to the ground, they are thrown out of their seat, and scramble into it as they can.

Leaps are taken standing or flying. The first is most difficult to sit, though always practised first, because the slow and steady Leaping of a properly broke horse, gives the rider time and recollection, and the master standing by can direct, and prevent accidents. 



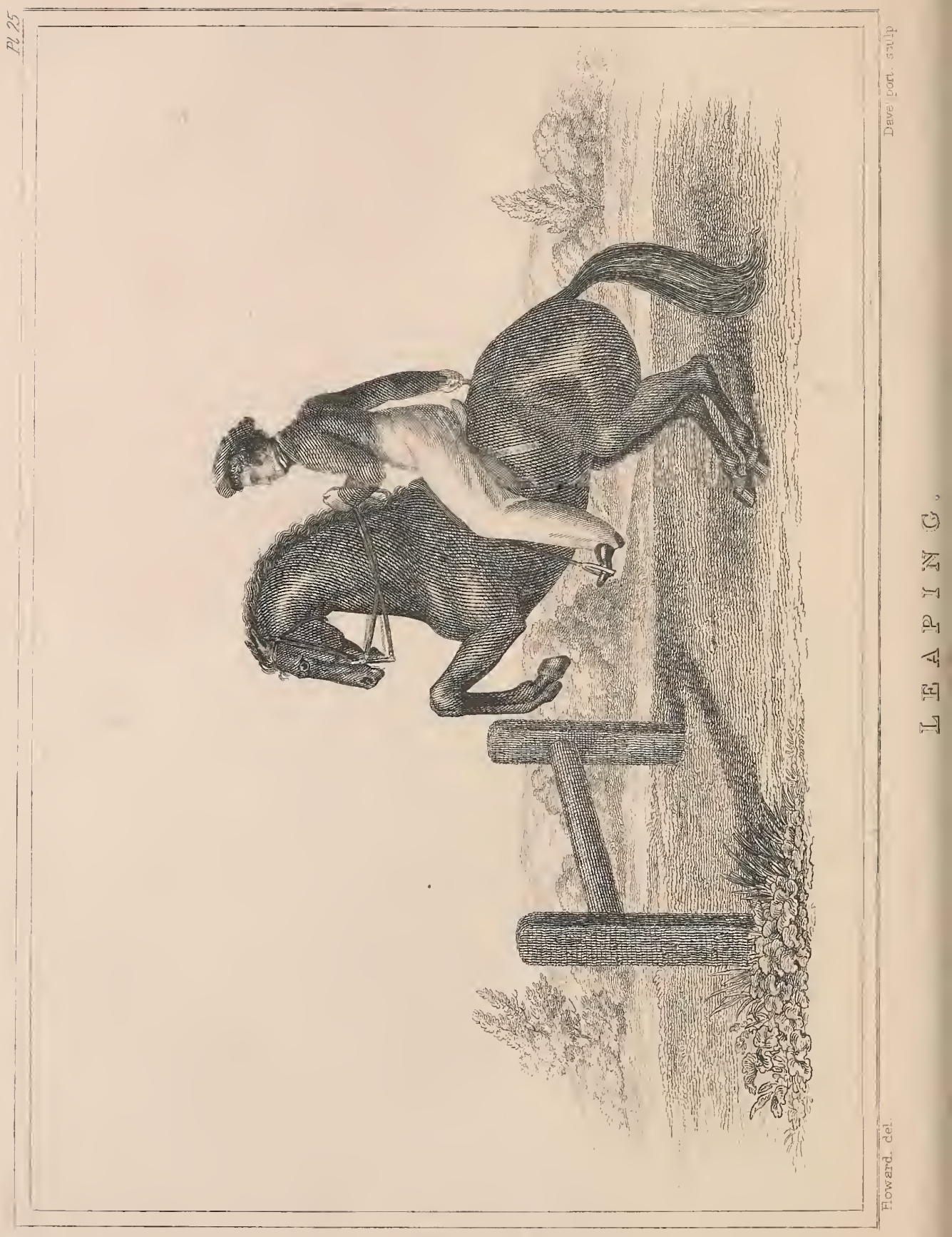




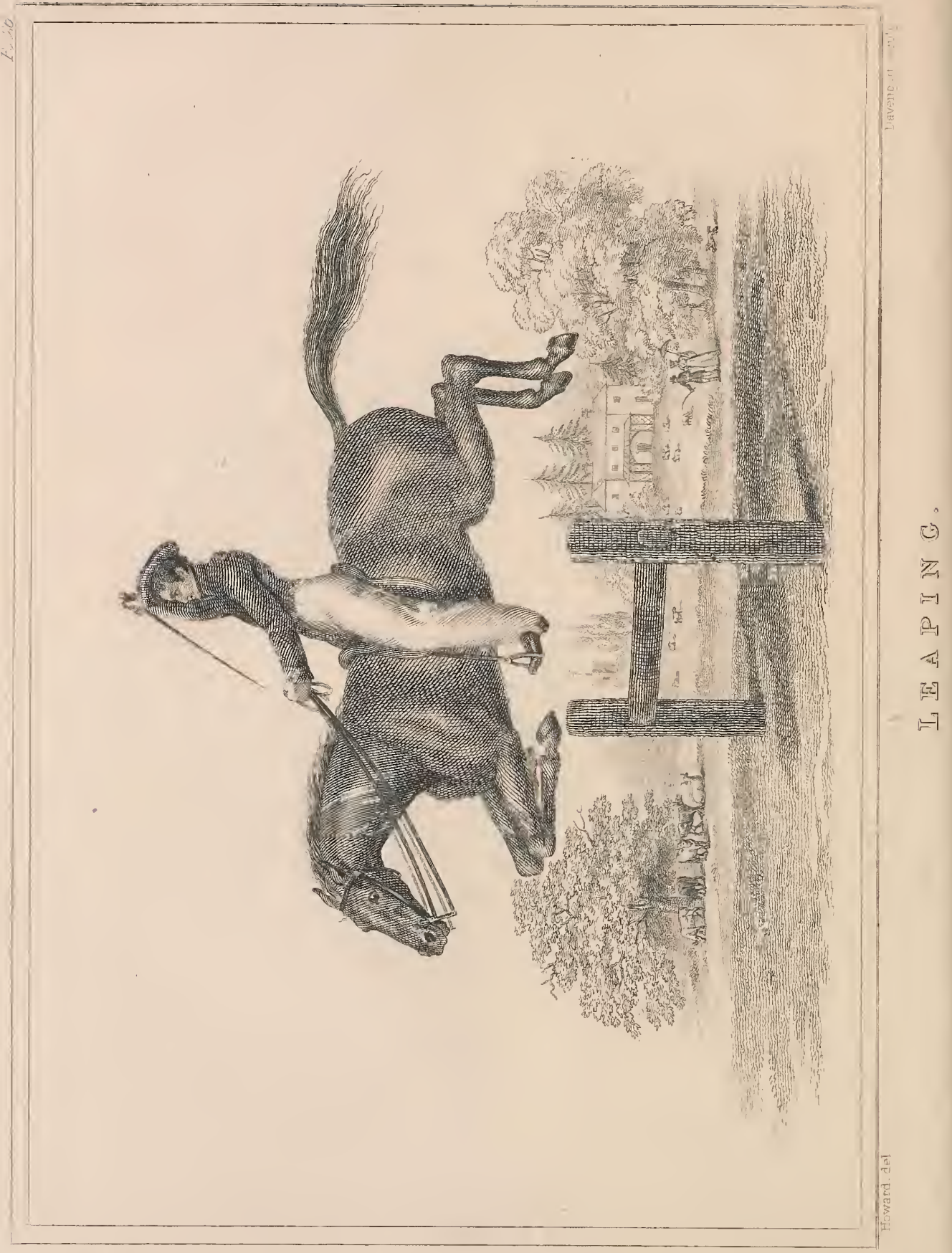





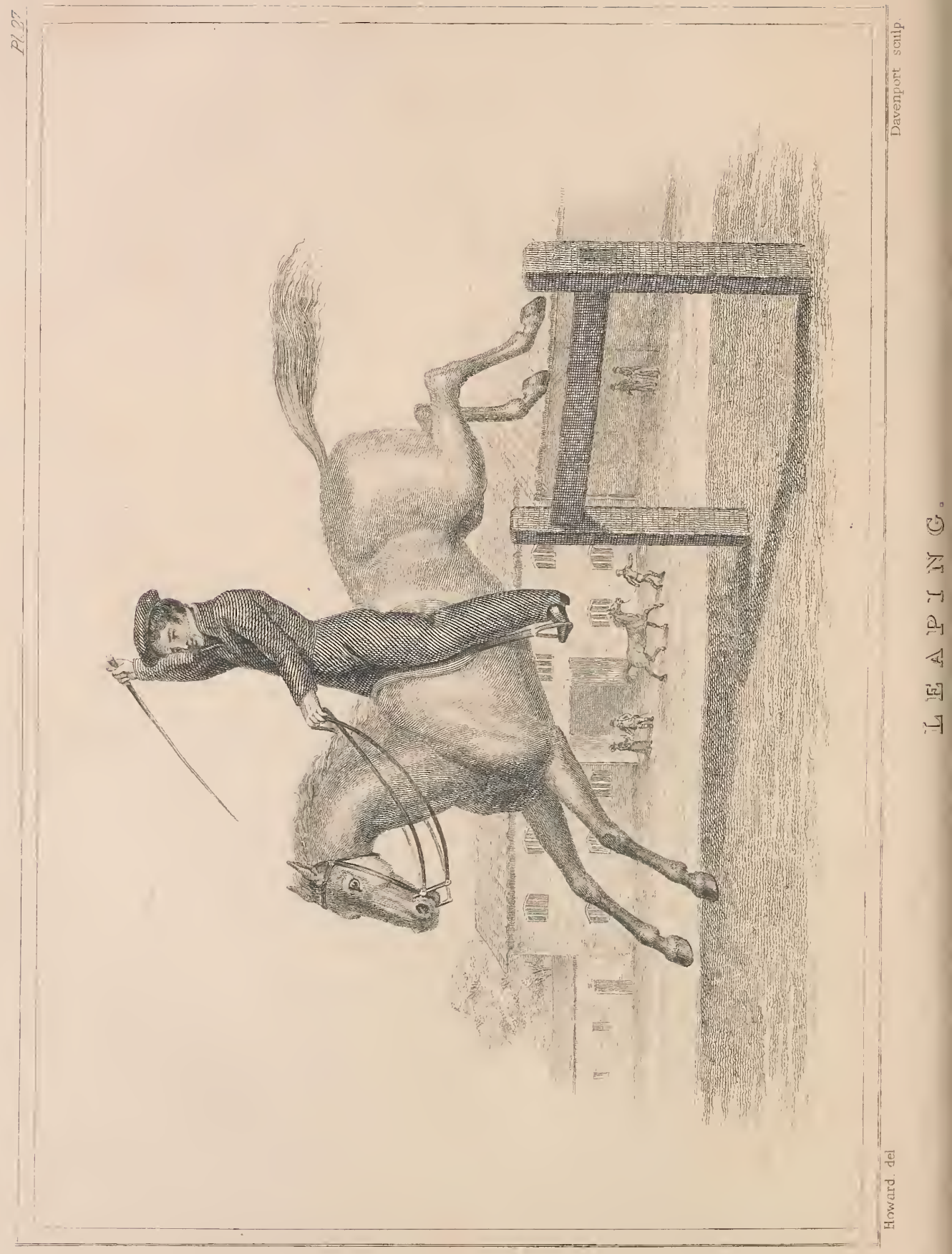




\section{Section II.-Of the Standing Leap.}

IN the Standing Leap, the horse first shortens, and then extends himself, in a considerable degree. Great readiness in the hand of the rider is, therefore, requisite to give the appropriate aids. These, if well timed, will assist the horse; but if otherwise, they will check or embarrass him, and endanger both the animal and his rider.

Plates XXV. XXVI. and XXVII. illustrate the Leap.

In commencing the lesson of Leaping, the rider must chiefly depend on the natural effort of his horse. The pupil who has the advantage of learning on a well trained horse, must therefore be first taught to leave him at liberty to extend himself by a ready and fearless yielding of the bridle, observing only to preserve his own equilibrium by leaning 
P. VII.

forward, as the horse rises, and backward, as he alights.-See the Plates.

By practice and attention, he will soon learn to apply the aids necessary to assist the horse. These are few; but to a beginner, they may be of difficult application.

The position, then, of the horseman when leaping changes as the horse changes his position.

Thus, when the horse is brought to the bar, the body is to be upright, exactly in the position which has been taught.-The legs are to be applied to the horse's side, with such firmness as to keep you down to the saddle, and in such place that the action of your own body shall not loosen or disturb them. The place of the legs, accordingly, must be perpendicular from the knee. If you place them more backward, the action backward which the body must take will loosen them, and then you have no hold. The toe must be pulled 
up, to make your muscles firm, and to prevent the spur from approaching too near the horse. If you find it necessary, you may turn your toes out a little to strengthen your hold; but if you have stirrups, bear no weight in them.-Keep your hand in the centre, and quite low; and your reins not too short, but just by the pressure of your fingers to feel the horse's mouth.

In this position you come to the bar. The pressure of your legs and fingers will invite the horse to rise; and, as he rises the body comes forward, and preserves its perpendicular.Be sure to keep the back in, and the head firm.

As the horse springs from his hind legs, you slip your buttock under you, and let your body go freely back, keeping your hands down, legs close, and body back, till the horse's hind legs have come to the ground.

Now we may explain the consequences of omitting any of these precepts. 
The application of the legs to hold you firm to the saddle carries conviction with it. -While the body indeed is upright, you will find a faster hold with your legs, when placed a little more backward than here directed, and you might therefore be induced to place them too backward; but you will perceive the impropriety of this if you lean the body quite back, for you can then have a firm hold only with your legs, where directed to be placed.

The hand being kept low is an essential thing. The hand is raised principally from fear. It is either done with the intention of holding on by the bridle, or of making the horse rise before.

The consequence of the latter motive so far as regards the horse, is, that they raise the horse's head and nose out of place, which straightens his neck, and he consequently cannot gather himself to rise, till he has dropped his nose and curved his neck. This, 
the hand will not suffer him in that situation to do; and the consequence is, that he makes an awkward short leap of all four together, which is dangerous and unpleasant both to horse and man.

As to the man, the hand raised in this situation prevents the body from going back; for, were the body improperly thrown back, the rider must then check the horse, and prevent him from covering his leap. This the horse is very sensible of ; and, therefore, he prepares himself to force the hand. The consequence is, the rider is pulled forward, and the shock he receives when the horse meets the ground, tumbles him on its neck, if not completely off.

We have said - the body comes forward to preserve its perpendicular, \&c. Were the body to hang back as the horse rises before, the weight would hang on his mouth, and prevent his leaping at least, if he did not pull the rider over backwards. 
We also said-The back should be hollow, \&c.-Were the body to be brought forward, with a round back and shoulders, it would not be in - a situation to get back in time, without much exertion of the rider; but if the back be hollow, when the horse springs forward, it will, of itself, fall backward if the hand be not raised to prevent it. If the head be loose, the action of the body may cause a small wrench of the neck, or a bite of the tongue.

Slipping your breech under you gives the body more liberty to lean back; and unless the body is well back, the shock, when the horse's feet meet the ground, will shake it forward, whereby you not only deprive the horse of the support, which at this time he should have from the hand, but are in danger of falling. If you recover your right position, or take your legs from their situation before the Leap is completed, you will be liable to disorder, loss of balance, and the like. 
These are the principles by which the seat is maintained in all violent exertions of the horse.

Such being the position and action of the body, - with regard to the reins, the pupil, in riding up to a Leap, must yield the bridle to his horse, guiding him in a straight line to the bar, or fence;--bring him in the Standing Leap up to the bar at an animated pace ;halt him with a light hand, and upon his haunches;-when he perceives the horse rising, only feel the reins so as to prevent their becoming slack; - -when the horse springs forward, yield the hand without reserve;and, when the horse's hind feet come to the ground, again collect his horse, and resuming his usual position, move on at the former pace.

If the horse be too much collected previous to his Leap, he will bound, or "buck over," as it is called. If not sufficiently collected or animated, he will probably not clear the 
Leap. The degree in which a horse should be collected or animated, must entirely depend on the temperament of the animal, and must be left to the judgment of the rider.

Section III.—Of the Flying Leap.

The pupil should not be put to the Flying Leap, until he is familiar with the Standing Leap. He will then find no difficulty in making it at any pace, if it be gradually increased from the walk to the gallop.

The Flying Leap is distinguished from the Standing Leap by its being made from any pace, without a previous halt; and although the action is quicker, it is much easier to the horseman than the Standing Leap.

The pace at which you should go at a Flying Leap, must always be moderate. You must never flurry the horse with a view of making him take a determined spring. By 
so doing you will often deter him from taking his proper distance, and make him leap at hap-hazard, to the great danger of your own neck. A horse, which rises too soon, seldom clears his Leap, and risks being strained by the effort to cover it; a horse, which rises too late, or too near the bar or a strong fence, will be likely to strike his knees against it, and thereby throw his rider, or hurt himself. The rider on the contrary must, with a light and ready hand, keep his head steady and straight to the bar.

If a horse leap willingly, let him take his own pace to it, and he will be sure to spring from his proper distance, and give himself that velocity which will assist his spring. 'Twelve yards from the Leap, the rider may turn his horse to it in a trot; the horse will strike into the gallop; and a stroke or two before he springs will increase his velocity, if he perceive that the height he has to cover requires that exertion. If a horse be indolent and require some animation, it is better to apply the spurs to rouse his apathy just 
before you turn his head toward the Leap, than while he is running at it.

The seat, in the Flying Leap, is exactly the same as in the standing one; but easier to sit, as already said, because, the horse's body keeps a more horizontal position; and if it is a Leap of inconsiderable height, it appears no more than a springing stroke in the gallop. On this account, the rider has no occasion to bring his body forward at the raising of the fore legs, for the spring from the hind legs immediately follows, and the body might not get back in time. It is even dangerous to let the body have a propensity to come forward at the raising of the fore feet, for sometimes a horse does not come fair, or will refuse to take his Leap, and check himself; in which case, if the body is forward, you may tumble over his head. Therefore, keep your body upright ; take hold with your legs; be sure to keep your hand down; and, as the horse springs forward, your body is sure to take the corresponding action of leaning back, particularly if you, at the in- 
stant, slip your breech under you, and bring your waist forward with an exertion proportioned to the spring the horse makes. Bring not your body upright, nor slacken the hold with your legs, till after the hind feet have come to the ground.

A horse requires but little support or assistance from the hand till he is over his Leap, or coming to the ground: then the support of the hand is proper and assists to bring the body upright. The assisting and lifting a horse over Leaps, may be done by old practitioners, but the attempting it by young ones is improper; they cannot judge when; and in the attempt would, most likely, balk rather than assist. At the best, it can only be done when a horse leaps freely and determinedly: at other times, the offer to assist would deter him from the Leap.

The necessity of caution and delicacy in the application of the aids naturally increases in proportion to the speed at which the Leap

$$
\text { P } 2
$$


is to be performed: but practice, under proper instruction, will remove every difficulty.

It will be advisable in early practice at the leaping bar, to use the snaffle rein only, taken in both hands.

Whips should not be used while the pupil practises in Leaping. The rider must be taught to depend upon his own aids to ensure the obedience of his horse. 


\section{CHAP. III.}

OF CRITICAL SITUATIONS.

\section{Section I.-Preliminary.}

WHEN a horse is addicted to rearing, kicking, and bolting, plunging, shying, and restiveness, the seat is maintained in like manner as in Leaps. Hence we consider these after Leaping.

In all these cases, the operation of the hands is to prevent, deter, and disarm him as much as possible. For this purpose, the arms are held firm to the body, the reins separated, and the hands kept up.

When you feel the horse disposed to play these tricks, you consequently prepare yourself for the encounter, by separating the 
reins, \&c. Now, the body must be kept upright, but very flexible, accompanying every action of the horse, to be ready to repel every effort he may make. Your balance is to be nicely preserved by the muscles of the thighs; and the legs are to be kept near the horse, but not to grasp till you feel the necessity, for the horse is in alternate motion with his fore and hind legs, and you know not whether he will rear before or kick behind. Your body, therefore, should accompany the action of his legs. Accordingly, when he lifts his fore legs, your breech must be thrust out behind, by which you are prepared if he rears. As the fore feet come to the ground, you slip the buttocks under, which prepares you for his kicking or springing forward. If either take place, your legs are in a situation at the instant to grasp, and keeping a firm hold with your hands, you support the horse from falling, and keep a proper restraint upon him.

On this subject, it is right to ascertain the horse's modes of defence, the action which he 
employs when inclined to disobedience, and his action when passion has subsided. Until this information is obtained, the man and horse cannot be said to have established their friendship; and patience with resolution, on the part of the rider, are the only means to effect it.

\section{Section II.-Of Rearing.}

OF all the defences a horse makes, that of rearing is the most dangerous, when they rise so rapidly and unexpectedly that you are scarcely aware of them, and so high as to endanger their falling backwards. 'It is fortunate that a horse, which rears to this extreme, seldom or never kicks. You have, therefore, principally to guard against his rearing.

Whenever the horse rises straight up, throw your body forward, and give him all the bridle. The weight of your body upon his fore parts will oblige him to come down.:. In the 
minute that his fore feet are coming to the ground, give him both the spurs firmly, and as quickly as you can.

These aids and corrections, however, must be given with the greatest caution and exactness; for were you to give him the spurs when he is in the air, he would fall over. If, however, you watch the time so as not to spur him, till he is coming down, and his fore feet near the ground, it is impossible he should fall backward; for then his balance is destroyed,- -he is upon all his legs again, and cannot rise without first touching the ground and thence taking his spring.

If, therefore, you give him the spurs before he is in a situation to rise again, you will punish him, and drive him forward at the same time.

Another method is the following:-Whenever you are aware of the horse's disposition to rear, have your reins separated and be prepared for him. The instant you perceive 
him going to rise, slack the one hand, and bend him with the other, keeping your hand low. This bending compels him to move a hind leg, and being thrown off his balance, he of necessity comes down with his fore feet. Twist him then round two or three times, to convince him of your superiority. This likewise confuses and baffles him.

By these means you may deter a horse from rearing to any dangerous height; and after he has convinced himself by a few experiments, he will give it up for that time.

To break horses of this dangerous vice, it has sometimes been expedient to quit the horse, and alighting to pull him backwards.

This, however, though an effective expedient, is to be attempted only at a particular crisis, and by persons perfectly collected, active, and agile. It indeed so frightens a horse to be thus foiled, that he is wary of giving the opportunity of using him so again. 


\section{Section III._Of Kicking.}

A ноRse addicted to kick high, seldom or never rears high, unless the firmness of the hand compels him to it.

Horses subject to kick, either when they go forward, or stand still, must be kept much together, or held in closely.

The hands, though fixed, are not to pull at the horse, if he do not attempt to force the hand and get his head. Give him the liberty to go forward, though not to get his head down, which woùld enable him to kick with such violence as to throw himself down. Confining the head up disarms him; and he makes a bolt from all fours, or springs forward somewhat like the awkward leap a horse makes when you confine his head to a standing leap, but not quite so rough.

If your hand confine the head, as has been directed, you may bid defiance to his kick- 
ing; and, when a horse finds his defences do not avail, he wisely gives it over.

The twisting a horse round a few times for this vice will have its effect.

Every horse has a favourite side, on which he is prepared for defence; your attack must, - consequently, be on his weak or unprepared side, not only in this, but in every other instance. If you seize a favourable opportunity to attack his feeble side, and have the opportunity of twisting him without his power of resistance, his astonishment and confusion will deter him from farther contention, unless you provoke it by ill timed correction, passion, and the like.

\section{Section IV.-Of Plunging.}

Plunging is seldom attempted by horses, but at their first backing or breaking. It is then attempted by some to a most violent degree; and it is so exhausting to the horse, 
that if he fails in throwing the rider, bursting his girths, or breaking any of his tackle, he soon gives it over. But if he succeed, he is encouraged to try again. Till horses are broke of this, they are not ridable without proper assistance.

When a horse plunges, he gets his head down, cringes his tail between his quarters, sets up his back, swells his body to burst his girths, and, in this position, kicks and plunges till he can hold his wind no longer. He holds his breath all the time; consequently, when he makes six or eight Plunges he is done: his breath can be held no longer.

'To sit these Plunges is to cure them. About three days' trial, of which the first is generally the most violent, decides the contest. Success in their endeavours, or improper treatment, may provoke farther attempts: otherwise the contest is given up.

To sit a horse when he plunges you must take a firm hold with your legs and be mindful 
that, in getting his head down, he does not pull your body forward. You are in no danger of his rearing; and, therefore, have only to keep your body back and hold firmly with your hands, to prevent him throwing himself down, which is not unlikely, if he get his head entirely loose.

\section{Section V.-Of Shying, \&c.}

ThE next danger the rider is exposed to is, when a horse, either by shying or restiveness, springs to one side, or turns short round.

Security, in these situations, depends on a strict conformity to the rules laid down. If you observe the precepts of not bearing in the stirrups; keeping the legs near to the horse, to be ready on these sudden and unexpected occasions to lay hold; and yielding the body to go with the horse; you will be safe. 
Section VI.-Of Restiveness.

Tue horse generally commences his attack by stopping, turning short round, mostly to the right hand, as taking the rider at the greatest disadvantage; for few men are so powerful with the left as the right hand.

The horse expects you will oppose the opposite hand to which he turns, to prevent him; he designedly attacks the weakest hand; and he is so prepared to defend against your utmost efforts that it is vain to attempt it. Instead of attempting to prevent him with your left hand, attack him rather with your right, and turn him completely round, so that his head is presented the way you were going.

Here an application of the whip may be tried, to compel him forward, but it seldom does. He generally turns round again; and you, in like manner, attacking his unguarded 
side, turn him two or three times, letting your heel and spur, if necessary, powerfully assist your hand, before he can arm or defend himself against it.

Finding themselves baffled in their defence, some give it up and go on; others will make a more obstinate resistance.

If he still refuse to go the way you want him, you must studiously prevent his going any other; and if you find him set himself against your endeavours to make him go forward, immediately change your attack, turn him about, and rein him backward. When a horse sets himself against going forward, he is easily compelled backward.

Here his defence is again baffled, and this is ever to be your rule-never to contend with him on that point he is prepared to resist.

In these contests, you must be collected, and have an eye to the surrounding objects, 
that you may not put yourself in an awkward situation, which through inattention you may do, without the design of the horse.

Yet it frequently happens, that restive horses try their utmost to get into these situations, by sidling to other horses, carriages, walls, rails, the foot pavement, the houses, \&c. \&c.

It is natural for persons to pull the horse from the object that he makes for; but this gives a determined horse the completest opportunity of accomplishing his intention, and some restive horses would be always crushing your knee against a wall, if you had not the means to prevent him.

Whenever, then, you find the horse so disposed, instead of pulling him from the wall, bend his head to it, by which the side of the horse next the wall is in a concave position, which prevents his utmost endeavours from doing you an injury. 
In the streets, or on the roads, innumerable objects more dangerous than a wall, will present themselves, which you must be attentive not to come near. The instant, therefore, that you perceive a horse sidling to any object, turn his head to that object, and back him from it.

By this means you protect yourself from injury, foil his intentions, and, after a fruitless contest, he is obliged to submit.

A horse's defences in the above instances, in a manner defeat their own purpose, because you immediately convert their defence to their punishment. There are, however, some few horses who fix themselves like stocks, setting all your endeavours at defiance to move them. Were they to move, you could convert that to your purpose; but while they stand as stocks, they defy you to move them forward, backward, to right or left. There happily they set up a defence that can in no way endanger your person. 
This defence, however, must also be converted to punishment. Let them stand; make no attempt to move them; and you will find that in a short space, frequently less than a minute, they will move of themselves. If you have patience to sit on their backs, and keep them there for a time, it is the most proper punishment for the offence, and will surely cure them of that mode of defence.

When these various defences, however, are not powerfully set up, the general rule is to push and carry your horse forward; and, for this purpose, at first make use of your switch, in order to drive him forward, as you will thus alarm him least; for the spurs surprise a horse, abate his courage, and are more likely to make him restive than oblige him to go forward, if he refuses to do so. Indeed the application of either whip or spurs in these contests, more than to shift the croupe, or give efficacy to the hands, is of little use. To repeat either, to make a horse go forward when he refuses, is certainly wrong. He must 
be immediately manœuvred by the hands, by turning about and about, reining back, and the like, till he finds his designs frustrated; he will then, finding he can go no other, reluctantly go your way; and when you present his head for that purpose, you may apply the whip or spurs sharply, compelling him at last to obey that which he at first refused.

Whatever passion possesses the rider, it prevents that concord and unity taking place, which ever should subsist between the rider and the horse. The rider therefore must always be disposed to amity, and should never suffer the most obstinate resistance of the horse, to put him out of temper. If the contest do not demand his utmost exertion of strength, he should be able to hum a tune, or converse with the same composure and indifference as though the horse were all obedience. By this means, the instant a horse finds himself foiled, he desists, having no provocation to contend farther, and is abashed at his own weakness. 

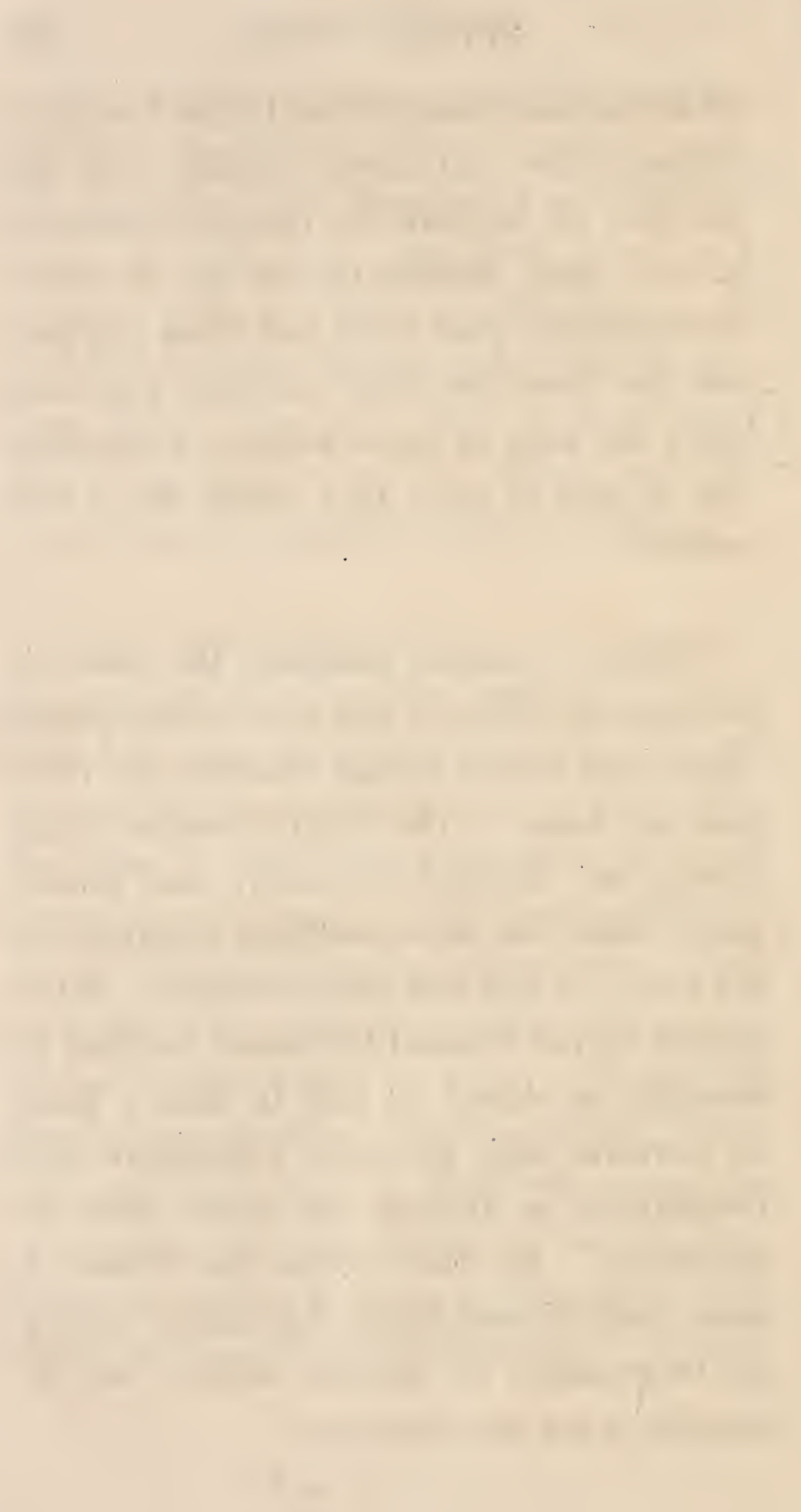


\section{PRINCIPLES}

\section{OF. M O D E R N R I I N G.}

PART VIII.

THE CURB, STIRRUPS, AND SPURS. 


\section{tint4 '}

-

\section{and 10}

$\because$ 


\section{PART VIII.}

OF THE CURB, STIRRUPS, AND SPURS.

\section{CHAP. I.}

OF THE CURB, ETC.

Section I.-Preliminary.

ALL the preceding lessons are supposed to be given with the snaffle alone.

When the pupil has attained some proficiency in horsemanship, and has acquired a proper degree of knowledge of the aids, he may be instructed to ride with the Curb in addition to the Snaffle.

The construction of the Curb, and the mode of using it, have been already explained. 
Section II.-Modes of Holding the Reins.

$W_{E}$ have already described the modes of holding the Snaffle either with two hands or with one. Those of holding the Curb are somewhat similar.

Considering these in the same order, we may first notice the practice of the army, who always ride with bits and bridoons. The bit or curb rein is placed within the bridoon or snaffle rein, and passes through the hand exactly in the same manner as the snaffle was before described to do; the little finger separating the left rein from the right, \&c. The left rein of the bridoon or snaffle then passes through the hand, laying smooth on the left rein of the bit or curb, with the thumb, as before observed, placed on it; and the right rein hangs loose.

Soldiers belonging to cavalry must necessarily be taught to ride with the curb; and 
that the hand may not be too much incumbered with reins, the bridoon rein, which, in military bridles, is always a light, short rein, passes through the left hand as above noticed, where it may be readily seized by the right hand, when occasion may require its assistance, either to bend the horse, enliven the mouth, or give more efficacy to the bridle hand, which are the principal uses of the bridoon rein.

Sometimes, however, instead of the right rein hanging loose, it is carried back through the left hand; and, as the left rein enters and passes through that hand by the side of the little finger, so the right rein enters and passes through it between the fore finger and thumb; the rein thus being doubled in the hand and its superfluous part forming a noose between the hand and the body.

The next method of holding the reins differs from the last only by taking up the right rein of the bridoon or snaffle with three fingers, thereby still having the curb rein 
P. VIII.

within the snaffle rein. The little finger alone separates the left reins from the right reins, and laying smooth through the hand, of equal length, the superfluous reins hang over the first joint of the fore finger.

The more usual method of holding the reins is that wherein the little finger separates the curb reins, and the second finger the bridoon reins.

Section III.-Of Shifting the Reins.

This should be done expertly without stopping the horse, altering his pace, breaking the time, or looking to the hands.

When the snaffle reins are held in one hand, the method of shifting from the left hand into the right is as follows.

Turn the thumbs toward each other, carry the right hand over the left, put the fore 
finger of the right hand downwards between the reins in the place of the little finger of the left hand, and lay the reins smoothly through the right hand.

By this means the fore finger separates the left reins from the right; the superfluous reins hang downward through the hand; and the thumb presses the left reins between the first and second joint of the fore finger.

If the reins are shortened by this method of shifting, it is easy to let them slip to their proper length; but, whenever they are too long, it requires the assistance of the other hand to shorten them.

The shifting them again into the left hand is only carrying the left hand over the right, putting the little finger of the left hand downward between the left and right reins, placing them smoothly upward through the hand, and letting the ends hang over the fore finger as at first. 
When both curb and snaffle reins are held in the last and more usual method, you shift them into the right hand (after turning the left thumb towards the right), by putting the fore finger of the right hand into the place of the little finger of the left, the second finger of the right into the place of the third finger of the left, and the third finger of the right into the place of the second finger of the left, placing the reins smoothly through the right hand, with the ends hanging down.

Thus you have every rein separate in the right hand.

When you shift them again to the left, put the fingers of the left hand into the places you took them from.

When you are handy and expert at this, your reins will never be in disorder.

The shifting of the reins is principally intended to relieve the left hand when cramped 
or tired, or when you have occasion to use it, or when you mean to work or attack your horse on the left side.

Section IV._Of Separating the Reins.

Separating the Reins, on several occasions, is very necessary. Two hands can execute more than one; and, consequently, when a horse refuses obedience to one hand, you take two.

You seldom have occasion to take more than one rein in the right hand, which, if a single-reined bridle, you cannot mistake; but when it is a double-reined bridle, you take the right rein only of the snaffle in the right hand.

For this purpose, turn the back of your right hand upwards; put the first three fingers over the bridoon rein, by which you receive the rein between your little and third 
finger, let the superfluous end hang over the fore finger with the thumb placed on it; and then carry the thumb upwards as you do the bridle hand.

Section V.-Of Changing the Reins.

Changing the Reins, when working with a double reined bridle, may, at times, be necessary.

For this purpose, when you are working to the right, you have the reins of the bit only in the left hand, the bridoon rein being entirely detached from it; and the right hand holds only the right rein of the bridoon.

Now, when you change to the left, first throw all the superfluous rein of the bridoon over to the right, so that the rein is straight from the horse's mouth to the neck on his left side, and quit it with the right hand. Then change the reins of the bit into the right 
hand, with the fore finger downward between them, as other reins have been directed to be shifted. Lastly, the left hand, being disengaged, lays hold of the bridoon rein, which, by the superfluous rein being over on the right, you can take as short as you please, and let it slip to the length you require.

In changing again to the right, be sure first to throw all the superfluous bridoon rein to the left, and then you will not be embarrassed when you come to take it up with the right.

\section{Section VI._Of Adjusting the Reins.}

Adjusting the Reins is altering them by shortening or lengthening in whole, or in part, as occasion may require. This will be as often as you change from one place to another. Besides, the reins, being held as pliant and easy as circumstances will admit, imperceptibly slip, particularly with beginners. 
To become expert at adjusting the reins, take the superfluous reins that hang over the fore finger of the left hand into the right hand altogether. Do not remove the left hand; but only open the fingers so that you can slip the hand up and down the reins smoothly and freely, while the right hand supports the horse, and feels every cadence or step the horse takes. By this method you will become handy in altering the reins altogether.

Would you shorten the curb rein and lengthen the bridoon, apply the right hand to the end of the curb rein, that hangs over the fore finger. First slip the whole of the reins too long: then slip the left hand down the reins, keeping the centre of the curb rein fast in your right hand, and feeling with your fingers whether both the curb reins are of equal length before you grasp with the left hand or quit the right.

In like manner you shorten the bridoon or snaffle, and lengthen the curb; first slipping 
the whole too long; and then applying the right hand to the rein you mean to shorten.

When any single rein wants shortening, apply the right hand to that part which hangs over the fore finger, and draw it tighter.

A little observation and practice will soon make you so perfectly acquainted with their situation, that you will find them as readily in the dark as in the light.

When the reins are separate, i. e. both hands occupied by reins, and they want adjusting, you bring the hands together to assist each other; remembering, that the hand that supports the attitude or position the horse works in, which is always what is termed the inner hand, is not to depart from its situation so as to occasion any disorder, but rather the outward hand to be brought to the inner, for the purpose of adjusting them. 
Section VII.-Of the Position of the Hand.

Tre left elbow is to touch the hip lightly. The arm is to be steady against the side, without force or stiffness. The hand is to be about three inches from the body, and as much above the pommel of the saddle. The little finger is to be in a line with the point of the elbow. The wrist is to be rounded. The finger nails are to front the centre of the body. The thumb is to point across the body.

From this position of the bridle hand, the little finger should at least have three lines of action, upward, to guide the horse;-towards the right shoulder,-towards the left,-towards the breast. The little finger should move on these lines only as the aids require. Thus the horse will be guided, and lifted up at each turn, by the inward, or leading rein; the outward acting in unity with it.

Pupils should be cautioned not to throw their right shoulders back, which they are 
apt to do, when they first take the reins in one hand. The right arm should hang in an easy and natural position by the side, with the hand by the side of the thigh ; or holding the whip it may be situate a little lower than the left, not to obstruct the operation of the bridle.

Section VIII._Of the Management of the Curb.

The Curb requires a light hand in the management. It is necessary to feel and ease the reins in the degree suitable to the individual horse. Some horses require rather a firmer feel than others, and most have some peculiarity, which experienced horsemen discover and turn to account.

The pupil cannot be too deeply impressed with the necessity of a constant attention to the proper management of the Curb, by means of which a correspondence is kept up between the mouth of the horse and the hand 
244 PRINCIPLES OF. P. VIII. of the rider. When judiciously held, it occasions a playful action of the horse's mouth. It is by a firm, easy, and light hand only, that the sensibility and freshness of feeling of the horse's mouth, so essential in riding, can be preserved. 


\section{CHAP. II.}

OF STIRRUPS。

THE pupil having been instructed in the use of the different aids, and how to maintain his seat, and to ride with ease to himself in the proper equilibrium without Stirrups, may be considered sufficiently advanced to be permitted to ride with them.

The proper length of the Stirrup is, when the upper edge of the bottom bar of the iron reaches one finger's breadth below the inner ankle bone.

The position on horseback with Stirrups, differs in nothing from that described for the position without Stirrups, except that, the thigh being relieved from the weight of the 
leg and foot by their resting on the Stirrup, the knee will be a little bent, and rather before the line described in the Position without Stirrups.

When the feet are in the Stirrups, the heels should be about two inches lower than the toes; and no more than the natural weight of the limbs should be borne in the Stirrups.

It is by an easy play of the ankle and instep, that the Stirrup is retained, and the position preserved. Till you have acquired this play of the instep, you will find, if your toe be too forward, the Stirrup will fall to the instep; and if too back, you will lose the Stirrup; but when the foot is in its proper situation, if the toe be raised, the Stirrup will not immediately depart from it.

It is a good practice for all horsemen to ride occasionally without Stirrups, for a short time in the course of the Manege Lesson. 


\section{CHAP. III.}

OF SPURS.

WHEN the pupil has learned to preserve his proper Seat and Balance in the several turnings and paces of the horse, and has acquired a knowledge of the Aids of the hand and legs, he may be permitted to ride with Spurs.

When it is necessary to use the Spurs, in order to urge the horse to action, they should be applied three or four inches behind the the girth, as low as the legs can reach, and with the lightest touch that will effect the purpose. 


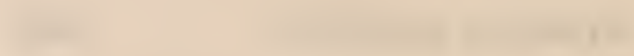

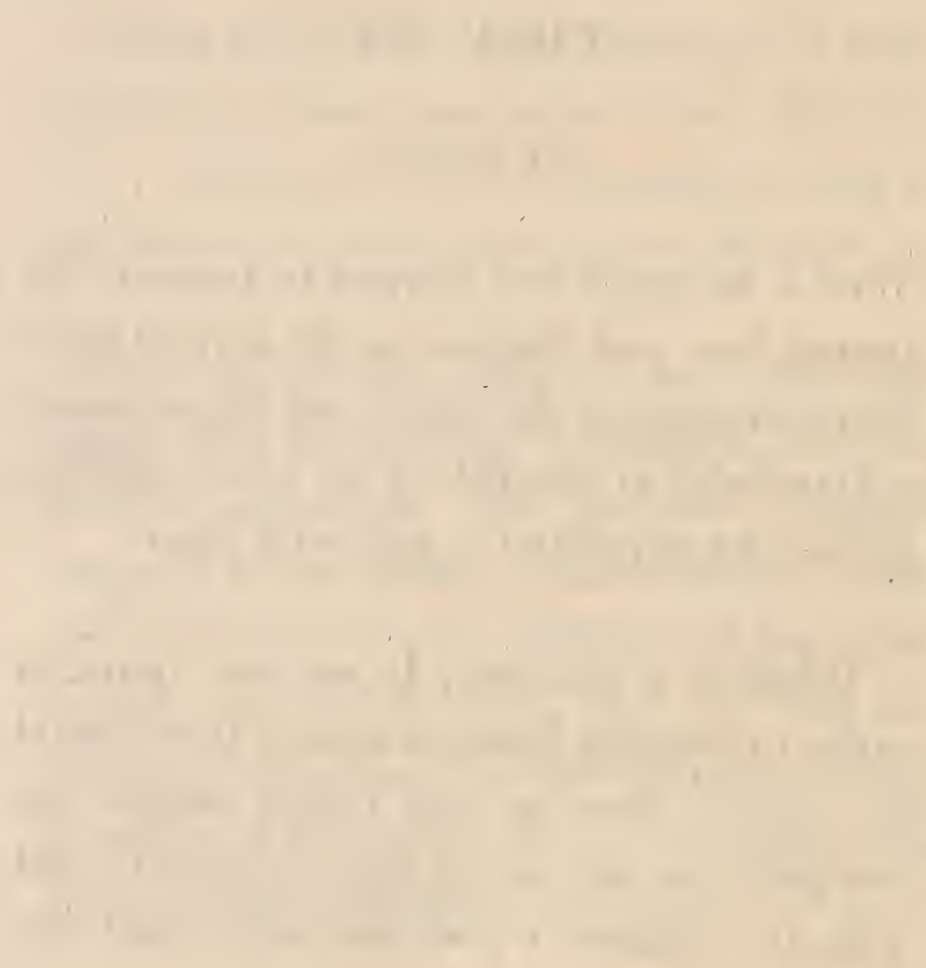




\title{
PRINCIPLES
}

\author{
oF \\ M O D E R R I D I N G.
}

\section{PART IX.}

of

ROAD RIDING, HUNTING, AND RACING. 



\title{
PART IX.
}

OF ROAD RIDING, HUNTING, AND RACING.

\author{
CHAP. I. \\ OF ROAD RIDING.
}

WheN persons are pursuing their business, pleasure, or recreation on the road, attention to the strict rules of manege riding would interrupt their enjoyment, and divert them from the various objects that present themselves, or the conversation of a companion.

The rudiments of the art, therefore, being once known, no more is to be applied on the road than will, with the greatest ease, facilitate our design. 
Although, however, we admit deviation from precise rules, yet we do not mean to vary the system of riding or substitute another for the road.

If, as already described, you place your feet parallel to each other, and about two feet asunder, and your body upright, then bend your knee, and sink your body that the knee shall just, and no more than, interrupt the sight of the toe, you will be in the exact position of the manege seat. Still, then, keeping the body upright, but sinking as low as you can without stooping, or projecting the knee before the toe, and you will be in a correct position for Road Riding. The difference, therefore, you find in a shorter seat, consequently a shorter stirrup.

The restraint to be thrown off is this: first that of the mind ; for having nothing to perform but what by your former practice you can now execute without an effort, your attention is amused by various other objects : - next of the body; for the exertions of the 
horse, in the manege lessons, are drawn from him by a similar exertion; but in the rider exertion now becomes unnecessary, since you require no more than the natural paces of the horse, performed with the greatest ease and freedom to himself; and your whole system falls into an easy flexibility, pleasant both to yourself and to the horse.

This freedom and ease, so desirable and so universally admired, are affected by every person who is in the habit of riding, but with this difference, that some unite system with negligence and ease, and others have negligence and ease without system.

This ease or inattention is not to suffer unseemly habits to take place, such as the back or shoulders to get round, the hand to shake, the legs to dangle against the horse's sides, or to be placed considerably forward to bear in the stirrups. These errors may creep on a person who has not confirmed the principles by sufficient practice; but when habits of 
good riding are firmly established, the ease and liberty he assumes will not exceed propriety, risk his security, nor neglect the horse - his hand will keep its situation and properties, though the body be turned to any extreme for the purpose of viewing, conversing, and the like. Nor will the body, by any freedom it takes, throw itself out of balance, nor take liberty at a period when it cannot be done with safety.

Since the rider's ease and convenience is the principal consideration in riding on the road, it is admissible, when the trot is extended to an unpleasant roughness, to ease the jolting by rising in the stirrups. This is so soon learned that it scarcely needs a description, since there are none in the habit of riding who do not actually accomplish it; and it is generally the first thing the young untutored horseman aims at, though a ridiculous awkwardness frequently attends some at their first attempt, and many imbibe unseemly habits which they cannot easily abandon. 
To do this with ease, the following remarks may be useful, or may at least prevent ridiculous habits.

Let the trot be extended to such a degree that the action of the horse may raise you considerably from the saddle, while the sitting becomes rough and uncomfortable. To attempt it before would be not only unseemly, but difficult: for the faster the horse trots, the easier it is to rise.

Beginners are apt to try this in a slow trot, in which the action of the horse does not sufficiently raise them, and they endeavour to raise themselves by the stirrups. This is labour instead of ease, and such persons are said, in derision, to ride faster than their horse.

It is then the action of the horse, and not any effort of your own, that should raise you. If you accordingly bring your body a little forward when the action of the horse raises 
you from the saddle, a greater proportion of your weight will be received in the stirrups, by which you ease your return to the saddle.

Now a horse leads with one or the other foot in the trot, the same as in the gallop, and the feet beat the time of one, two. The foot which the horse leads with, determines the one you are to rise to, and you cannot change the order if you would by rising to the contrary; but if the horse change his foot you are necessitated to change with him, till which your time is broken and you are disunited; so that you rise and fall with his leading foot, which, beating the time of two, you rise at one, the leading foot being in the air, and fall at two when it comes to the ground.

Thus the horse renders it perfectly easy to you by raising the body and marking the time, which, if you do not counteract by any endeavours or efforts of your own, you soon fall into. 
The rise and return of the body are to be smooth, even, and as regular as the beats of the feet. If you, through inattention lose your time, you get bumped upon the saddle till you fall into it again.

Though this is called rising in the stirrups, it is to be remembered that no great stress or dependance is to be made on them.

A person can rise to the trot without the assistance of the stirrup, but not with so much ease to himself. It is, therefore, to be used as such and no more. Thus, when the body is raised from the saddle, the feet have a momentary pressure in the stirrups, which subsides' as the body returns to the saddle. If you make more use of the stirrups than this, you risk your own safety; for an improper use of the stirrups occasions many persons to be thrown, and a horse shying" or suddenly turning round would occasion such a disaster. 
The rising of the body is not to be accompanied by any motion of the arms or lifting the shoulders.

The body must have no assistance from the bridle to accompany the action of the horse, the hand must be held steady, and the reins of that determined length which preserves a correspondence between the hand and mouth; and though the rising of the body diminishes the effective operation of the appui, yet still there remains a proportion according to the goodness of the rider's hand, and the quality or fineness of the horse's mouth.

The small forward inclination of the body, moreover, is not to occasion any roundness in the back; this is invariably to be hollow, not only for the seemliness, but for the safety of your person.

The action of the body likewise must not cause the legs to move. 
Plate XXVIII. illustrates the seat, \&c. in road riding.

In road riding, the rule of taking the right hand of all you pass is well known; but there are some exceptions which are noticed by Mr. Bunbury, as follows, in his ironical style.

"In riding the road, observe, in passing a whisky, a phaeton, or a stage coach, in short, any carriage where the driver sits on the right hand, to pass it on that side, he may not see you on the other, and though you may meet with a lash in the eye, what is the loss of an eye to a leg, or perhaps neck.Should a man on horseback be on the road, and leading another horse, always dash by the led one; you might otherwise set the man's horse capering, and perhaps throw him off; and you can get but a kick or two by observing my instructions. - In passing a waggon or any tremendous equipage, should it run pretty near a bank, and there be but a ditch, and an open country on the other side, 
if you are on business, and in a hurry, dash up the bank without hesitation; for should you take the other side, and your horse shy at the carriage, you may be carried many hundred yards out of your road; whereas by a little effort of courage, you need only graze the wheel, fly up the bank, and by slipping or tumbling down into the road again, go little or nothing out of your way." 


\section{CHAP. II.}

OF IUUTING.

Every system of riding, except the manege, is occasionally used in Hunting, but the seat which is properly called the Hunting-seat, is that of riding in the stirrups.

The intention of this style of riding, is to give the horse a steady and firm support from the hand, and to relieve yourself from the friction and heat which you would receive from strong and continued gallops, if seated close down in the saddle.

The first thing to be considered is the length of stirrup, which must not be too short, though somewhat shorter than what was recommended for road riding. That 
P. IX.

length of stirrup, though it would raise you sufficiently from the saddle to ride in the stirrups for a while, yet would not be found short enough for a long gallop.

The stirrup must be shortened to prevent the bottom coming in too close contact with the saddle.

It must likewise permit you to stoop the body forward to go under boughs of trees and the like, without losing your centre of gravity, and thereby abandoning your horse.

Therefore, from the above position, if you stoop the body forward, and preserve the centre of gravity, and the powers of supporting your horse, you are necessitated to sink and thrust the rump out behind.

Were you to stoop your body forward, without thrusting the rump out behind, you could not support your horse; and if you thrust the rump out beyond the proportion that the body is projected forward, you im- 
pede the horse. The first of these circumstances should never happen; and the other only for the purpose of impeding.

The uprightness or forward inclination of the body, is to be that which is most natural and pleasant to yourself, and will be more or less according to the rate you gallop, and the support the horse requires. If you affect to stoop beyond a certain medium, it looks ridiculous.

The centre of gravity must be preserved independent of any assistance from the bridle.

A little practice will soon discover to you the exact length you should ride. Observe, however, that you cannot ride too long, when you can sit as described, and the bottom, after strong galloping, does not bump or come in contact with the saddle.

I shall now note the precise position of every part, that errors and unseemly habits may be avoided. 
When the horseman is raised in the stirrups the body must have a forward inclination from about twenty to forty-five degrees short of a perpendicular, as the rider shall find most pleasant and convenient for himself. If he is galloping at a moderate pace, from twenty to twenty-five degrees of inclination might be most pleasant, and to stoop to forty-five degrees would look ridiculous, as being unnecessary; but when galloping at full speed, you may find it necessary to thrust your rump out farther behind to increase your powers to support the horse, and this gives the body a greater inclination. But whether the body has a great or small inclination, the position otherwise must be the same as when upright-that is, the breast open, the shoulders down, the back hollow, the head firm.

The thighs are more or less oblique, as the rump is more or less thrust back, but they otherwise act and have the same functions, as explained in the seat. The situation of the leg is, as before described. The toe is 
to be perpendicular to the knee, horizontal with the heel and foot, and nearly parallel with the horse's sides.

Many sportsmen, in the habit of riding home in the stirrups, will object to the method of not riding home; and their reason is because they from custom cannot ride otherwise. If, however, they had begun and continued this method, they would have found no difficulty in it, and the chafing their legs and galling their insteps would have been avoided. Beside, they lose a considerable easement; for when you ride in the stirrups under the ball of the foot, you have the play of the instep, which acts as a spring, as does also the knee, and the hip, which save the body from a great part of the roughness which the action of the horse occasions.

The arms must be placed firmly, and close to the body; and the reins are mostly held by both hands without separating, for the eagerness of horses when hunting will occasion them to pull even in their slow paces: 
you therefore require the assistance of both hands. Now the firmest hold you can have with both hands, without separating the reins, is to apply the right hand before the left, put the middle finger downward between the reins, then grasping the hand, turn your elbows down close to your body, and your thumbs up, you will find this a secure hold.

Though you can ride the trot in this position, nevertheless begin your practice in a moderate or slow gallop, as being the easiest. Raise yourself in your stirrups, and, if necessary, at the same time shorten your reins. That you may not in this, nor in any other change of position, abandon your horse, when raised in your stirrups, endeavour to find and preserve your gravity without the least assistance from the bridle, for which reason begin with a slow gallop, in which the horse rides light, and plays upon the bit. So that you are completely poised in your stirrups, it is immaterial what elevation, or inclination you give your body; you must be able to vary that after awhile, as circumstances may re- 
quire: for the present, let it be that which you find most pleasant to yourself. Endeavour, then, to obtain a firmness that neither the action of the horse, nor his tugs, or playing on the bit, shall in the least disturb.

This firmness depends on the correctness of your position, aided by the grasp of muscles in the thighs just above the knees. Not that you are to fatigue yourself by applying unnecessary exertion: sufficient to keep you steady in the saddle, and afford the horse the required support, is all that is necessary; and that may be more or less, according to the roughness of the action, the speed the horse goes at, and the pull or support he takes.

Thus having considered the position of every part in this system of riding, let us consider the situation, operation, and effects of the hands, in particular.

The situation of the hand or hands (if both are employed), is to be in the centre. The arms being pressed to the body will be the 
exact situation in respect to the body which was originally directed; but the position of the body makes it operate lower or nearer to the pommel of the saddle. In this situation, the reins properly collected to retain and support the horse, in a slow or short gallop, you will feel the appui at every cadence, light, obedient, and pleasant, or you will feel the horse champ and play pleasantly on the bit.

Should the eagerness of the horse make him desirous of going faster, you will feel the appui stronger, inviting liberty, and trying to force it. This it is in the power of any middling horseman to prevent. If however, you permit him to increase his speed, give him a little more liberty; and grant him that support which the extension you have allowed requires, for the more a horse extends his speed, the more support he takes from the hand. By practice you will be able to discover what is the requisite support the horse should have, and to check what he improperly takes through eagerness or the habit he 
has acquired by bad riding. When you let the horse extend himself in the gallop, you will feel the support he takes to be a steady pull; and when this support, with his eagerness to get on, occasions him to pull beyond your strength to hold, you are to check him, by raising your hand and body, and thereby throwing your weight off the centre backwards. This checks and pulls him a little together, an advantage you must endeavour to keep, by not letting him get so much superiority again, for you are not to continue with your weight out of centre, but ride with your body more upright, which will raise your hands, and increase your power, while it diminishes the horse's.

If it should happen that by raising your hand and body to check, and get the ascendency of the horse, you raise and throw his head out of place, you must let him drop it again, for no horse can gallop well, nor safely, if his head is not in the place in which, according to the make of his forehand, nature intended he should carry it. 
P. IX.

As, then, all horses pull more or less when extended in the gallop, and as some from their formation, and the situation in which they carry their heads, together with the confirmed habit of being rode with heavy insensible hands, pull so hard that a weak or inferior horseman cannot hold or govern them, for the harder he pulls, the faster they run, it becomes necessary to show the most powerful means to stop them.

This is done by repeated efforts to raise the head, and get the haunches under, which diminishes his power, and gives your hand the ascendancy.

First, then, as directed in the stop, seize the time, and with all your strength and weight throw your body back, taking a firm hold with your legs, bracing your arms strong, and letting your hands have a firm upward operation to get the head up. The instant this is performed (it will not do afterwards), let the body come upright, that the hands may be eased. 
The first throwing of the whole strength and weight of body back, while the hands operate to raise the head, is a great check; and the body then instantly coming forward to ease the hands, deprives the horse of the support which even in that check he depended on. This deters him from extending himself so freely as before.

The next stroke you must repeat your effort, which will have a greater effect in proportion to the check the first effort made. The third effort will generally, if firmly and properly applied, bring the horse in hand that you can stop, turn, or do as you please with him. If not, you must repeat your efforts till you can.

Be mindful to leave no interval between your efforts, whereby the horse would recover one check before you gave him the next.

Should the horse obstinately defend himself against the efforts of the hand, to raise the 
head, separating the reins will increase your power, and moving the bit by opening the fingers first of one hand and then of the other, will disarm a part of his defence.

The planting your feet forward in the stirrups, to pull against, is not to be done in these cases; your hold must be from the grasp of the legs and knee, and the check which you give the horse will not then disturb your seat; but were your legs planted forward, the check of the horse would throw you high from the saddle, and, if it should be on one side, you might come to the ground.

There are occasions on which the legs are placed a little forward to increase your pull, but this is only when you intend to impede the horse without stopping. You then put your legs forward, and throw your weight out of centre, for the moment only; for by this you increase the weight or pressure of the saddle on the horse, which would be 
very distressing to him, were it for a continuance.

To direct and turn a horse in those extended paces requires neither art nor delicacy. The horse should obey the pressure, which must be given forcibly, in proportion to the pull or support he takes from you. Where he does not readily obey the pressure, you assist and compel him by pulling the rein of the side to which you wish to turn, as before explained.

This extension of the horse and your inability to stop him at the instant, shows the impropriety of such riding on the road near town; and that when in the field it is necessary that you carry your eyes well forward, to be aware of pulling your horse together in time whenever you have occasion either to stop or change your direction; for a horse, when extended, requires considerable space to turn in. Should you neglect this caution, the horse may precipitate himself and you into imminent danger; or, checking him- 
P. IX.

self unawares, may throw you out of your seat.

In hunting, spare your horse as much as possible, and never rate him against other horses, though you find him or them inclined so to do. You must necessarily ride to keep up with the hounds, but you must be mindful to keep sufficiently behind, never to ride among them. By being a moderate distance behind, you may observe the course of the leading hounds, and save a considerable deal of ground. Should the doubling of the game put you in a situation before the hounds, though you view it and know the course, you are not to ride till the hounds have passed you. Avoid hallooing to the hounds : it is the business of the huntsman; and it is generally offensive to him and to the proprietor.

Should circumstances throw you out, or leave you considerably behind, fast riding may be necessary. Do not, however, rate your horse at speed; for, by this, you would 
soon distress him, so that he could not cover his leaps. A rate considerably short of speed will bring you up. Therefore, the freeness of your horse, even in this case, must not induce you to let him exhaust himself, but pull at, and save him as much as you can.

Look before you leap, is a necessary caution; a person who knows the country may ride more forward than one who is a stranger to it. Never take unnecessary leaps to display your horse, nor leap at gate or rail, if you can get through or over the hedge or fence. Nay, if your horse is not a very safe leaper and used to take timber, it is advisable to go round, if you cannot open the gate.

Never push your horse up hill, nor too fast down, and spare him all you can in unfavourable ground, such as ploughed fields, swamps, and the like.

Fern, furze, heath, hillocks, \&c. to persons not accustomed to them, may appear great 
obstacles; but horses and men, when accustomed to hunt, find them small impediments, and ride as freely over them as on plain ground.

Be cautious of riding into close covers, lest you should not find your way out. Where there are rides on passable tracts, you may ride in, being mindful to avoid and defend your head from the boughs, \&c. In forest hunting, or among trees, hard mouthed and untractable horses are not only unpleasant, but dangerous, and therefore must be rode with more care.

For the care and accommodation of the horse, let him take either leg, or change his leg as often as he pleases; and, for your own ease, change your mode of riding as often as you find it pleasant and convenient. You can frequently keep up in a trot, in which you can, by way of change, sit close to the saddle, rise in the stirrups, or stand in the stirrups. 


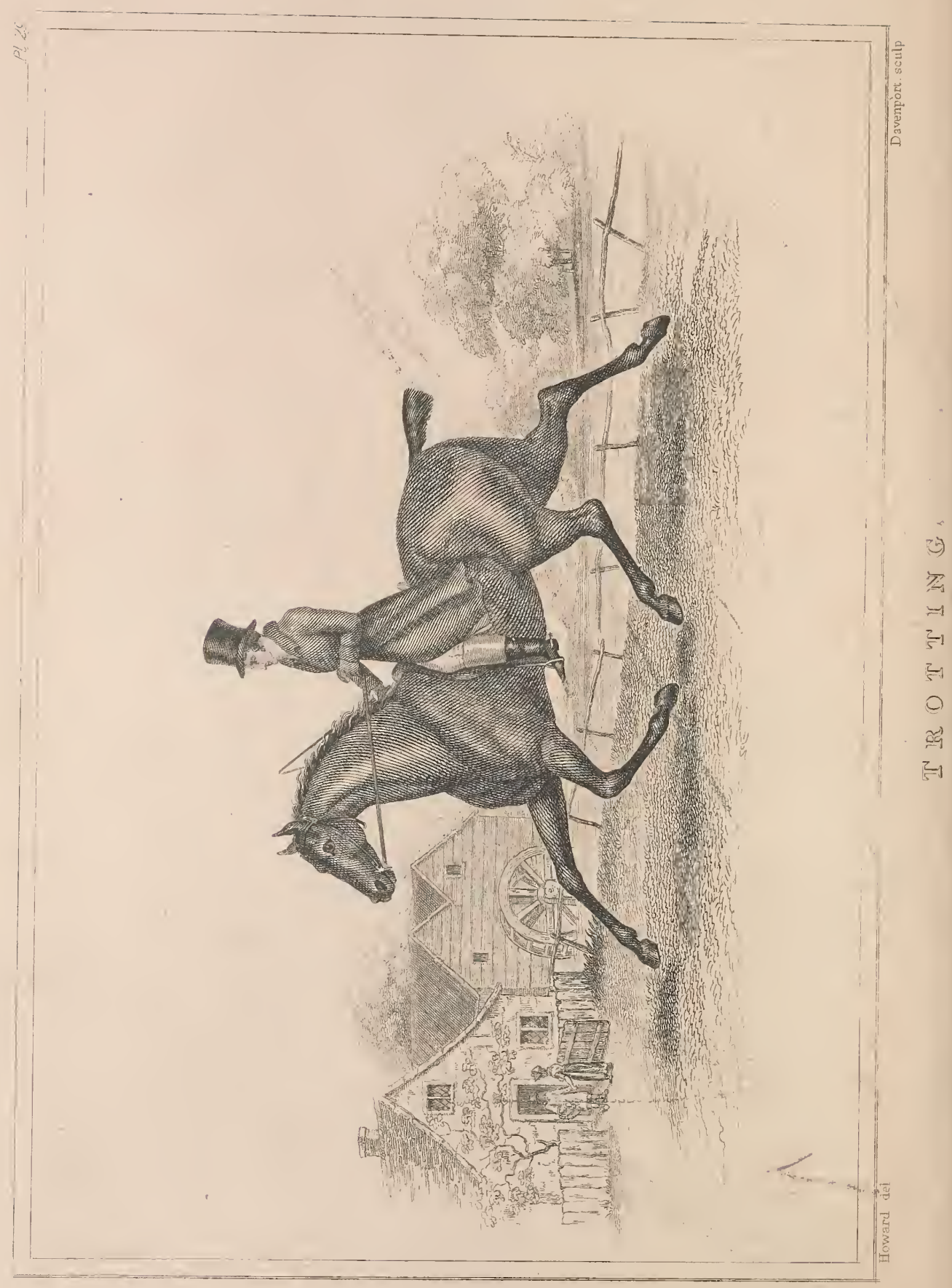


. 


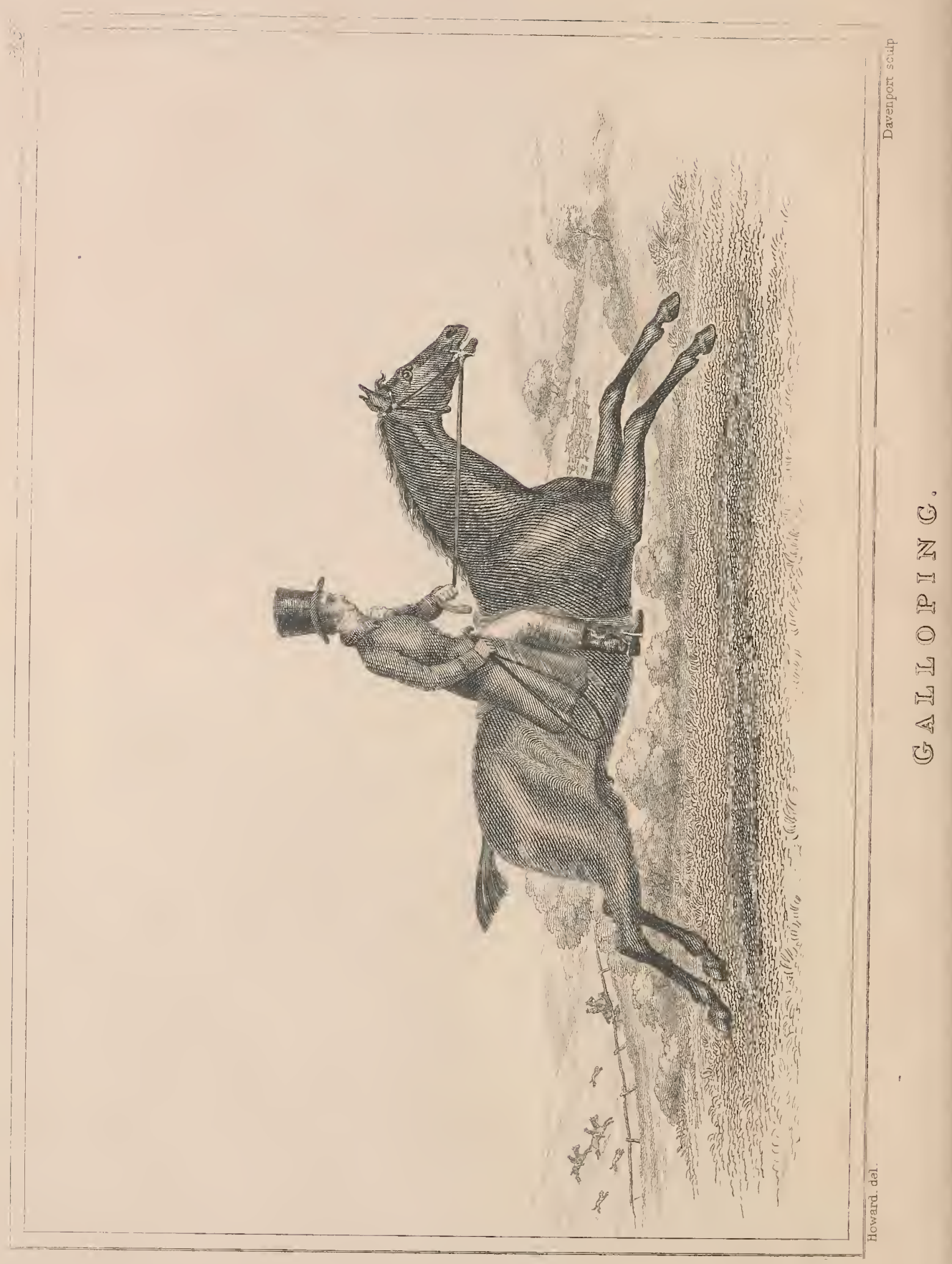




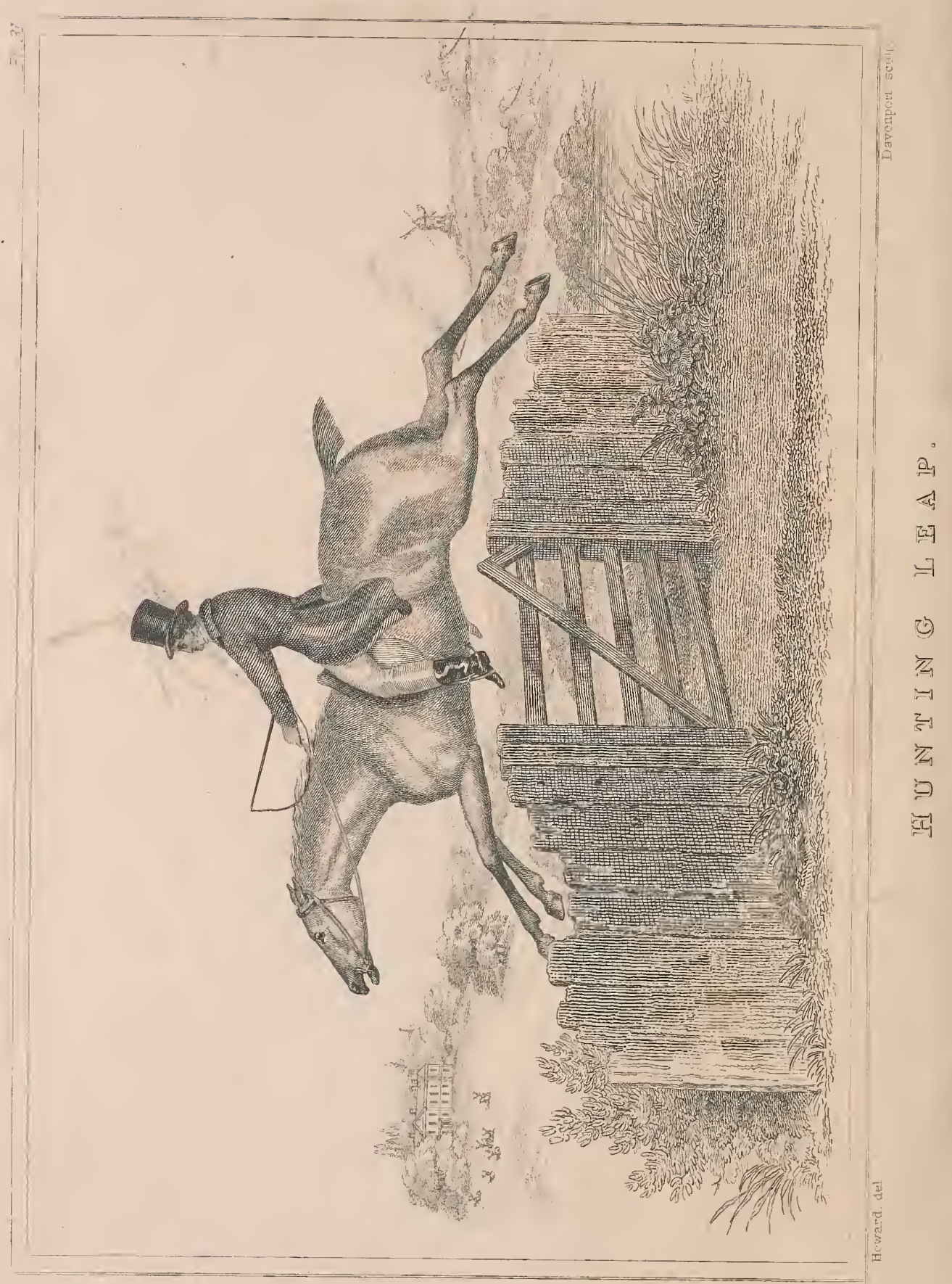





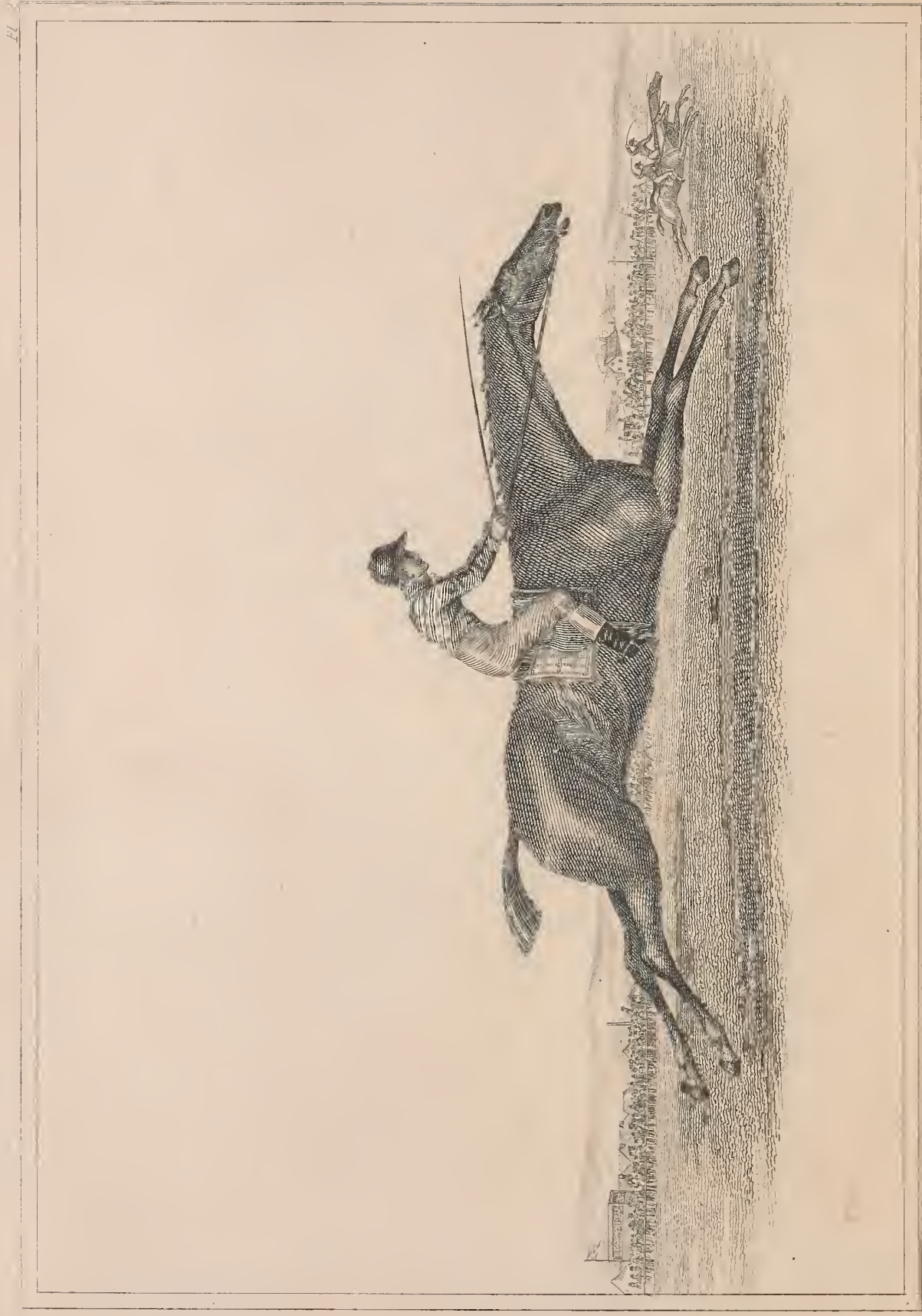

(2)

$\mathbb{3}$

$\because$

(2)

辽

닥

$\frac{\vec{g}}{3}$
$\frac{\pi}{5}$
$\frac{3}{3}$
$\frac{3}{4}$ 
Attending to these remarks, the young sportsman may appear in the field without being ridiculous.

Plates XXIX. XXX. and XXXI. illustrate the seat in.Trotting, Galloping, and in Leaping in Hunting. 


\title{
CHAP. III.
}

\author{
OF RACING.
}

TuE system of riding adapted for Racing is exactly the same as the hunting seat, when rode in the stirrups. 'There is, consequently, but little more to say on a subject that has been so fully discussed. A few remarks, which were foreign to the subject of hunting, are all that is requisite.

The person who is to ride a race (besides in hired riders, the grand requisite of honesty) should have qualities which fit him for the performance.

His strength should be sufficient to hold, support, and assist the horse, otherwise the 
horse will exhaust his wind. If he is obliged to pull him together by raising his hands, or throwing his weight out of centre, these checks produce an additional stress on the hocks or loins, which must tend to weaken or exhaust; and, if it is a close match, the heat might be lost by the riding. That the horse therefore may have every fair advantage, the rider should be strong enough to hold him without raising his hands, which might put the horse's head out of place; and though it were but an inch, this would be unpleasant and detrimental to him.

His judgment should be able to discover how the horse gallops with the greatest ease to himself-if he carries his head lower than is pleasant to the rider, -if he is accustomed to bear more on one rein than the other,-or has a favourite leg. This is a material thing to know; for no horse can be made the most of, that is put out of his usual method of carrying himself; and this being known or discovered, should be submitted to. This is 
not the time to dispute or quarrel,--you must find his favourite manner, and comply with it.

Such being the case, start your horse coolly and temperately. If you flurry him at starting, his own eargerness will be very detrimental. Endeavour to keep him moderate, that his gallop may be smooth and steady. You must give him all the support he requires from the hand in a smooth steady pull, and not increase it.

If his eagerness to get on compels you to do this, you must increase your pull, with the same steadiness as before, which will hold him and save his wind. If you raise your hand to keep him in, you will raise his head out of place, which will cause him to fret, and he will be fighting for the ascendancy of the hand. If you are obliged to do this, to prevent the horse from running away with you, your strength is not competent for such a horse. Neither must you throw your body 
out of centre; nor plant your feet forward to increase your pull without raising your hands. These operate to the disadvantage of the horse.

In situations where you are to push and do your utmost, you must assist the horse's efforts with the greatest exactness and judgment, without depriving the horse of the requisite support. Your hand must permit him to extend himself to the utmost, and assist him in collecting himself together. This is done by permitting the horse to draw your hand from your body, to favour his extension; and, as he collects himself, the hand returns to the body, and assists him in collecting his haunches under him.

This action of the hands must be done with the nicest judgment: otherwise you would abandon, deceive, deter, and prevent rather than assist the horse's exertion. Be mindful, therefore, that the hand does not move till the extension of the horse removes it; and; during this removal, that the hand 
affords the same support that the horse requires. When the horse gathers himself together, the reins would be slack if the hand was not to return back again, and the horse would not be able to bring his legs so close, as by the assistance of the rider's support he would be enabled to do. Therefore, as the horse gathers himself, the hand must return, yielding him that support which assists the haunches coming forward.

This skill of the rider is mostly displayed at the running in. Over eagerness of the rider, flurry, or the like, may sometimes take place with young jockeys. Gentlemen who choose to ride their own matches should be collected at this time; for, if it is a near match, their winning or losing depends on the riding. A steady support must be given, which at this crisis must be neither more nor less than the horse requires.

'The over doing or under doing is equally detrimental. Were you to yield your hand too much, you abandon your horse; and if 
in gathering him together, you over do your part, you check his next extension.

If you do not sufficiently support the horse, he dare not extend himself so far as he could under a confident support of the hand, because that support is a great assistance in gathering himself together. The eagerness of the horse will make him extend himself as far as he can safely, independent of the hand; and the labour and exertion of gathering himself, without support from the hand, exhausts his wind and strength, and the horse is said to be blown. It is therefore necessary that the rider's strength should hold out with that of the horse: the one depends on the other.

On the other hand, the support the hand is to afford is to be no more than what the horse takes; for the hand is not to dictate to the horse at what rate he is to pull. If the horse rides cool and steady, he will take a support equal to the rate or extension he is 
at; but, if hot and eager, he will require a greater support to restrain him from over running and exhausting himself, and the hand must give that support to prevent such consequences. At the push or running in for the heat, you must give him the liberty to exert his utmost, and so much support, and no more than will enable him to do it-if you give him more, you restrain him-if you give him less, he cannot confidently throw himself out.

If, in endeavouring to assist the horse, you pull him too much together, you check him, particularly if your horse is nearly spent. When you find the horse has done pulling, it is time you had done running: he is then exhausted, and must lose if the others are not in the same state. If you find your horse strong, and close pushed at running in, the application of the whip, given at the instant, before he takes his stroke, may draw an additional spring or two from him, and give you some assistance. The whip or spurs, at 
other times, are of little service; the emulation and eagerness of horses will carry them beyond what they can hold; and the whip or spurs discourage, if too much or injudiciously applied.

You will observe in the hunting and racing systems of riding, that pressing the feet in the stirrups to increase your pull, is not allowable if it can be avoided, but particularly in racing; for you must thereby considerably increase your weight or pressure on the saddle. Though it is called riding in the stirrups, when you ride properly, the stirrups sustain a very inconsiderable weight; and when the horse is extended and pulls fair, you may ride in the same position without the stirrups and the grasp with the knees, and the pull of the horse will keep your position steady.

Having pointed out what operates to the advantage and disadvantage of the horse's speed, the rest must be left to that practice 
which perfects every art. Without so far studying theory, however, practitioners are very liable to run into error.

Plate XXXII. illustrates the Seat, \&c. in Racing.

THE END. ) 






$$
27
$$





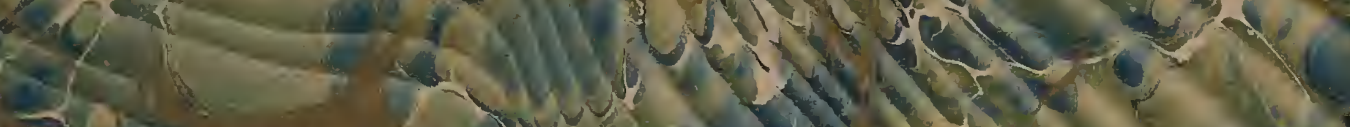

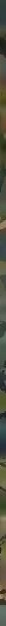

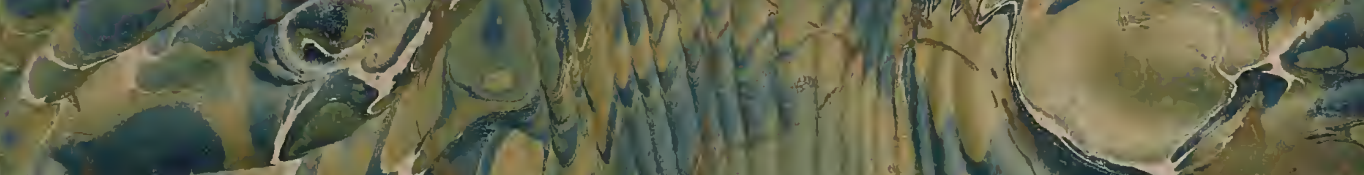
6

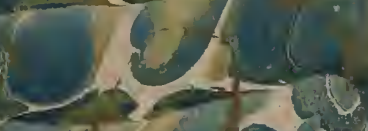

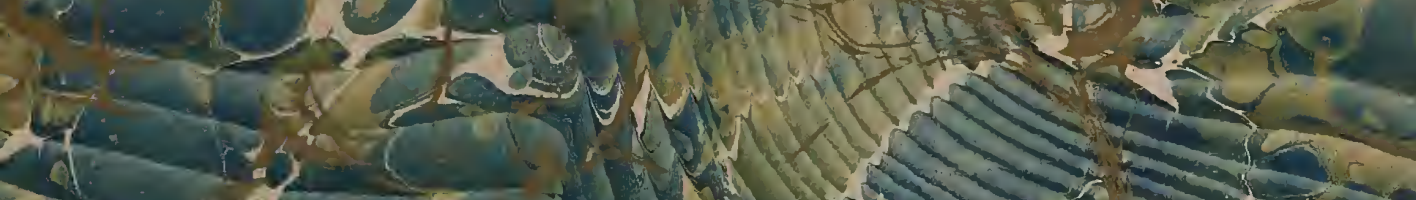

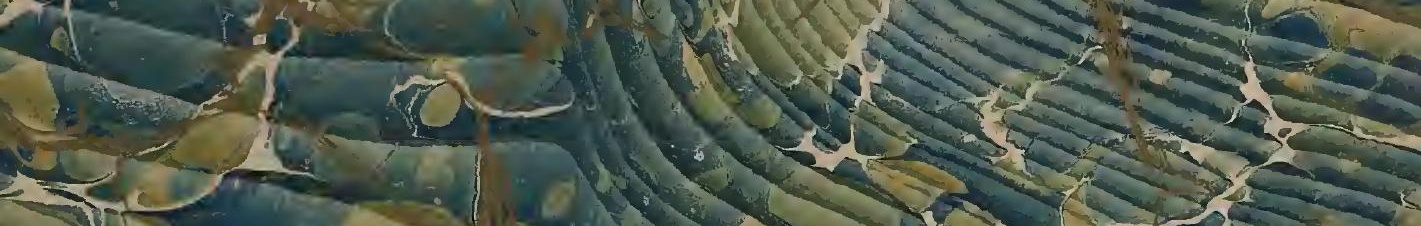

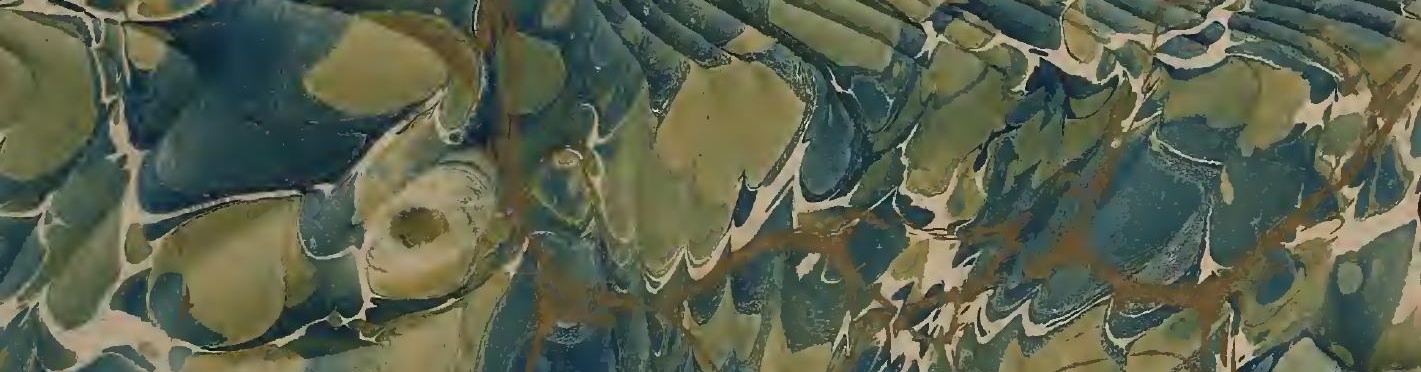

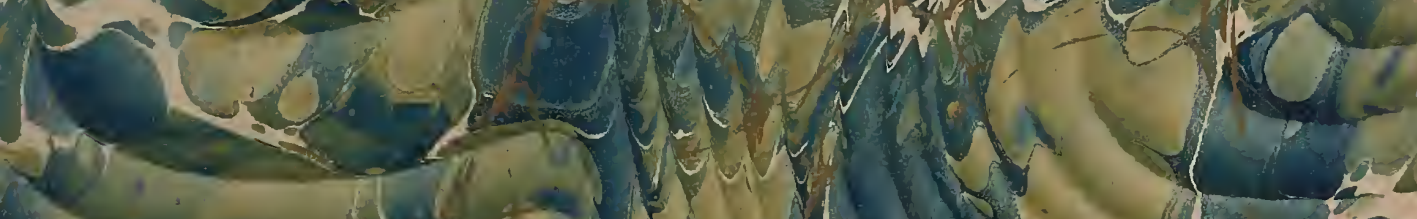

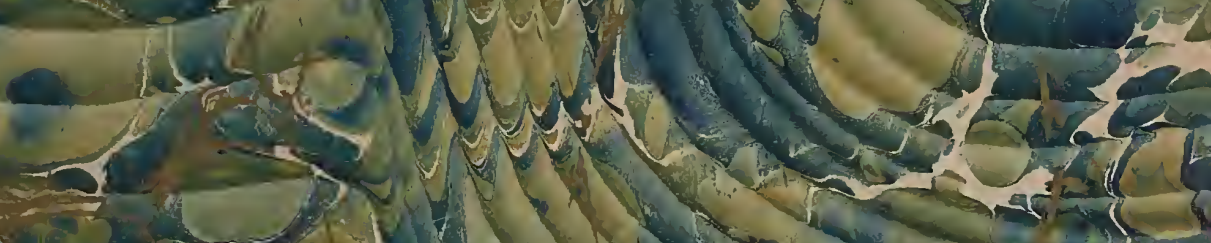
)

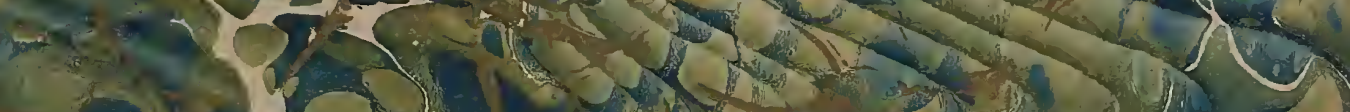

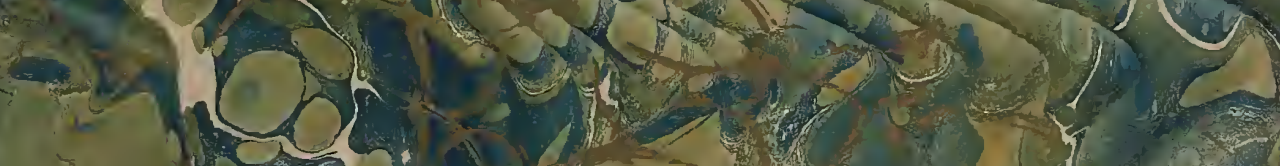

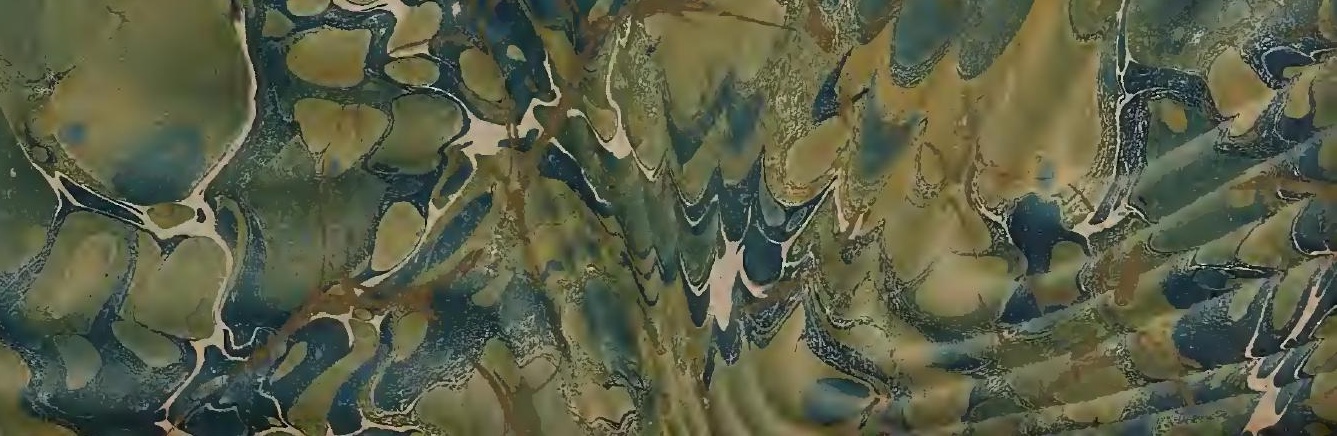


